\title{
Development of a Physical Shoulder Simulator for the Training of Basic Arthroscopic Skills
}

Laura C. McCracken, The University of Western Ontario

Supervisor: Dr. Michael Naish, The University of Western Ontario

Joint Supervisor: Dr. Ana Luisa Trejos, The University of Western Ontario

A thesis submitted in partial fulfillment of the requirements for the Master of Engineering

Science degree in Biomedical Engineering

(C) Laura C. McCracken 2015

Follow this and additional works at: https://ir.lib.uwo.ca/etd

Part of the Biomedical Devices and Instrumentation Commons

\section{Recommended Citation}

McCracken, Laura C., "Development of a Physical Shoulder Simulator for the Training of Basic Arthroscopic Skills" (2015). Electronic Thesis and Dissertation Repository. 2955.

https://ir.lib.uwo.ca/etd/2955

This Dissertation/Thesis is brought to you for free and open access by Scholarship@Western. It has been accepted for inclusion in Electronic Thesis and Dissertation Repository by an authorized administrator of Scholarship@Western. For more information, please contact wlswadmin@uwo.ca. 


\title{
DEVELOPMENT OF A PHYSICAL SHOULDER SIMULATOR
}

FOR THE TRAINING OF BASIC ARTHROSCOPY SKILLS

(Thesis format: Monograph)

by

Laura Catherine McCracken

Faculty of Engineering

Graduate Program in Biomedical Engineering

\author{
A thesis submitted in partial fulfillment \\ of the requirements for the degree of \\ Master of Engineering Science \\ The School of Graduate and Postdoctoral Studies \\ The University of Western Ontario \\ London, Ontario, Canada
}

(C) Laura McCracken, 2015 


\title{
Development of a Physical Shoulder Simulator for the Training of Basic Arthroscopic Skills
}

\author{
Laura McCracken \\ M.E.Sc Thesis, 2015 \\ Graduate Program in Biomedical Engineering \\ The University of Western Ontario
}

\section{Abstract}

Increasingly, shoulder surgeries are performed using arthroscopic techniques, leading to reduced tissue damage and shorter patient recovery times. Orthopaedic training programs are responding to the increased demand for arthroscopic surgeries by incorporating arthroscopic skills into their residency curriculums. A need for accessible and effective training tools exists.

This thesis describes the design and development of a physical shoulder simulator for training basic arthroscopy skills such as triangulation, orientation, and navigation of the anatomy. The simulator can be used in either the lateral decubitus or beach chair orientation and accommodates wet or dry practice. Sensors embedded in the simulator provide a means to assess performance.

A study was conducted to determine the effectiveness of the simulator. Novice subjects improved their performance after practicing with the simulator. A survey completed by experts, recognized the simulator as a valuable tool for training novice surgeons in basic arthroscopic skills.

Keywords: minimally invasive surgery, arthroscopy, orthopaedic, shoulder, surgical, physical simulator, training, validation 


\section{Acknowledgments}

First and foremost I would like to thank my supervisors Dr. Michael Naish and Dr. Ana Luisa Trejos for their guidance, patience, and support. I truly appreciate being given the opportunity to combine my interests in biology and engineering in pursuing my thesis.

I would like to express my sincere gratitude to Dr. LeBel for her constructive feedback throughout the project, and for allowing me a glimpse into the world of orthopaedic surgery.

I am grateful for my wonderful, supportive colleagues at CSTAR. In particular, I would like to thank Abelardo Escoto and Chris Ward for providing their expertise in 3D printing and microcontroller programming. I would like to thank Behnaz Poursartip for being a wonderful collaborator to work with while conducting the study.

Last but not least, I would like to thank my husband for his loving encouragement and unwavering support over the course of my studies.

This research was supported by the Ontario Research Fund. 


\section{Table of Contents}

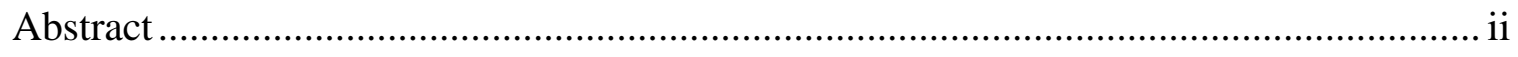

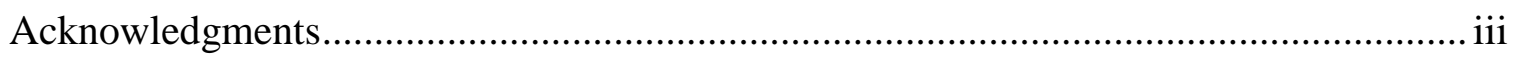

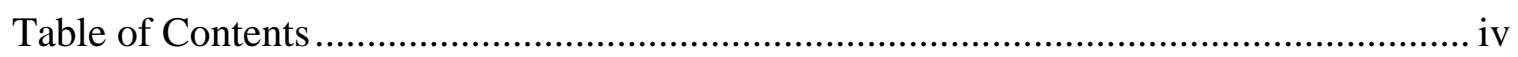

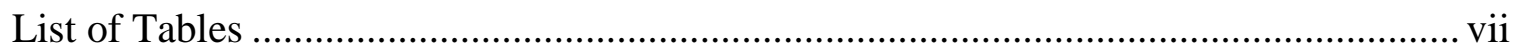

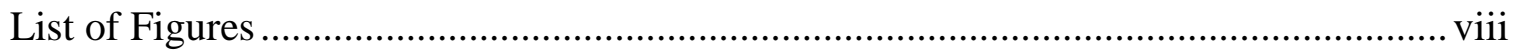

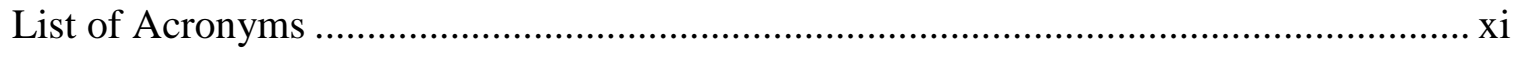

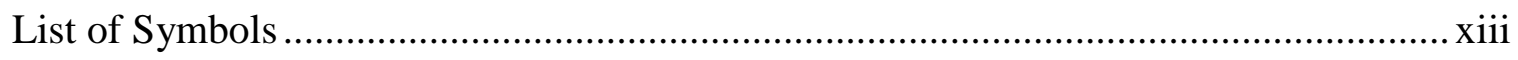

List of Appendices ................................................................................................ xiv

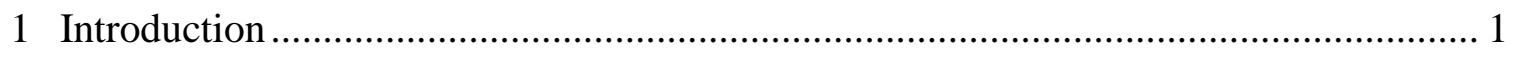

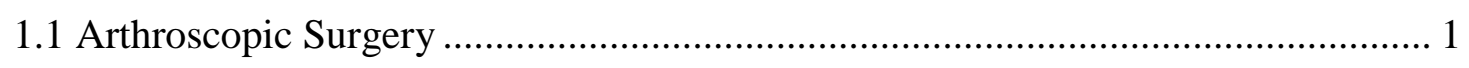

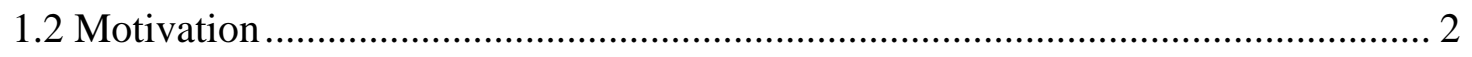

1.3 Research Objectives ...................................................................................... 3

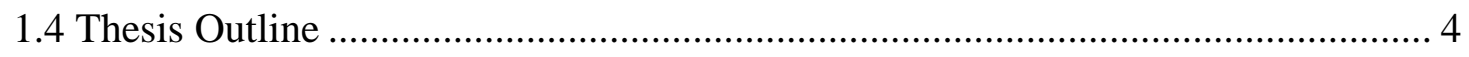

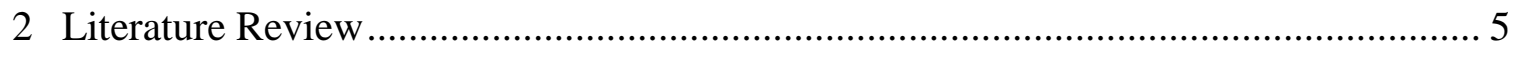

2.1 Psychomotor Skill Acquisition ........................................................................ 5

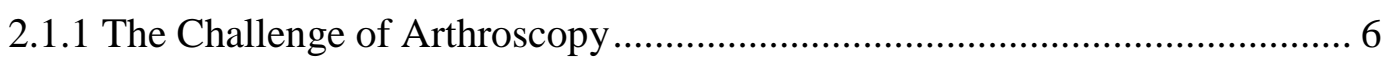

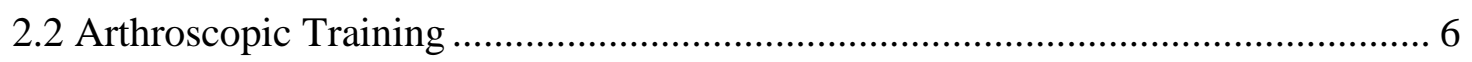

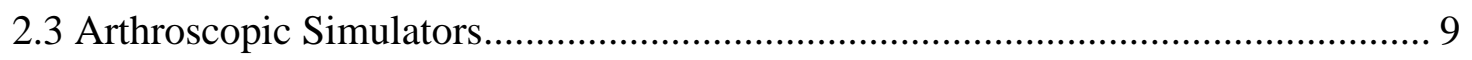

2.2.1 Virtual Reality Simulators ......................................................................... 10

2.2.2 Physical Simulators............................................................................ 12

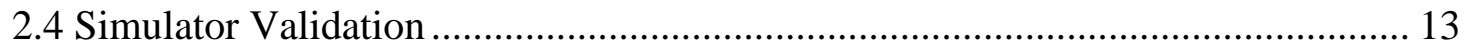

2.4.1 Face and Construct Validity...................................................................... 14

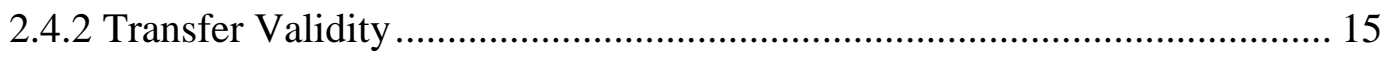

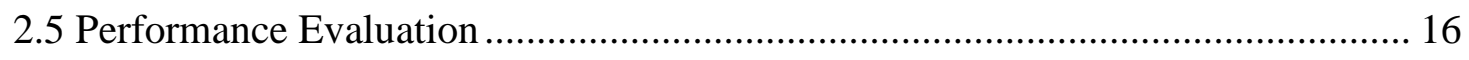




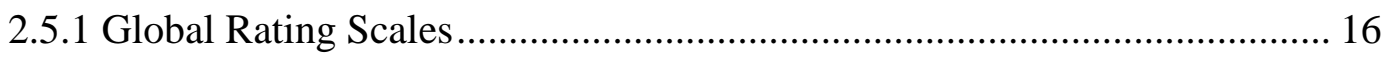

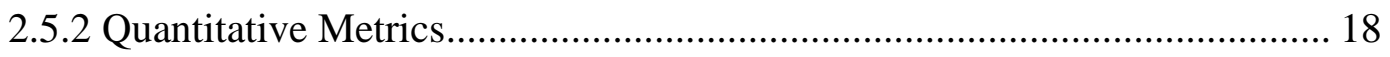

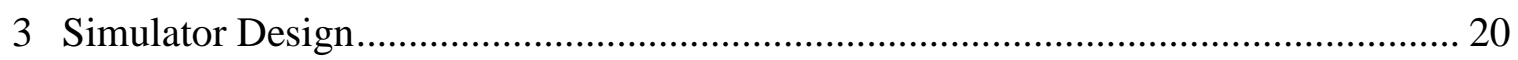

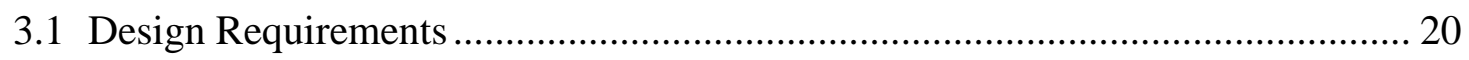

3.2 Conceptual Design and Specifications.............................................................. 21

3.2.1 Range of Motion for the Arm .............................................................. 21

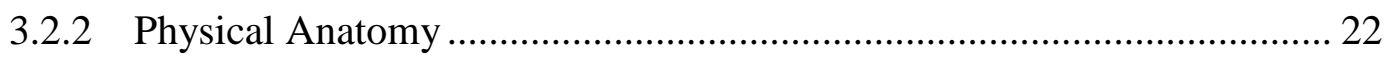

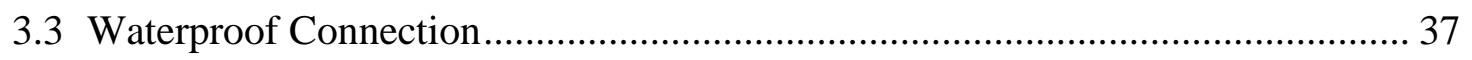

3.4 Switches for Objective Assessment of Probing Tasks.......................................... 40

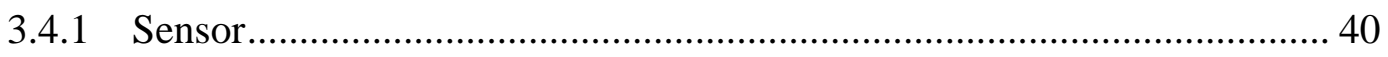

3.4.2 Data Recording and Graphical User Interface ........................................ 42

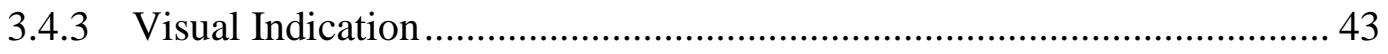

3.5 Simulator Base and Integrated Force/Torque Sensor ........................................... 44

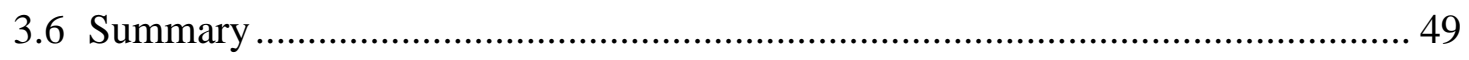

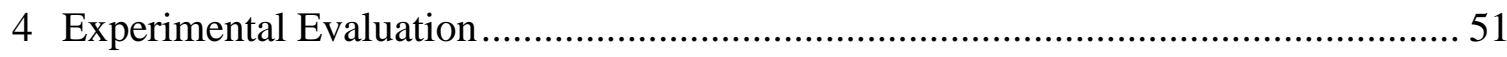

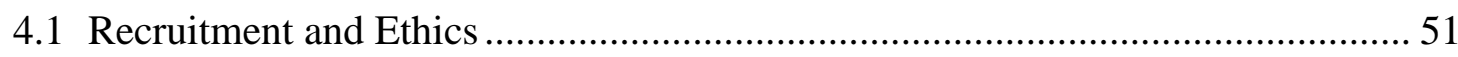

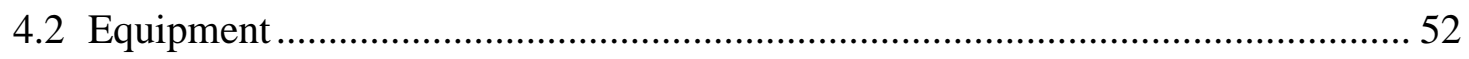

4.3 Instructions to Novice and Intermediate Trainees: ............................................... 55

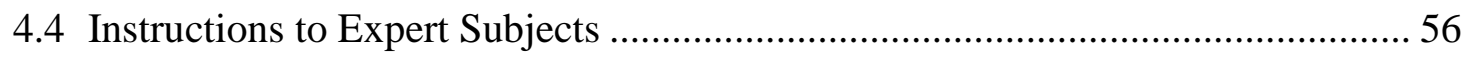

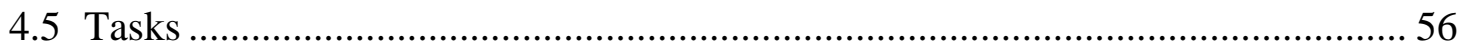

4.5.1 Task 1: Intra-articular Probing .................................................................. 57

4.5.2 Task 2: Subacromial Probing ................................................................... 58

4.5.3 Task 3: Intra-articular Grasping ............................................................. 59

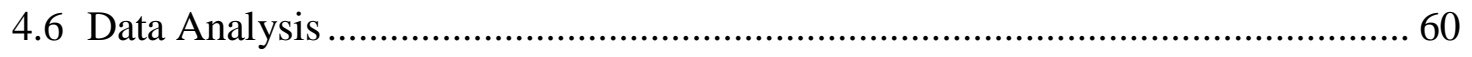

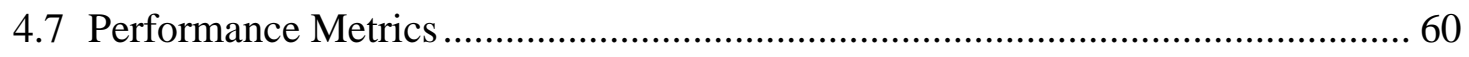

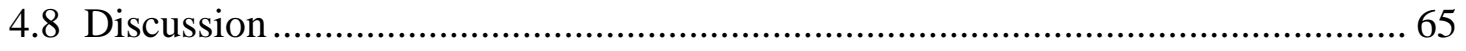




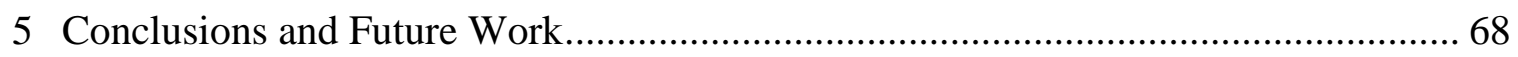

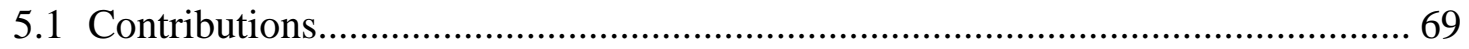

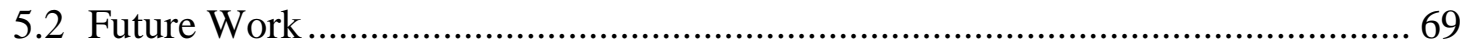

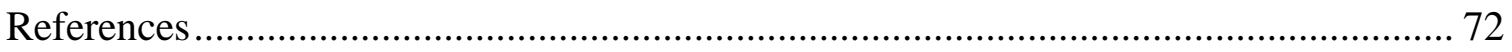

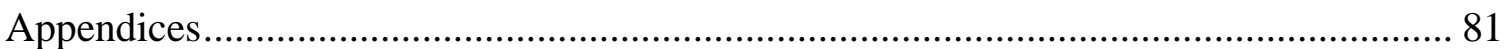

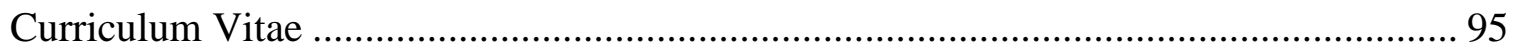




\section{List of Tables}

Table 3.1: Bones of the shoulder. .............................................................................. 24

Table 3.2: Results of the shaving test averaged over 10 samples..................................... 28

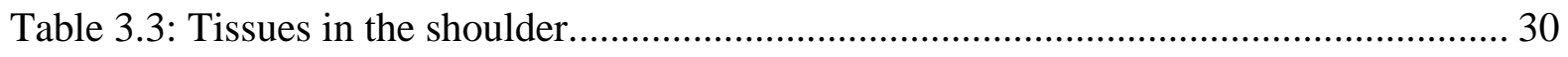

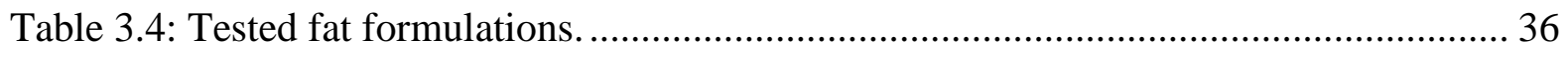

Table 3.5: Stress analysis for select parts in lateral decubitus position............................. 46

Table 4.1: Agenda for novice subjects.................................................................. 56

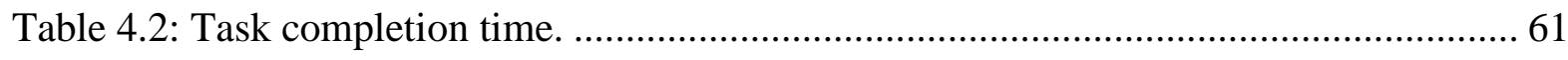

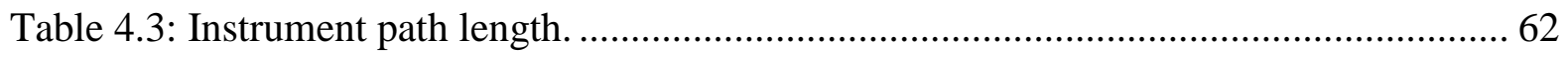

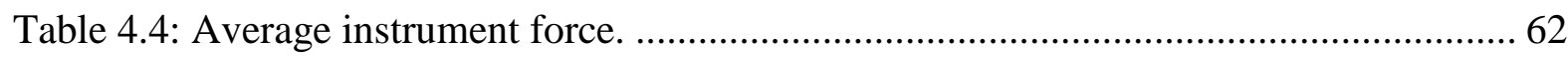

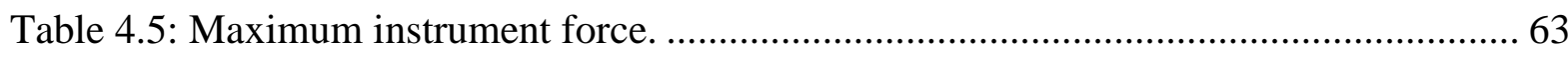

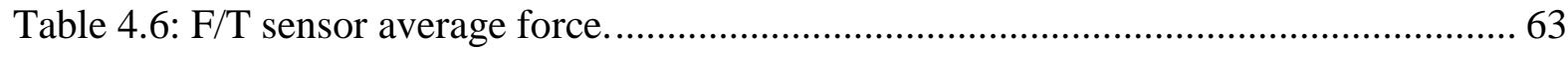

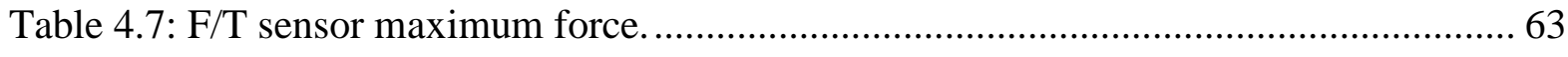

Table 4.8: Results of questionnaire from expert and intermediate respondents. .................. 64 


\section{List of Figures}

Figure 1.1: (a) Beach chair position (b) Lateral decubitus position ..................................... 1

Figure 3.1: Required range of motion for the arm........................................................ 22

Figure 3.2:Sagittal view of the shoulder joint showing the glenoid ................................... 23

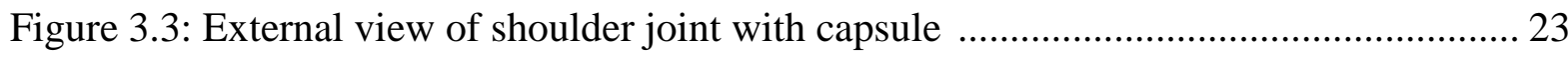

Figure 3.4: (a) Instron machine performing the three point bend test. (b) Polyurethane foam

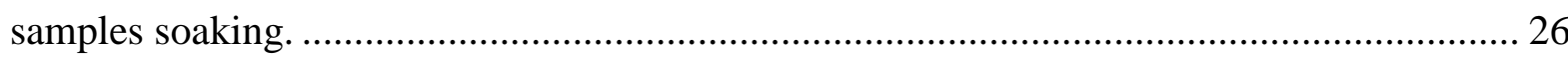

Figure 3.5: Results from day one of the three point bend test by density $\left(\mathrm{kg} / \mathrm{m}^{3}\right) \ldots \ldots \ldots \ldots \ldots . .27$

Figure 3.6: Results from day 2 of the three point bend test by density $\left(\mathrm{kg} / \mathrm{m}^{3}\right)$.................. 27

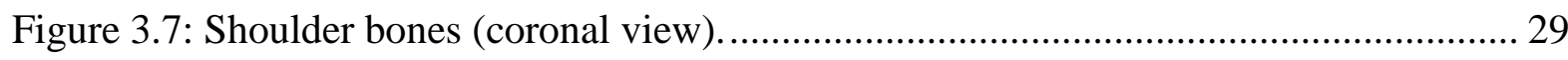

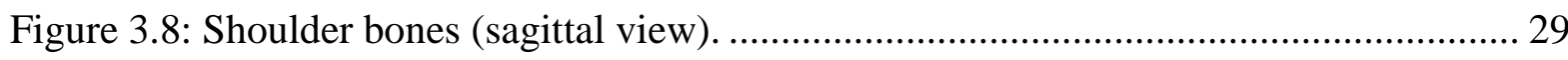

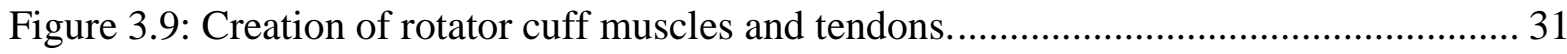

Figure 3.10: (a) Straw mould and biceps tendon. (b) Biceps tendon attached to glenoid. ..... 32

Figure 3.11: (a) Synthetic joint capsule (b) Capsule attached to glenoid with velcro............. 32

Figure 3.12: Arm with humerus inserted and sealed using silicone. .................................... 33

Figure 3.13: (a) Sculpted foam torso. (b) Torso covered by drape........................................ 34

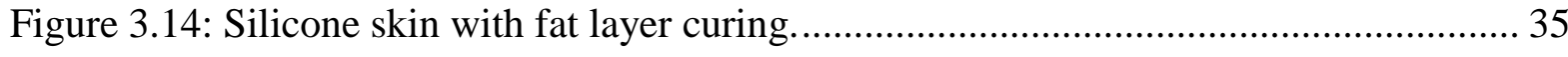

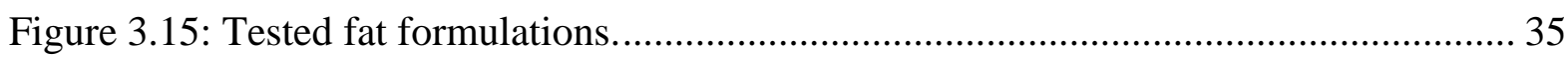

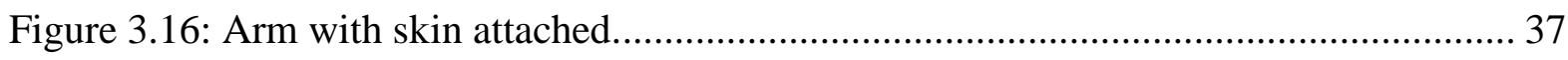

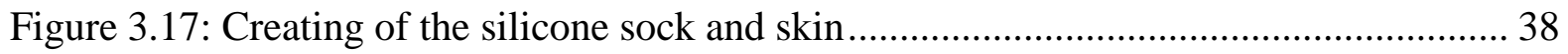


Figure 3.18: Locations of the three portals.

Figure 3.19: Seal around portal.

Figure 3.20: (a) Switches for probing task. (b) Wires for switches threaded through the bone.

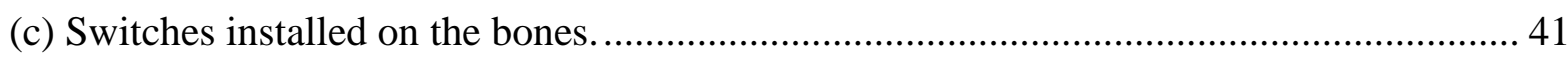

Figure 3.21: (a) Switch submerged in water. (b) Circuit with 5 VDC power supply............. 42

Figure 3.22: Microcontroller and wiring. ....................................................................... 43

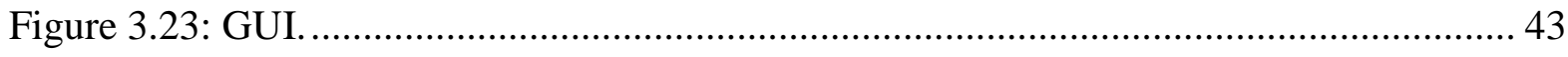

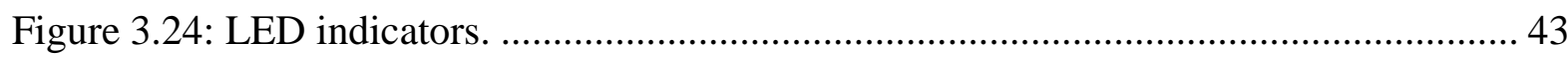

Figure 3.25: Non-ABS parts of torso and support base....................................................... 44

Figure 3.26: ABS printed parts of support base ................................................................. 45

Figure 3.27: Simulator in the beach chair position. ............................................................. 47

Figure 3.28: Simulator in the lateral decubitus position..................................................... 48

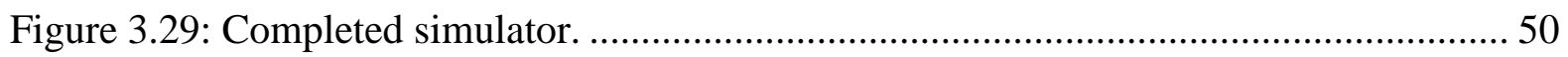

Figure 3.30: Simulator in use by an expert surgeon. ....................................................... 50

Figure 4.1: Equipment setup for simulator study.............................................................. 52

Figure 4.2: The sensorized arthroscopy probe tool............................................................. 53

Figure 4.3: The sensorized arthroscopy grasper tool........................................................ 53

Figure 4.4: Arthroscope and camera with position sensor attached. ..................................... 54

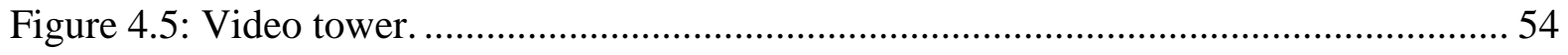

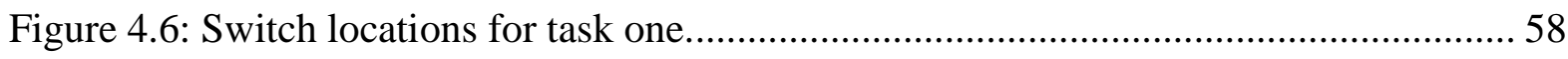

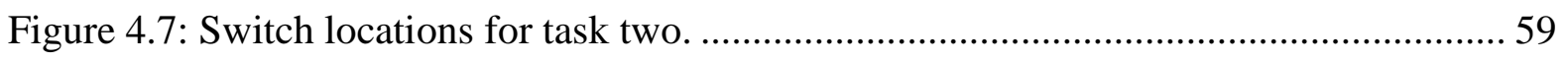


Figure 4.8: Loose bodies used in grasping task.

Figure 4.9: Grasper reaching for loose body. ............................................................. 59 


\section{List of Acronyms}

\begin{tabular}{|c|c|}
\hline $\mathrm{ABOS}$ & American Board of Orthopaedic Surgery \\
\hline ABS & Acrylonitrile Butadiene Styrene \\
\hline ASSET & Arthroscopic Surgical Skill Evaluation Tool \\
\hline BAKSSS & Basic Arthroscopy Knee Skill Scoring System \\
\hline CSTAR & Canadian Surgical Technologies and Advanced Robotics \\
\hline DOF & Degree of Freedom \\
\hline ESSKA & European Society of Sports Traumatology, Knee Surgery \& \\
\hline \multicolumn{2}{|l|}{ Arthroscopy } \\
\hline FAST & Fundamentals of Arthroscopic Surgery Training \\
\hline FLS & Fundamentals of Laparoscopic Surgery \\
\hline $\mathrm{F} / \mathrm{T}$ & Force / Torque \\
\hline GOALS & Global Objective Assessment of Laparoscopic Skills \\
\hline GRS & Global Rating Scale \\
\hline GRSSA & Global Rating Scale for Shoulder Arthroscopy \\
\hline GUI & Graphical User Interface \\
\hline IGARS & Imperial Global Arthroscopy Rating Scale \\
\hline LED & Light-Emitting Diode \\
\hline MIS & Minimally invasive surgery \\
\hline
\end{tabular}


MISTLES

OR

OSATS

PASSPORT

PCF

PGY

ROVIMAS

SPST

USB

VR
McGill Inanimate System for Training and Evaluation of Laparoscopic Skills

Normally Open

Operating Room

Objective Structured Assessments of Technical Skills

Practice Arthroscopic Surgical Skills for Perfect Operative Real-life Treatment

Pounds per Cubic Foot

Post graduate year

Robotics Video \& Motion Assessment Software

Single Pull Single Throw

Universal Serial Bus

Virtual Reality 


\section{List of Symbols}

$\begin{array}{ll}\mathrm{cm} & \text { centimetres } \\ \mathrm{g} & \text { grams } \\ \mathrm{gf} & \text { gram-force } \\ \mathrm{GPa} & \text { gigapascals } \\ \mathrm{kg} / \mathrm{m}^{3} & \text { kilograms per cubic metre } \\ \mathrm{lb} & \text { pounds force } \\ \mathrm{m} & \text { metres } \\ \mathrm{min} & \text { minutes } \\ \mathrm{M} & \text { megapascals } \\ \mathrm{MPa} & \text { neconds } \\ \mathrm{P} & \text { newtons } \\ \mathrm{N} / \mathrm{m}^{2} & \\ & \\ & \\ & \end{array}$




\section{List of Appendices}

Appendix A: Letter of Information and Consent .................................................... 81

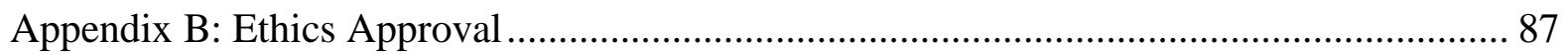

Appendix C: Novice Informational Handout........................................................... 88

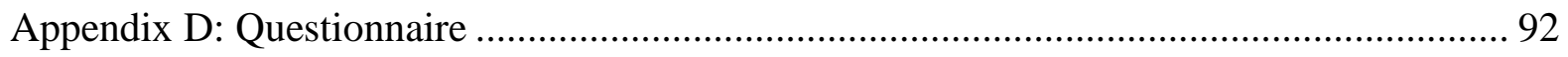

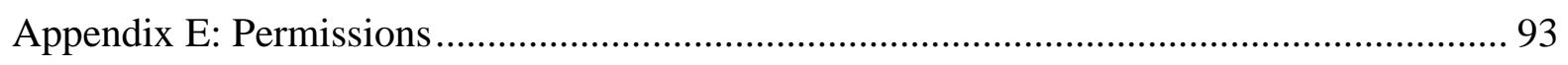




\section{Chapter 1}

\section{Introduction}

\subsection{Arthroscopic Surgery}

Surgical interventions of the shoulder are increasingly performed using a minimally invasive approach known as arthroscopic surgery [1]. In arthroscopic surgery, the surgeon enters the joint through small incisions using long, slender instruments and a long slender video camera. Images from the camera are displayed on a two dimensional screen and used to navigate the joint. A low-pressure saline solution is pumped into the joint in order to clear debris and inflate the joint space. The benefits to patients are several when compared to open surgery, including reduced tissue trauma, less postoperative pain and a shorter recovery time.

Arthroscopy is performed with the patient in one of two positions: beach chair or lateral decubitus. The operating position is selected based on the type of procedure and the surgeon's preference. For some procedures, the lateral decubitus position offers better joint visualization and instrument access, while the beach chair position has the advantage of easier set-up and easier conversion to open surgery if required [2].
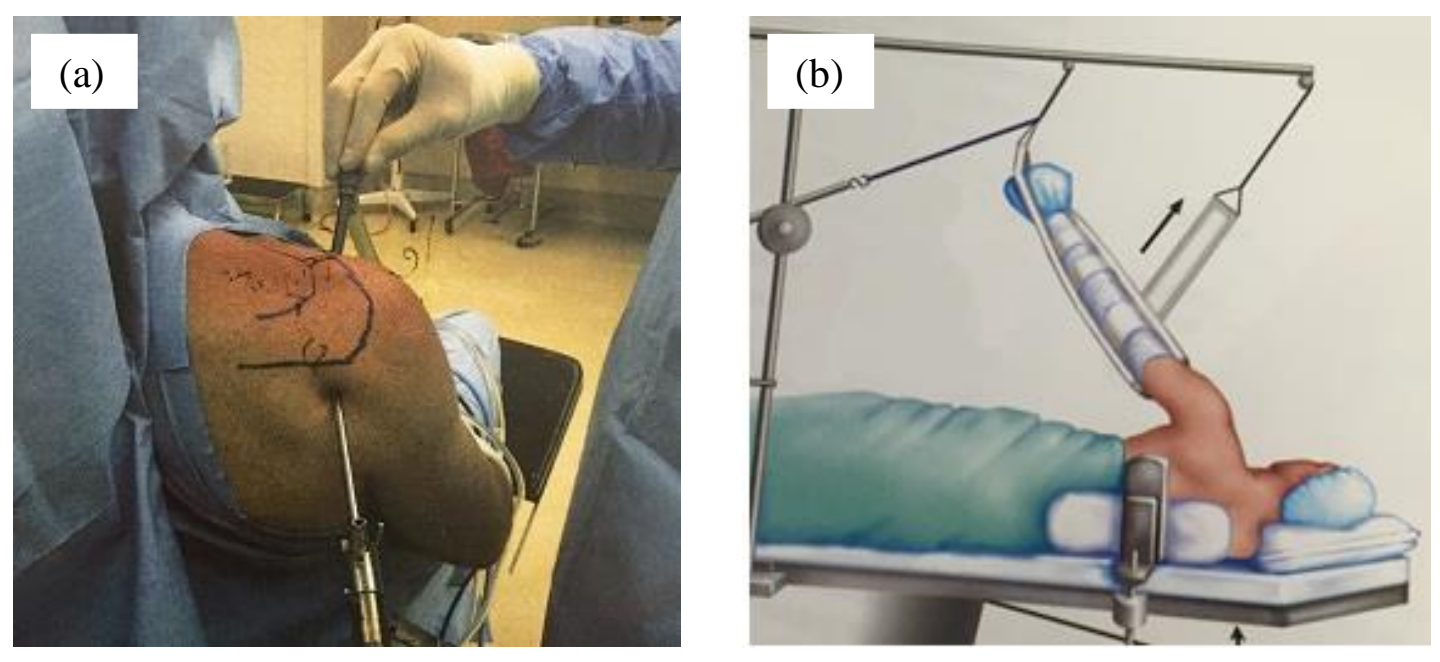

Figure 1.1: (a) Beach chair position [3] (b) Lateral decubitus position [3] 


\subsection{Motivation}

Arthroscopic surgery has now become a standard component of orthopaedic residency training programs $[4,5]$. At the same time, surgical residents are receiving fewer hours of training, while still having one of the busiest schedules of the surgical specialties [6, 7]. In a survey across 151 programs, Hall, et al. reported that only one third of fifth-year orthopaedic residents felt that they had adequate training in arthroscopy and 66\% did not feel as prepared to use arthroscopic interventions when compared to open surgery [5]. Arthroscopic surgery presents new challenges when compared to traditional open surgery, as surgeons are operating in an environment with different demands on their hand-eye coordination and limited tactile feedback [8]. For novice trainees, even the basic skill of triangulating an instrument tool tip in the view of the arthroscope can be challenging.

Inexperienced residents are at a high risk of committing errors, with the potential to inflict irreparable damage to a patient's joint while learning. They are also slow to complete tasks, due to a steep learning curve. Ideally, residents would be trained to a level of basic competence to ensure the safety of their first patients before entering the operating room $(\mathrm{OR})$.

A simulated surgical environment would allow for the teaching and practice of basic skills, resulting in lower risk to patients and with the added benefit of saving valuable OR time and the time of the expert surgeon. With the availability of a simulator, students are permitted to explore and repeatedly practice in a way that allows for one to learn from their mistakes, whereas traditionally there was no room for "teaching through errors" and students did not have "permission to fail" while learning [9]. By learning and practicing the basic skills before they enter the OR, residents would be able to use their time with their mentor to focus on more advanced skills and procedures [4].

Existing surgical simulators fall into one of two categories: Virtual Reality (VR) and Physical Simulators. A physical simulator is a bench top box trainer or anatomical model that is physical by nature, while a VR simulator is defined as "the computer-generated simulation of a three-dimensional image or environment that can be interacted with in a 
seemingly real or physical way by a person using special electronic equipment" [4]. Physical simulators have an advantage because they can realistically simulate the "feel" of the target anatomy and allow the trainee to use real surgical tools. By manipulating physical objects, trainees experience realistic tactile feedback. VR trainers have the advantage of easily offering "knowledge of results" in the form of performance metrics and results to the trainee, while this type of feedback has historically been lacking in physical simulators. Objective measures of performance are helpful to motivate trainees and track improvement during training. This "knowledge of results" has been found to be key to the learning process and the acquisition of psychomotor skills [10]. A detailed review of existing simulators is presented in Chapter 2.

This research focuses on the development of a physical shoulder simulator constructed with realistic anatomy, and a flexible joint, in order to provide a realistic feel to the trainees. Existing physical shoulder simulators lack quantifiable performance metrics which can provide valuable feedback to the trainees. The proposed simulator will allow for quantifiable performance metrics to be calculated.

\subsection{Research Objectives}

With shoulder surgeries increasingly being performed using an arthroscopic approach, there is a need for more effective training tools and improved evaluation methods to help train orthopaedic residents. The shoulder joint is second only to the knee in the number of arthroscopic procedures performed annually[11]. While many simulators have been developed for the knee, few are available for the shoulder. The physical shoulder simulators that exist lack a flexible joint that is able to accommodate both lateral decubitus and beach chair positions and have limited anatomy. The goal of this thesis is to develop, construct, and test a novel shoulder arthroscopy learning aid in the form of a physical simulator that could be used to train junior residents.

To achieve this goal, the following objectives were identified: 
- To design and build a novel physical shoulder joint-shaped simulator that helps novices to improve their basic arthroscopy skills through practice, while providing a means of assessing performance.

- To evaluate the simulator by collecting data from novice and expert users. Metrics will be calculated to determine if the simulator helps improve performance.

\subsection{Thesis Outline}

\section{Chapter 2: Literature Review}

This chapter details the existing work in the field of arthroscopic education using joint simulators. Existing simulators are reviewed. Work that has been done on evaluative metrics and validation is also discussed.

\section{Chapter 3: Simulator Design}

In the third chapter, the criteria that formed the basis of the simulator design are presented. The process followed towards creating the shoulder simulator and meeting the design criteria is discussed. The final version of the simulator is also presented.

\section{Chapter 4: Testing and Validation}

This chapter outlines the methods used for testing the surgical simulator and collecting data towards determining validity. The metrics that were computed based on force and position are also described. A summary of the results is presented.

\section{Chapter 5: Conclusions and Future Work}

This chapter presents the concluding remarks for this research and outlines future work, which could build and improve upon the current research. 


\section{Chapter 2}

\section{Literature Review}

\subsection{Psychomotor Skill Acquisition}

Certain basic motor skills have been shown to correlate with arthroscopic competence [12]. Learning to effectively use a new surgical tool requires processing visual and proprioceptive sensory information in order to produce the desired muscle movements to manipulate the tip of the instrument. The process involves creating internal models of both our body and the instrument through repeated practice. To a certain extent, these skills are innate to an individual, with motor skill proficiency equating to the trainee's psychomotor ability multiplied by the amount of practice they have undergone [4]. Psychomotor skill is defined by the Oxford English Dictionary as "the potential to produce voluntary muscular movements after practice" [13]. Therefore, lower psychomotor ability can, to an extent, be compensated for with increased practice [10]. In the mastery approach to training, all trainees should achieve a certain level of competence in order to function as a professional. With this approach, the training period should vary in length, as some trainees will require more practice time than others [10].

The acquisition of psychomotor skills was proposed by Fitts and Posner to occur in three stages: cognitive, associative and autonomous [14]. The cognitive stage requires the trainee to understand the task that they are setting out to complete. This is followed by the associative stage, which requires practicing, and learning from errors. During this stage, it is important that the trainee receive a "knowledge of results" to determine if they have performed the task adequately. After sufficient practice, the trainee moves to the autonomous third stage, at which very little cognitive intervention is required to perform the task. This learning paradigm is echoed by Satava who describes a two-step process: cognitive and psychomotor skill. Through repeated practice the trainee can automate many of the manual dexterity skills, thus freeing up cognitive resources for situational awareness. One of the main differences between expert and novice surgeons is that the 
experts have reached the autonomous level for simple tasks and can then focus on perception of the anatomy and forecasting the subsequent steps to be taken [9].

\subsubsection{The Challenge of Arthroscopy}

Arthroscopic surgery requires the practitioner to learn delicate and precise motor skills. The surgeon must combine muscle strength, dexterity, and spatial perception in order to achieve good control over the instruments and tissues being manipulated [10].

There are several aspects of arthroscopic surgery that make it especially challenging to learn and master. The view from the arthroscope is two-dimensional and appears zoomed-in on the display screen, with the power of magnification initially unknown to an inexperienced trainee. This often results in the novice underestimating of the motion of the instrument tip, and over-extending their movements [4]. Second, the standard and most generally used arthroscope captures the image from a viewpoint that is offset from the longitudinal axis by 30 degrees and can rotate a full 360 degrees. The result is that the visual system is no longer aligned as expected, making coordinated movements challenging. Third, since the instruments are being manipulated through a narrow portal, there is a fulcrum effect, where the subject's hands move in the opposite direction to the desired motion at the instrument tip. Furthermore, since the long, slender instruments are gripped outside of the joint, frictional forces from the portal and tissues can distort the forces experienced at the handle, resulting in confusing feedback sensations [4].

\subsection{Arthroscopic Training}

Arthroscopic surgery is taught as a core component in a majority of orthopaedic residency programs. Traditionally, this learning has occurred using a mentor-apprentice approach in the OR, with trainees using real instruments on human anatomy. However, this is not an ideal venue for novice trainees. With a patient's safety at stake, trainees are not permitted to make errors, which can be an important element of learning psychomotor skills.

In July 2013, the American Board of Orthopaedic Surgery (ABOS) introduced simulation requirements for resident education, signaling a shift in training philosophy [15]. A 
curriculum for teaching basic skills, known as the "Fundamentals of Arthroscopic Surgery Training" (FAST) program, is currently under development by The American Academy of Orthopaedic Surgeons in collaboration with the Arthroscopy Association of North America and the ABOS. The FAST program will determine what basic motor skills are required for arthroscopic surgery and develop training modules aimed at improving the identified motor skills [15], [16]. In the future, it is anticipated that the FAST program may become an American Board certification requirement, much like the Fundamentals of Laparoscopic Surgery (FLS) program is required for general surgery certification [7].

The European Society of Sports Traumatology, Knee Surgery \& Arthroscopy (ESSKA), introduced the ESSKA Basic Arthroscopy Course (EBAC) in November 2013. The threeday course uses a cow knee, cadaver knee and shoulder, and physical knee and shoulder simulators to hone trainees' motor skills and teach simple procedures.

In general, formal simulator based training initiatives for basic arthroscopic skills are still in the early stages of introduction. While a national training program has not yet been developed in Canada, some Canadian residency programs already encourage the use of simulators to hone arthroscopic skills. A well-constructed training program aligns learning objectives with means of training and methods of assessment [17]. The learning objectives should identify what skills are to be learned, and to what level of proficiency.

Research has been conducted into which skills should be learned for basic arthroscopy. In 2008, Safir et al. conducted a survey of orthopaedic surgeons across Canada. They investigated which elements are important for a simulator to possess to train residents in arthroscopic surgery before entering the OR [18]. Surgeons were asked to rank 35 skills on a five-point scale, and 111 responded. The top-rated specific skills were: 1) Precise portal placement 2) Triangulation of the probe with a 30-degree scope 3) Identification of specific structures of the knee, and 4) Insertion of the scope into the anterolateral portal. In a second questionnaire, surgeons ranked the importance of five skills for a trainee to possess prior to performing in the OR. Anatomical knowledge and triangulation/depth perception were ranked as the most important, followed by spatial perception, manual 
dexterity and tactile sensation. When asked which simulator type would be most helpful for a trainee, cadaveric specimen was ranked first, followed by a high-fidelity physical simulator, a VR simulator and lastly, a box trainer.

In 2013, Hui et al. [19] surveyed orthopaedic residents across Canada to identify what skills they felt were important to possess before entering the OR. The survey consisted of 35 questions and was answered by 67 residents. The top four specific skills for knee arthroscopy were, in terms of importance: 1) Triangulation of the tip of the probe, 2) Precise portal placement, 3) Arthroscopic examination-identification of specific knee anatomy, 4) Shaving of the synovium, cartilage and meniscus. These top five skills did not vary with year of residency. The top five general skills were 1) Anatomical Knowledge, 2) Spatial perception, 3) Triangulation/depth perception, 4) Manual dexterity, and 5) Tactile sensation. The residents preferred using cadaveric or synthetic knees as simulators, above VR or bench top models.

Preliminary results from a similar survey by the Dutch Arthroscopy Society among residents and experienced surgeons suggest that the most important priorities relating to simulator-based training prior to entering the OR are [4]: 1) Anatomical knowledge, 2) Spatial perception, 3) Tactile sensation, 4) Manual dexterity, and 5) Triangulation.

All three studies rated anatomical knowledge and triangulation as key area for training with a simulator, and in a review of these three studies, Karahan and Tuijthof concluded the important skills for training to be those required to gain access to and navigate the joint [17]. A 2008 study by Bayona et al. agreed with this finding. They asked 94 arthroscopists to examine a VR simulator. The surgeons rated anatomical knowledge, hand-eye coordination and manual precision as important factors for novices training on the simulator [20].

A review study in 2014 by Frank et al. indicated that the basic skills needed for arthroscopic surgery are: 1) Visual-spatial coordination to interpret 3-dimensional structures from 2-dimensional camera images. 2) Hand-eye coordination to triangulate and adjust the visual field. 3) Psychomotor skills to perform the desired procedure 
without causing iatrogenic injury [6]. These should be the skills that new residents acquire before encountering their first patient.

There has been debate on the level of fidelity that should be present in simulators for novice trainees. Low-fidelity box trainers have been reported as less useful for training basic skills because they lack simple anatomy, which is regarded as a key element in training novices [17]. However, Norman argues that having a simulator with very high fidelity results in unnecessary higher costs, and cognitive overload where the additional sensory information may overwhelm novices and detract from learning basic skills [21]. Norman concludes that training with either high fidelity or low fidelity simulation results in improved performance. However the gains for very high fidelity simulation over lower fidelity simulation are not statistically significant and rarely justify the higher cost. Norman reports that for motor skills, the feel of instruments and tissues is important, while the colour and shape are less important. The paper by Norman also calls into question the importance of context in training. Contextualized practice is when the simulator and environment more closely mimics the operating environment.

\subsection{Arthroscopic Simulators}

The historical beginnings of simulator training can be traced back to the early days of the aviation industry, as a way to train pilots in the principles of flying an aircraft without risk to the trainee [4]. Since then, industries such as the military and nuclear power have also embraced simulators as a way to train personnel. Simulators were introduced as a way to train surgeons in the late 1980s, with neurosurgery and vascular surgery acting as the early adopters [9]. While orthopaedic surgery has been slow to adopt simulation as a training method, this is beginning to change [22].

Cadavers are often the first choice of surgeons for practice because they provide a real anatomical experience [4]. However cadaver use in a training program is limited by expense, availability, and locations at which residents can train. There may also be

concerns related to the presence of pathogens. Animal models have also been used to teach surgical skills [23] and have been proposed as a model for teaching knee arthroscopy [24], [25]. However, there are concerns with the moral and ethical issues that 
arise from the use of animal models for training, especially when alternatives are available. Animal models can also be expensive and difficult to acquire [23]. Furthermore, while a bovine knee may be a representative model for the human knee joint; the anatomy of the human shoulder joint is quite different from animals due to our bipedal stance. As a result, animal models are much less useful for training arthroscopy of the human shoulder joint. While both cadavers and animal models have limited opportunity for integrated performance feedback, synthetic simulators offer the possibility to include quantitative performance feedback metrics so that trainees can follow their own progression. Synthetic simulators are a promising alternative to animal or cadaver practice. With the use of simulators, residents will be able to gain exposure at their own pace, as often and whenever they want.

There are two main categories of synthetic joint simulators: physical and VR. Arthroscopic surgery relies on the senses of touch and vision, so an effective simulator should provide a realistic feel and visual feedback.

\subsubsection{Virtual Reality Simulators}

VR simulators provide a computer-simulated environment that includes the main characteristics of the joint anatomy. Through the use of haptic devices, these simulators can provide force feedback and create a somewhat realistic interaction with the simulated environment.

VR trainers have the advantage of easily offering performance metrics and results to the trainee, while this type of feedback has historically been lacking in physical simulators. Objective measures of performance are helpful to motivate trainees by allowing them to track their improvement during training. This "knowledge of results" has been found to be key to the learning process and to the acquisition of psychomotor skills [10]. The main drawbacks of VR simulators are high costs and poor haptic feedback [17].

Several VR arthroscopy simulators have been researched and developed over the past decade and a half. The Virtual Environment Knee Arthroscopy Training System (VEKATS) was introduced in 2001 and recorded task time and the percentage of anatomical 
structures visualized [26]. In 2004, Heng et al. described the PHANToM Desktop for knee arthroscopy, along with a mock-up leg and sensors. The setup allowed for both visual feedback and robotic haptic feedback, however there was no performance evaluation of trainees [27]. The Mentice Corp Procedicus shoulder arthroscopy simulator was evaluated by Srivastava et al. in 2004 [28]. The simulation of a right shoulder was found to be much larger than a human shoulder and the anatomic model was static and had poor resemblance to a human shoulder joint. The authors note the need for standard performance measurements of accuracy and efficiency, which are lacking. The Munich Knee Joint Simulator consisted of an "interactive phantom" with a user interface providing haptic, visual and acoustic feedback. A force sensor located between the phantom joint and the actuator recorded the forces applied by the user. Position based performance metrics were not included in the system [29]. In 2006, the Sheffield Knee Arthroscopy Training System (SKATS) was shown to produce metrics such as task time, ability to locate pathologies, and arthroscope path length. The simulator included physical bone models in the limb interface to provide passive haptic feedback. The authors note that it is important for the simulator to feel realistic and have a physical sense of resistance [30]. Bayonat et al. collaborated with GMV to design the instightMIST shoulder simulator, with graphical and haptic rendering, in order to provide a more realistic environment to trainees. An evaluation module was available to record performance metrics; however it was not validated [31]. This group later reported the development of the insightArthroVR simulator for knee and shoulder surgery, which was validated. In 2012, the Simbionix Corporation acquired the insightArthroVR and renamed it the ArthroMENTOR training system. The system is commercially available and has active haptic feedback provided by robotic force feedback devices and can simulate diagnostic and therapeutic procedures as well as presenting statistical data for training assessment [32].

There have been several other VR simulators that have recently become commercially available. VirtaMed offers the ArthroS knee and shoulder trainers, which combine a plastic model of the anatomy with a VR visual user interface. Their knee simulator was evaluated by Fucentese et al. in 2014 and the study noted that there was a mismatch between the anatomical replicas and their virtual counterparts which can lead to 
inaccurate haptic feedback $[33,34]$. ToLTech has developed the ArthroSim Arthroscopy Simulator for the knee and shoulder. The simulator employs active force-feedback haptic devices and is currently exclusively used for training in diagnostic procedures.

The main difficulty in the development of the VR simulators is achieving realistic kinesthetic and tactile feedback [31]. Existing haptic devices do not provide a true representation of the forces that exist. The impaired instrument motion realism or reduced quality of certain graphic designs' realism can compromise the applicability of VR simulators to training for real surgery.

\subsubsection{Physical Simulators}

Physical simulators have an advantage because of their realistic "feel", as the trainee can use real surgical tools to manipulate physical objects providing them with realistic tactile feedback.

Physical simulators are often described as either "box trainers" or "anatomical bench models" depending on their level of realism [4]. Box trainers are low-fidelity simulators that do not have a close resemblance to a human joint. Anatomical bench models, otherwise known as phantoms or dummies, more closely resemble the human joint when compared to box trainers. Meyer et al. created a knee trainer in 1993 called the "Black Box", which could be used in either a dry or wet configuration. The "Black Box" also included electrical feedback for the dry configuration, such that contact of the probe and the metallic meniscus completed an electrical circuit, producing a buzzing sound. However, the electrical components had to be removed before using the trainer in the wet configuration. The "Black Box" design was considered low fidelity and did not realistically resemble a knee [35].

Hillway Surgical have developed anatomical bench models of the knee and shoulder with replaceable parts that can be utilized in both wet and dry training [4], however no automated performance feedback is available [36]. Escoto et al. reported the development of an anatomical knee trainer that could be used in a realistic wet environment [37]. Force and position sensors were included to collect data for the objective evaluation of trainees. 
The probing task used a visual estimate to determine completion of the task. Stunt et al. described the PASSPORT version one and version two knee simulators, developed to imitate the surgical setting. The system uses standard arthroscopic tools on a physical simulator consisting of an anatomically correct knee model accessed using the three most common portal locations and irrigation provided by a gravity pump and suction. The goal of the system was to provide clinical variety, visual and force feedback and performance feedback. Motion is recorded in a two dimensional plane and force is recorded by sensors placed at the tibia plateau and the femur [38]. Sawbones offers several anatomical bench models of the knee and shoulder (ALEX II and III Shoulder Professor, ACL Knee Trainer, and Encased Knee) [39], which offer replaceable parts. Some of these models can be used in both wet and dry conditions. However they have yet to add sensors to these models to provide feedback. Other anatomical bench top models of the knee and shoulder that provide realistic anatomy but lack any sensing ability are available from Adam, Rouilly, CLA, and Beijing Yimo [40]-[42].

In their 2015 textbook, ESSKA acknowledges that physical simulators have the advantage of offering natural feedback through the user's visual and proprioceptive senses, due to their physical nature. Physical simulators are typically less expensive than VR simulators, making them more affordable. The main criticism of physical simulators lies in their ability to provide meaningful, objective feedback to the trainee [4].

In their survey of orthopaedic surgeons, Safir et al. found that simulation with a highfidelity physical model ranked after cadaveric specimens as the most helpful method for a novice trainee to prepare for the OR. VR simulators ranked third, ahead of box trainers [18].

The shoulder simulator proposed herein combines the desired sensory feedback available in physical simulators with the objective measurements available in the VR designs.

\subsection{Simulator Validation}

In order to ensure that the simulator effectively accomplishes what it proposes, it must be validated. There are different types of validation that can be performed; a few relevant 
types are presented here. Face validity is typically the first validation performed. It is a subjective measure that relies on expert opinion to determine how closely the simulator appears to resemble what it is supposed to. Construct validity is important as it shows the ability of the simulator to distinguish between levels of performance, such as between experts and novices. Transfer validity indicates that skills trained on the simulator transfer to the OR or to performance on a cadaver. The literature contains several examples of these validities for arthroscopy simulators.

\subsubsection{Face and Construct Validity}

In 2011, Tuijthof et al. evaluated two VR knee simulators for face and construct validity [43]. They invited novice, intermediate and expert subjects to use the simulator. To test face validity they used a questionnaire that asked about realism, perception and educational value. To assess construct validity, the time to perform a task was measured and compared between novice, intermediate and expert subjects. They found satisfactory face validity and partial construct validity.

The insightArthro VR knee and shoulder simulator was assessed by Bayona et al. for face and construct validity [20]. They recruited 94 arthroscopists at a conference and asked them to perform a task on the simulator, and to answer a questionnaire. The results supported face and construct validity for the VR simulator.

Another VR shoulder simulator, the Procedicus from Mentice Corp, was validated by Srivastava et al. [28]. The study showed construct validity by verifying that experienced surgeons score better than novices on three tasks: anatomical identification, hook manipulation, and scope navigation.

The PASSPORT physical knee simulator was assessed in 2014 [38]. A standardized joint navigation task to probe 9 landmarks was timed, and used to assess construct validity. A questionnaire was used to determine face validity and participants rated the realistic tactile feedback as the simulator's greatest strength. 
Correlation between performance on a VR shoulder simulator and level of surgical experience was shown by Gomoll et al. in 2007 [44]. The metrics that were compared were time to completion, distance travelled compared to an "optimal distance", average probe velocity, and number of probe collisions with the tissues. A strong correlation was found between these results and level of surgical experience.

In 2011, Martin et al. showed a correlation between performance on a cadaveric shoulder and a VR shoulder simulator. The task completion time on the simulator was shown to predict performance on a cadaver [45].

\subsubsection{Transfer Validity}

Transfer validity is important to demonstrate because it shows that skills learned in simulator training can translate to performance in the OR. This provides justification for incorporating arthroscopic simulation into core residency training. Transfer validity in laparoscopic training is well established and shows that skills training on a simulator transfers to performance in the OR [46] [47] [48]. It is less established for arthroscopic simulators; however several studies have been published that demonstrated skill transfer to cadavers and patients.

In 2008, Howells et al. studied junior orthopaedic trainees who trained on a physical knee simulator with three sessions per week and six simulations per session. They were compared to trainees who received no additional practice. The trainees who used the simulator performed significantly better in the OR, demonstrating transfer validity of arthroscopic skills from the physical knee simulator [49].

A second study demonstrating the transfer validity of simulator-trained arthroscopic skill to the OR was published in 2014 by Cannon et al. and utilized a VR knee simulator. The study spanned seven academic institutions, involving 48 PGY three residents, who were randomized into two groups for either simulator training or no additional training. The residents who were in the simulator training group underwent four rounds of progressive training on the simulator for visualization and probing skills. Both groups then performed a diagnostic knee arthroscopy procedure on a live patient. Their surgeries were recorded 
and sent to the AAOS for evaluation [50]. The residents trained on the simulator showed greater skill in the OR, in particular when completing the probing tasks, thereby demonstrating transfer validity. No difference was shown for the visualization task.

A study conducted in 2013 by Henn et al, demonstrated transfer validity from VR shoulder simulator to a cadaver by comparing the effect of training on 17 first-year medical students with no prior experience. All candidates performed a baseline task on a cadaver. Nine students received six training sessions over three months, while the other 8 students received no training. The students then repeated the same cadaveric arthroscopy. The simulator group was found to have significantly improved time to completion, compared to the untrained group, demonstrating a value of simulator training in arthroscopy [51].

In a separate 2013 study by Butler et al., subjects were trained to perform a diagnostic arthroscopy on a physical knee simulator before training for the same procedure on a cadaver. The control group had no prior training before performing the diagnostic arthroscopy on the cadaver. The two groups were compared based on the mean number of trials required before attaining proficiency on the cadaver, and the mean number was found to be significantly lower for the group who received training on the simulator, indicating a transfer of training [52].

The demonstration of transfer validity from these studies offers strong support for further work developing arthroscopic simulators and their use as a training tool.

\subsection{Performance Evaluation}

Providing trainees with an objective assessment of their performance is an important part of the motor learning process. Feedback to the trainee can be given using global rating scales or quantitative metrics. An effective evaluation is reliable, valid, and unbiased.

\subsubsection{Global Rating Scales}

Global rating scales (GRS) are structured scoring rubrics with well-defined anchors. They are used by expert surgeons to objectively judge performance. Scales such as OSATS 
(Objective Structured Assessments of Technical Skills) and GOALS (Global Objective Assessment of Laparoscopic Skills) have been developed, validated and used to evaluate performance in laparoscopic surgery [23][53]. Recently, several global rating scales have also been proposed for performance evaluation in arthroscopic surgery.

In 2009, Insel et al. developed the Basic Arthroscopy Knee Skill Scoring System (BAKSSS), which showed a strong correlation between scores from a 5-point Likert type global rating scale and arthroscopic experience [54].

A "Global Rating Scale for Shoulder Arthroscopy" (GRSSA) was proposed in 2011 by Hoyle et al. as the first such scale for arthroscopy of the shoulder. The global scale used six criteria for assessment, each of which were scored on a 5-point Likert type scale [55]. The GRSSA was shown to be able to discriminate between different levels of training, but lacked inter-rater reliability.

The Arthroscopic Surgical Skill Evaluation Tool (ASSET), described in 2013, uses a 5point Likert-type GRS scale. The ASSET tool aims to evaluate a resident's global arthroscopic technical skill using eight domains to assess a particular part of arthroscopic skill acquisition. The tool was shown to have the ability to discriminate between levels of surgeon experience, as well as have good inter-rater reliability [1].

Bayona et al. created the Imperial Global Arthroscopy Rating Scale (IGARS) in 2014. It was tested on a VR shoulder simulator and comprised ten criteria rated on a 5-point Likert type scale. The IGARS scale was able to distinguish between levels of experience on the simulator [56].

It can be noted that the scales are similar, with several arthroscopic skills being rated on a 5-point scale. Such Global Rating Scales can provide validated and meaningful feedback to trainees. However, they require an expert surgeon to rate the performance either during the training session, or later via video replay. This evaluation can be a costly and substantial time burden when used for very basic skills training. The GRS may be better justified for training more complex skills and procedures. 


\subsubsection{Quantitative Metrics}

Alternatives to the GRS are quantitative metrics that can be monitored and rated by a computer. A metric is defined by ESSKA as "a quantity that in this context is supposed to reflect part of the performance of a trainee" and is synonymous with a measure or parameter [4]. Objective metrics are recorded by sensors and the data can be used to provide real-time feedback, or it can be post-processed to provide feedback after the task. Time based, position based and force based metrics have been previously studied in laparoscopic and arthroscopic surgery.

The task time, which is the time elapsed between start and finish of the task, is a widely used metric and is easy to measure. It has been used in many studies [8], [43], [57]-[59] [47]. Although it is not a good reflection of the quality of executed task, it does highly reflect economy of motion [60].

The PASSPORT V2 training environment incorporated force and motion sensors into their physical knee simulator, in addition to task time. Motion was measured using a webcam and yellow markers that were attached to the scope and instrument. The 3D force sensors measured the forces applied to the simulator at the tibia plateau and the femur and were used to deliver a warning to subjects when a maximum force was exceeded [38].

Tashiro et al. used an electromagnetic motion tracking system and a force sensor with a physical knee simulator to collect task performance data. Experienced surgeons were compared to novices and found to follow a shorter path length and have a higher probe velocity. The novices were found to apply stronger forces to the joint during a probing task [61].

Motion analysis was investigated as a way to distinguish between orthopaedic surgeons and non-surgeons by Howells et al. in 2008. The study used a physical shoulder simulator combined with the Patriot motion tracking system from Polhemus. Subjects performed probing and grasping tasks. Experienced surgeons were found to travel shorter path lengths and have fewer hand movements compared to the non-surgeons [57], [57]. Path 
length and hand movements were also shown to correlate with learning curves in two arthroscopic tasks (one shoulder, one knee) in a study by Alvand et al. in 2011 [36].

Jerk, or motion smoothness $\left(\mathrm{m} / \mathrm{s}^{3}\right)$ is a metric that measures changes in acceleration and reflects jerky movements of the instrument. Smooth motion is important for safe tissue manipulation. In 2012, Oropesa et al. showed significant differences between groups, in particular for grasping tasks involving bimanual coordination in a laparoscopic surgical context [62]. Jerk was also shown to be a relevant metric in laproscopy by [63]. Whether jerk is also relevant to arthroscopy has not yet been determined. Smoothness was considered to be an important metric for the IGARS scale, but was not quantified [56]. Other possible motion based metrics that could be investigated are average velocity and peak velocity.

In a 2014 review paper by Frank et al., it was concluded that a standardized objective measurement scheme to evaluate performance based on simulator use is necessary [6]. In this thesis, a Likert-type scale will be used to assess the face validity of the simulator while quantative metrics based on time, force and position will be used to assess construct validity.

The current state of arthroscopy simulation suggests that a physical shoulder simulator which provides realistic tactile feedback, realistic anatomy for the training of navigation skills, and accommodates both the beach chair and lateral decubitus positions, would be helpful in training novice surgeons. The following chapters present the design and development of such a simulator, as well as an evaluative study. 


\section{Chapter 3}

\section{Simulator Design}

The literature review revealed a lack of physical simulators for the shoulder joint that provide quantitative feedback to the trainee. To address this limitation, a physical simulator was designed in order to provide novice trainees with a means for practicing basic arthroscopy skills, such as triangulation, navigation of anatomy, and probing, before they enter the operating theatre.

The physical shoulder simulator was conceived with guidance from Dr. Marie-Eve LeBel, an orthopaedic surgeon at St. Joseph's Health Care Centre in London, Ontario, who specializes in arthroscopic procedures. The simulator was designed in response to a need for better training devices for junior orthopaedic residents.

\subsection{Design Requirements}

The design of the physical shoulder simulator was driven by a number of requirements. The most important of these being:

- The simulator must include basic anatomic structures of the shoulder, and permit the completion of realistic arthroscopic surgical actions.

- The design must utilize economical and replaceable parts.

- The simulator must facilitate either dry or wet practice.

- The design must accommodate both lateral decubitus and beach chair operating positions.

- The simulator must allow measurement of the actions of trainees while developing basic arthroscopic skills in tasks such as triangulation, precise instrument motion, locating and removing debris/loose bodies. 
- The simulator must include the posterior, anterior and lateral subacromial portals to access the joint.

\subsection{Conceptual Design and Specifications}

In order to specify the design, each component of the simulator was carefully evaluated and selected, as detailed in the following sections.

\subsubsection{Range of Motion for the Arm}

Arthroscopic surgery can be performed in either the beach chair or lateral decubitus position. In the beach chair position, the arm is down by the patient's side and the torso is reclined. In the lateral decubitus position, the patient is lying on their side with their arm suspended above. The simulator's arm must be able to accommodate both positions. The required range of motion was determined through consultation with an orthopaedic surgeon and is shown in Figure 3.1. 


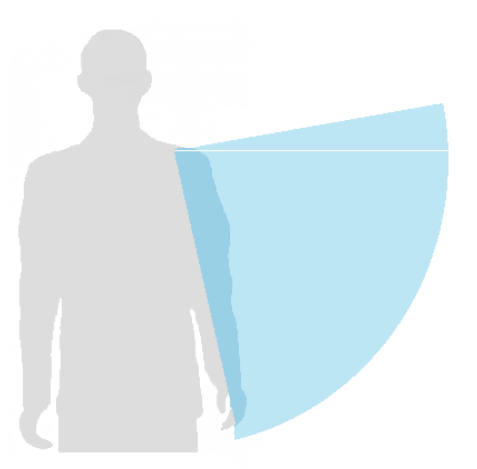

Abduction: 90 degrees

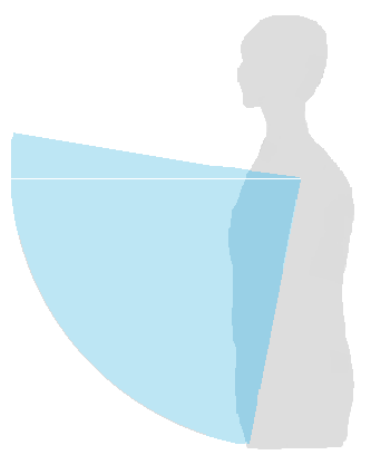

Forward Rotation: 90 degrees

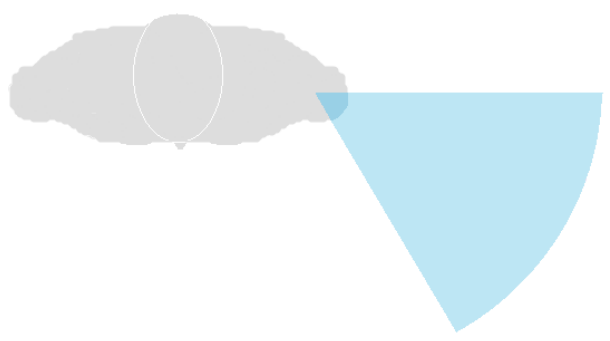

External Rotation: 60 degrees

Figure 3.1: Required range of motion for the arm.

\subsubsection{Physical Anatomy}

Another requirement of the simulator was that it needed to include basic anatomic structures of the shoulder. The glenohumeral joint of the shoulder is the most mobile joint in the human body, and comprises the head of the humerus in articulation with the surface of the glenoid. The coracoid process is an anterior protrusion of the scapula (shoulder blade), while the acromion is a posterior bony protrusion of the scapula (Figure 3.2). A fibrous capsule covers the glenohumeral joint, and the biceps tendon travels over 
the head of the humerus, inside the joint capsule, attaching to the top of the glenoid (Figure 3.2 and Figure 3.3). The muscles of the rotator cuff cover the capsule, and act to stabilize the shoulder. These muscles have origins on the scapula and their tendons insert on the humerus.

The simulator aims to teach basic arthroscopic skills such as navigation of the anatomy. As such, the simulator design must include the basic anatomic structures of the shoulder (bones and soft tissues).

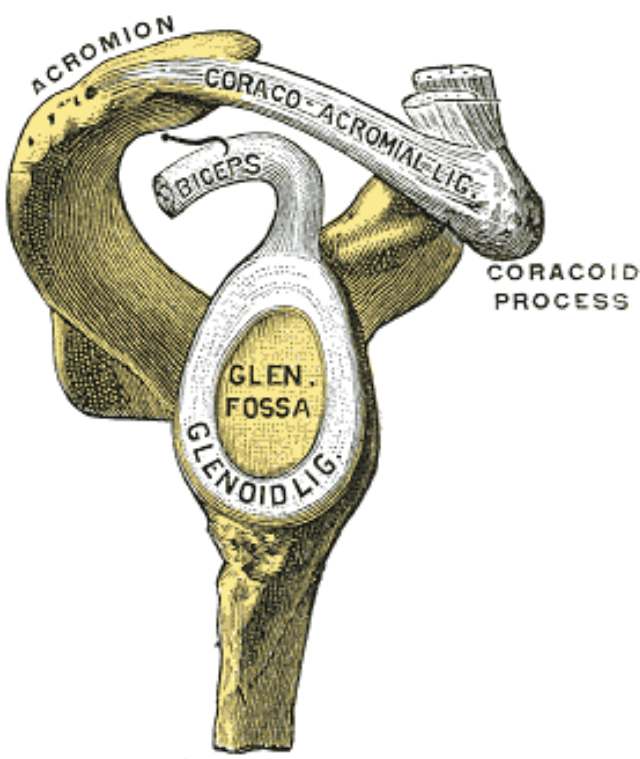

Figure 3.2: Sagittal view of the shoulder joint showing the glenoid [64].

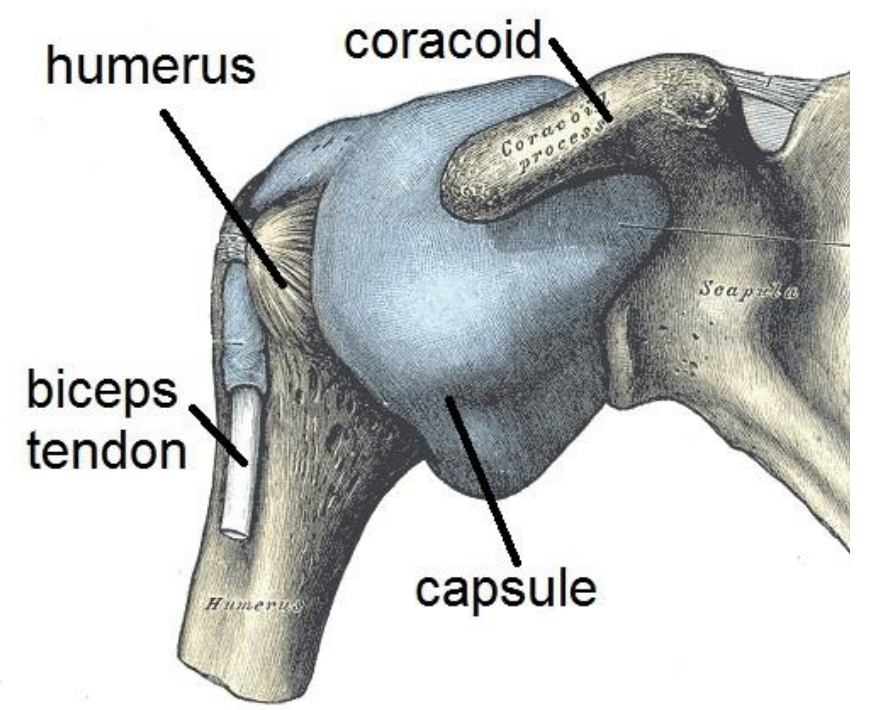

Figure 3.3: External view of shoulder joint with capsule [64]. 


\subsubsection{Synthetic Bone Selection}

The selection of which bones should be included in the simulator was determined through consultation with an orthopaedic surgeon. The selected bones are shown in Table 3.1, as well as whether or not they will be visualized by the arthroscope during use. The scapula and diaphysis of the humerus are not visualized during basic arthroscopy tasks but are included in the simulator for structural reasons. The clavicle is normally seen through the arthroscope, and would contribute to the realism of the simulator, but was excluded from the design because it would breach the waterproof compartment around the shoulder joint.

The realistic feel of the properties of human bone had to be considered, as the simulator could be used to train residents using a shaving tool to remove bone. Currently, arthroscopy surgical residents use cadaver bones to practice the use of a surgical shaving tool. However, cadavers are not readily available, are expensive and can present a biohazard. Foam bones are advantageous to use for training because they have consistent mechanical properties, are relatively inexpensive, are readily available, and can be used anywhere [65].

Table 3.1: Bones of the shoulder.

\begin{tabular}{lll}
\hline Bone & Included in simulator & Visualized with arthroscope \\
\hline Humerus (epiphysis) & yes & yes \\
Humerus (diaphysis) & yes & no \\
Glenoid & yes & yes \\
Scapula & yes & no \\
Acromion & yes & yes \\
Coracoid process & yes & yes \\
Clavicle & for future development & yes \\
\hline
\end{tabular}

Polyurethane foam was selected as a material for the synthetic bones because the mechanical properties have been reported to approximate those of human bone [65]. This conclusion is supported by the ASTM Standard Specification for Rigid Polyurethane Foam for Use as a Standard Material for Testing Orthopedic Devices and Instruments 
which states: "the uniformity and consistent properties of rigid polyurethane foam make it an ideal material for comparative testing of bone screws and other medical devices and instruments" [66]. Polyurethane bones are easily moulded into realistic shapes, which make them ideal for building physical orthopedic models, including surgical simulators.

Pacific Research Laboratories (Vachon Island, WA) produces synthetic polyurethane bones from rigid thermoset polyurethane foam under the brand Sawbones. Sawbones have been previously used to construct surgical simulators [37]. However, the Sawbones product is typically used to approximate human bone in dry applications. Preliminary tests showed that the Sawbones were more difficult to shave when submerged in water, compared to shaving in a dry environment. It was hypothesized that using lower density foam for submerged shaving tasks could improve the realism of the task. In order to select the correct foam density for the simulator, tests were performed to examine the mechanical changes in the synthetic bone between wet and dry environments, as described below.

Methods:

A total of seven polyurethane solid foam samples were obtained from Sawbones with density ranging from $80 \mathrm{~kg} / \mathrm{m}^{3}$ to $640 \mathrm{~kg} / \mathrm{m}^{3}$. A series of evaluations were performed on the foam samples, as follows:

Three Point Bend Test: The modulus of elasticity was measured, to see if a change occurred in the physical properties after soaking the polyurethane foam in water. A three point bend test was performed using an Instron 8874 machine as directed in the ASTM standard [67], as shown in Figure 3.4 (a). Testing blocks were cut from five different density Sawbones' bones $\left(300 \mathrm{~kg} / \mathrm{m}^{3}, 350 \mathrm{~kg} / \mathrm{m}^{3}, 360 \mathrm{~kg} / \mathrm{m}^{3}, 390 \mathrm{~kg} / \mathrm{m}^{3}\right.$ and $450 \mathrm{~kg} / \mathrm{m}^{3}$ ) into the standard test size. On day one, samples were tested dry and tests were repeated at 5, 15, 30 and 60 minutes of total soak time, Figure 3.4 (b). The samples were left to air dry overnight and on day two the tests were repeated. 


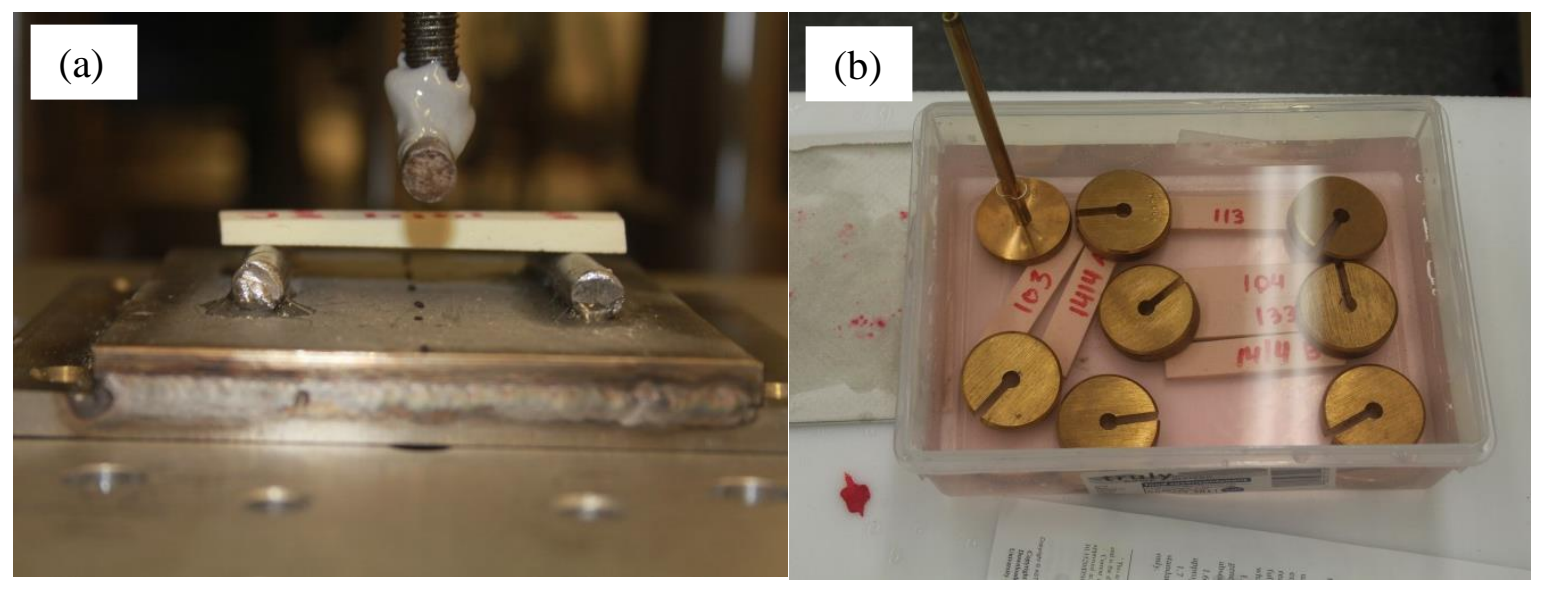

Figure 3.4: (a) Instron machine performing the three point bend test. (b) Polyurethane foam samples soaking.

Cutting Test: The "machinability" of the Sawbones was also tested directly by shaving a section of the bone for a set period of time and measuring the depth of the cut. A Stryker arthroscopic hand controlled shaver was attached to a weighted board set up to pivot as the shaver moved through the substrate with the force of gravity. The shaver was applied to the sample block while dry and also while the blocks were submerged, after soaking for 15 minutes. The test was repeated 10 times. For this test, a wider range of bone densities was used for testing $\left(80 \mathrm{~kg} / \mathrm{m}^{3}, 300 \mathrm{~kg} / \mathrm{m}^{3}\right.$, and $\left.640 \mathrm{~kg} / \mathrm{m}^{3}\right)$ in order to highlight any effect of density. The test was also performed on a human cadaveric humerus for comparison, as this was a customized test and there were no published values for reference.

Results:

The results of the three point bend tests are presented below. On average, the elastic modulus decreased by $6 \%$ after 60 minutes of soaking on day one, as shown in Figure 3.5 and by $7.9 \%$ after 60 minutes of soaking on day two as shown in Figure 3.6. As expected, the elastic modulus was found to increase with density and the density was the most influencing factor. The blocks were found to have the highest elastic modulus when dry, compared to the soaked samples. The results were found to be similar to published values of 164-260 MPa for Sawbones with foam densities of $320-332 \mathrm{~kg} / \mathrm{m}^{3}$ [68], [69]. The values were found to be lower than the published values for human cortical bone and on 
the low end for human cancellous bone $[70,71]$. The decrease in elastic modulus was not significant and was not considered sufficient to explain the difficulty with shaving the bones under water.

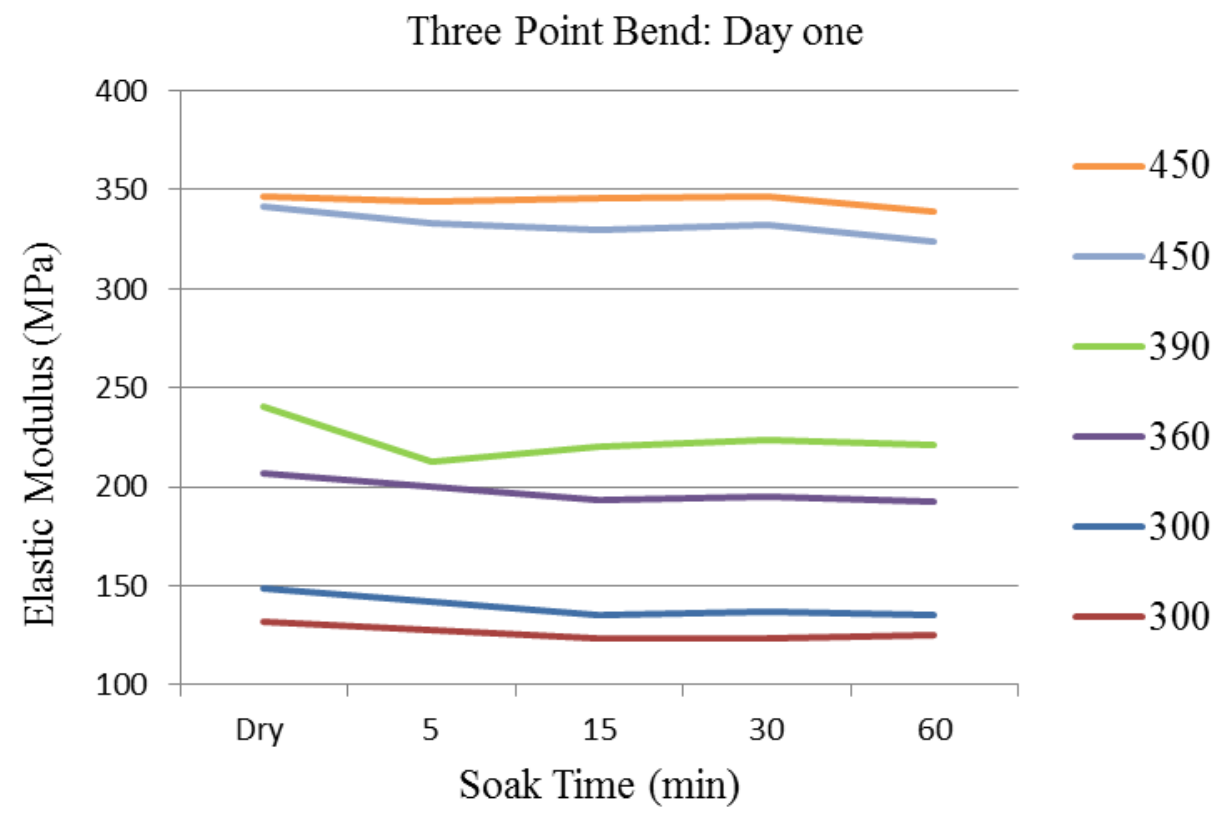

Figure 3.5: Results from day one of the three point bend test by density $\left(\mathrm{kg} / \mathrm{m}^{3}\right)$.

Three Point Bend: Day two

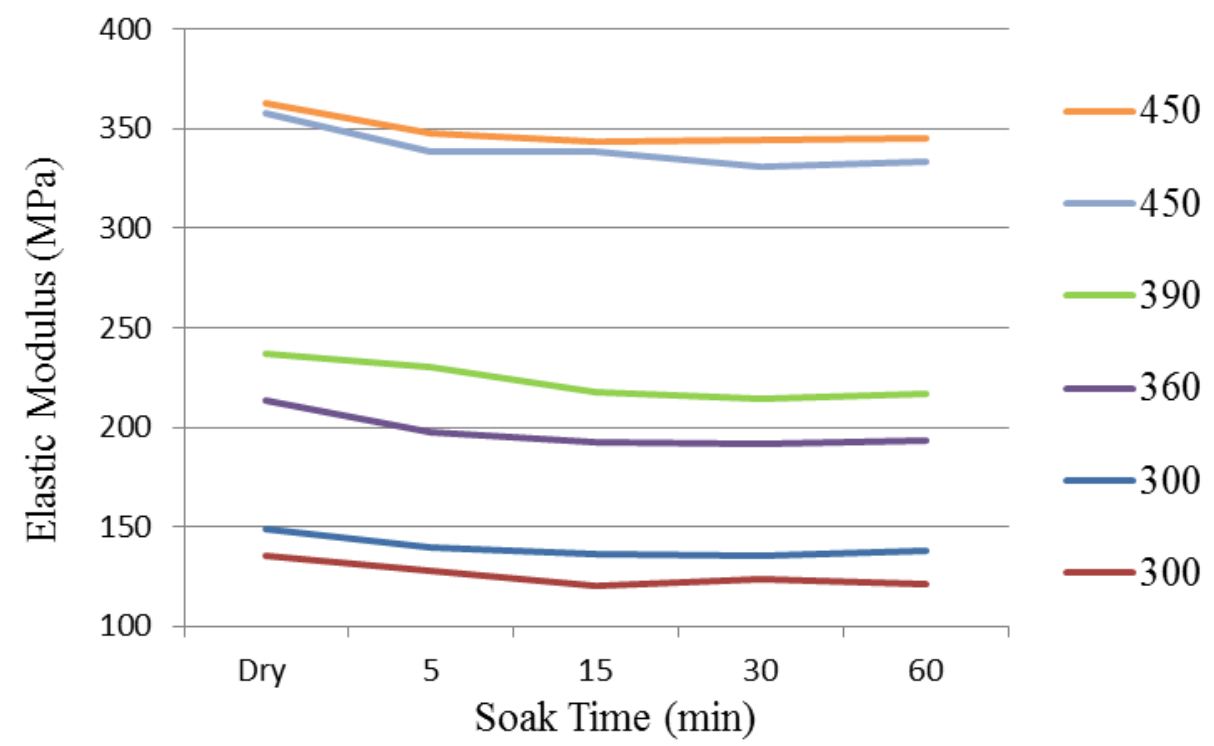

Figure 3.6: Results from day two of the three point bend test by density $\left(\mathrm{kg} / \mathrm{m}^{3}\right)$. 
With respect to the cutting test, there was a significant change noticed in the depth of the cuts when the blocks were cut with the shaver in a dry environment compared to a wet environment (Table 3.2). The human humerus was a defrosted fresh frozen sample, which was inherently moist. It was not dried for testing because the goal of the test was to select a foam density to use while in water.

Table 3.2: Results of the shaving test averaged over 10 samples.

\begin{tabular}{llll}
\hline Material & Dry $(\mathrm{mm})$ & Submerged $(\mathrm{mm})$ & $p$ value \\
\hline $80 \mathrm{~kg} / \mathrm{m}^{3}$ & 12.72 & 3.55 & $3.4 \times 10^{-6}$ \\
$300 \mathrm{~kg} / \mathrm{m}^{3}$ & 6.50 & 2.32 & $1.4 \times 10^{-5}$ \\
$640 \mathrm{~kg} / \mathrm{m}^{3}$ & 1.88 & 0.73 & $1.86 \times 10^{-5}$ \\
Human humerus & -- & 1.16 & -- \\
\hline
\end{tabular}

As expected, the density varied inversely with machinability, both in the wet and dry environments. A thermocouple was attached to the shaver tip to measure the cutting temperature while dry. The temperature was found to exceed $150{ }^{\circ} \mathrm{C}$. One explanation for the increased shaving depth in dry environments could be that the increased temperature of the shaving tool in the dry environment allows for easier cutting, compared to the quenched wet environment.

Based on the results, it was determined that the preferred foam density for performing shaving tasks in water is slightly higher than $300 \mathrm{~kg} / \mathrm{m}^{3}$, which is the standard density foam used by Sawbones.

\section{Procured Bones}

The bones (Figure 3.7 and Figure 3.8) were procured from Sawbones (Models 1051-26, 1051-27, 1050-34-4, and 1050-69, Vashon Island, Washington). The acromion, humerus head and glenoid (with labrum) are replaceable parts and therefore could be used for destructive tasks such as shaving. The bones were available for the left shoulder only, and so it was decided to design the simulator for the left shoulder. 


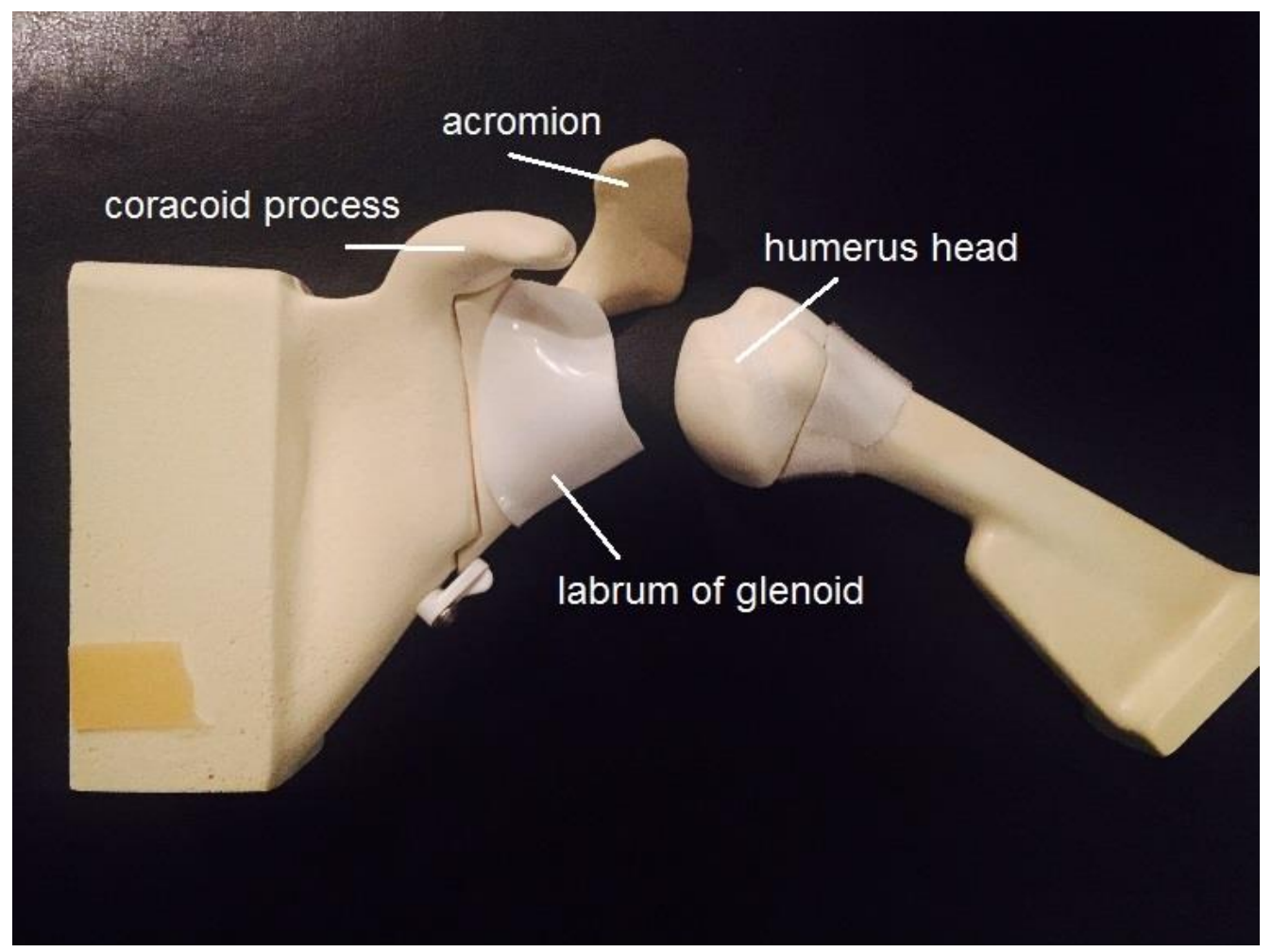

Figure 3.7: Shoulder bones (coronal view).

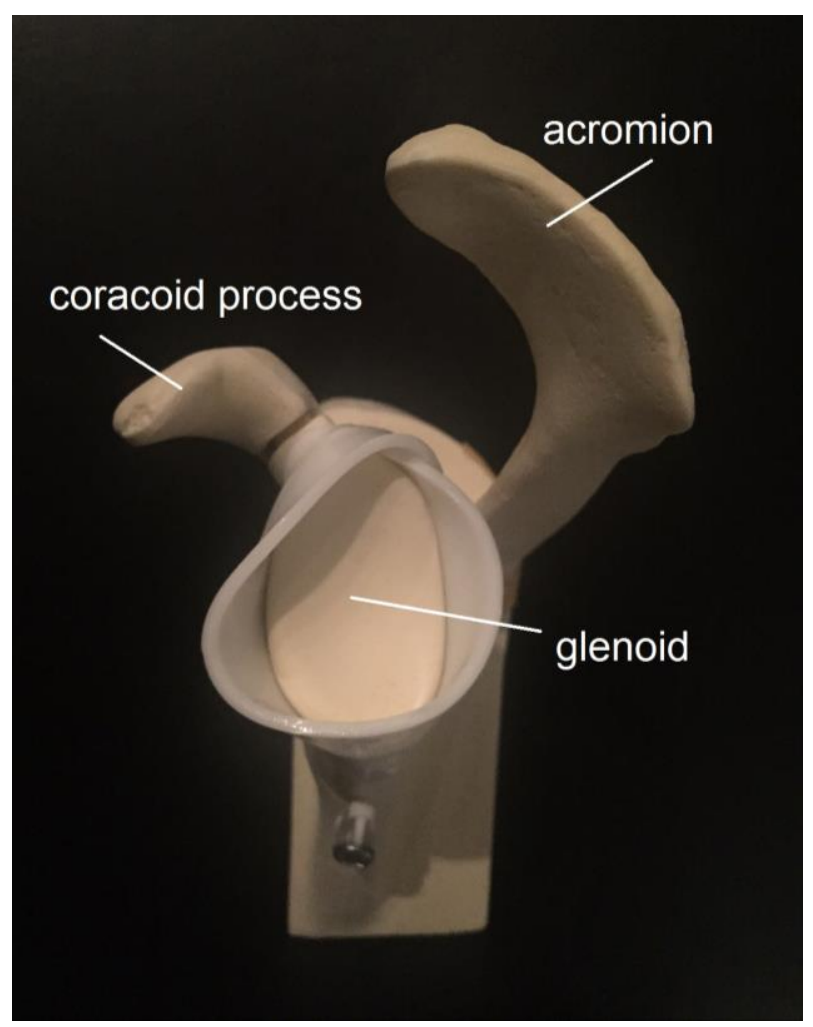

Figure 3.8: Shoulder bones (sagittal view). 


\subsubsection{Soft Tissues}

Certain soft tissues were identified for inclusion in the simulator through consultation with an orthopaedic surgeon. In particular, the labrum, biceps tendon, capsule and rotator cuff tendons were identified as required components. The subacromial bursa, coracoacromial and acromioclavicular ligaments were identified for inclusion in future simulator versions that are aimed at training more advanced skills. The remaining tissues were not included in the simulator as they would not be visualized with the arthroscope and are not required for structural integrity.

Table 3.3: Tissues in the shoulder.

\begin{tabular}{lll}
\hline Tissue & Included in simulator & Seen through scope \\
\hline Rotator cuff tendons & yes & yes \\
Biceps tendon & yes & yes \\
Capsule & yes & yes \\
Labrum & yes & yes \\
Rotator cuff muscles & yes & yes (partially) \\
Subacromial bursa & for future development & yes \\
Coracoacromial ligament & for future development & yes \\
Acromioclavicular ligament & for future development & yes \\
Coracoclavicular ligament & no & no \\
Other bursa & no & no \\
\hline
\end{tabular}

The soft tissues needed to be made of a flexible material that also allowed for a method of attachment to the bones. After testing different materials, it was found that Ecoflex 0030 Silicone rubber (Smooth-On, Inc., Macungie, PA) with nylon reinforcement was a good combination. The silicone provided structure and flexibility. The nylon allowed for stretch, while preventing the silicone from tearing, and it also permitted Velcro to be sewn onto the structure. The materials tolerate both wet and dry environments.

The muscles and tendons of the rotator cuff were formed using a Playdough mould, textured by using the surface of a hard plastic shoulder muscle model. Two colours of silicone, white and maroon, were used to distinguish the tendon and muscle. The process is shown in Figure 3.9. 

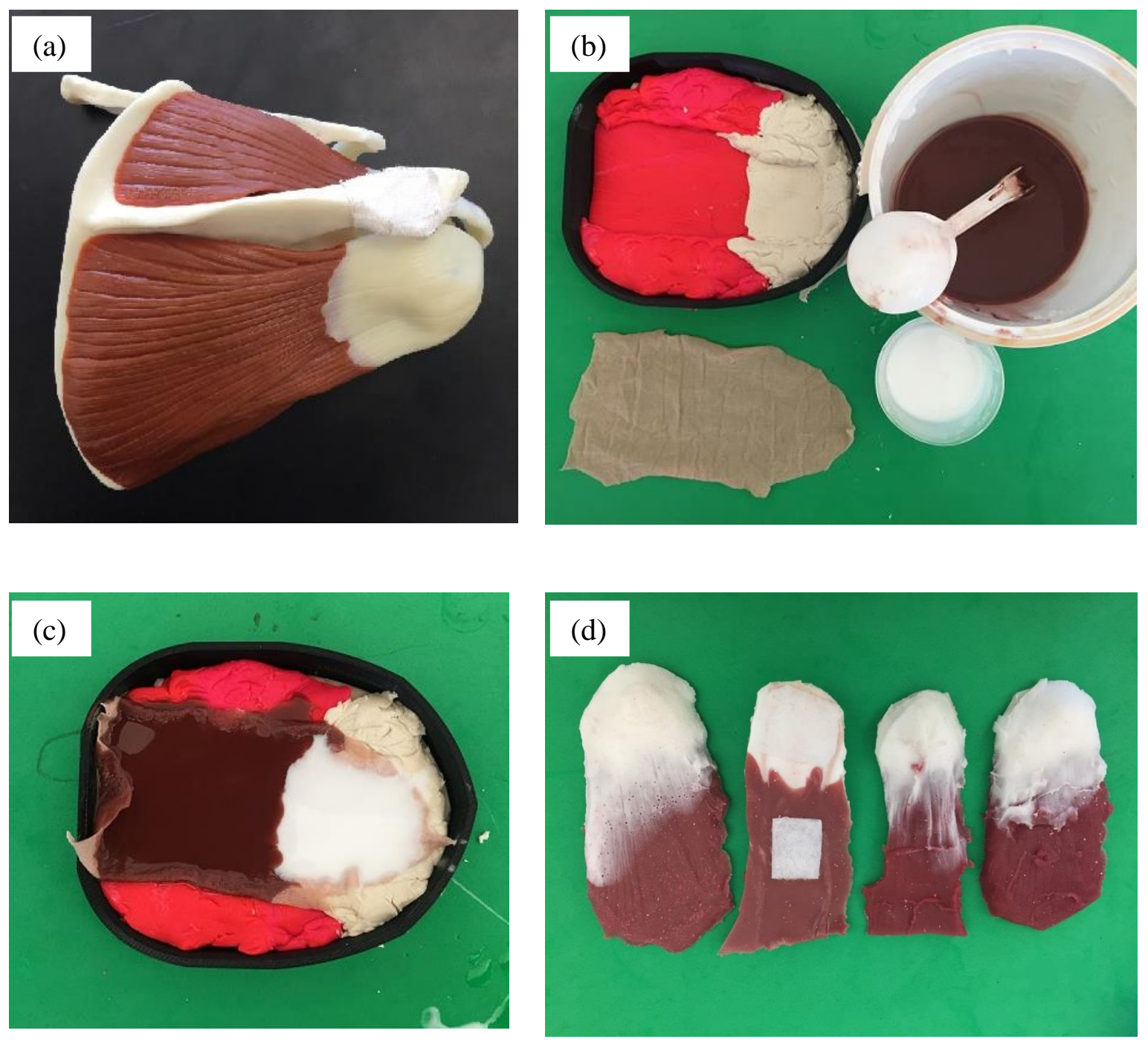

Figure 3.9: Creation of rotator cuff muscles and tendons. (a) Plastic shoulder model (b) Materials used to construct muscles and tendons. (c) Silicone and nylon in mould. (d) Finished muscles.

The biceps tendon was also moulded from nylon-reinforced silicone using a plastic drinking straw, as shown in Figure 3.10 (a). The biceps tendon was sewn to the top of the glenoid under the labrum and attached to the humerus using Velcro, as shown in Figure 3.10 (b). 

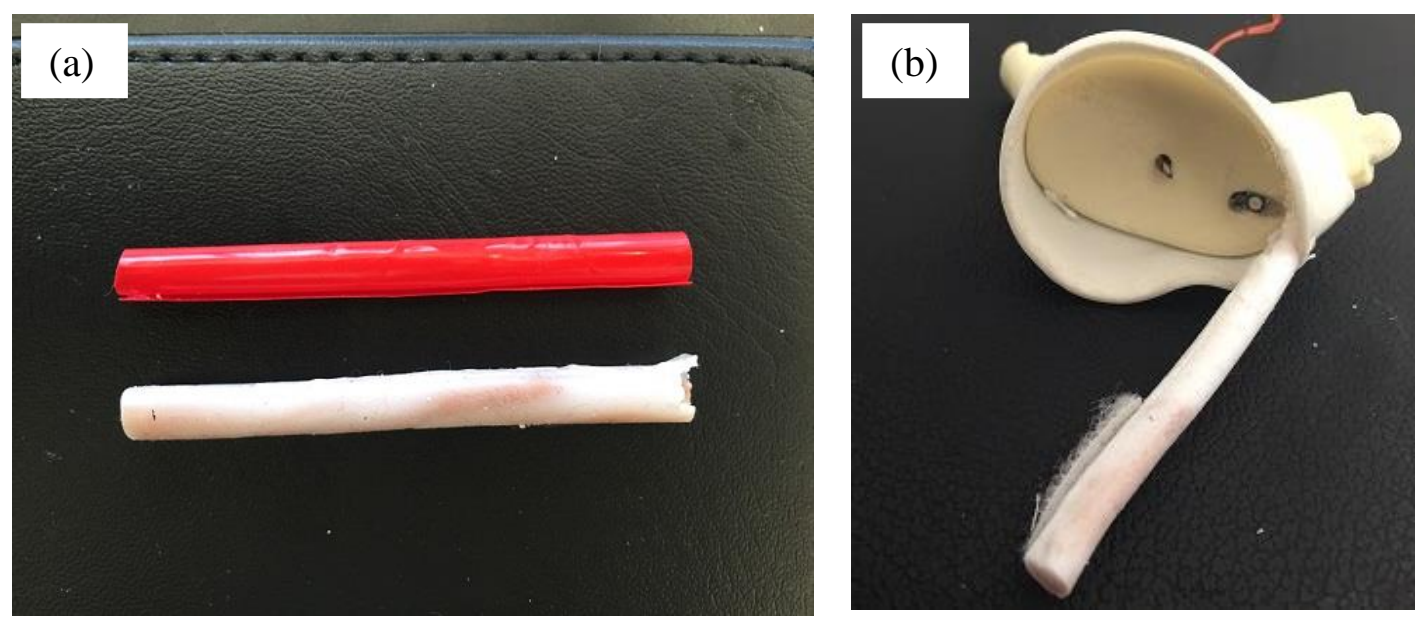

Figure 3.10: (a) Straw mould and biceps tendon. (b) Biceps tendon attached to glenoid.

The joint capsule is a thin layer than sheathes the glenohumeral joint beneath the rotator cuff tendons. During arthroscopic surgery, portals are created in the capsule to allow the arthroscope and instruments to access the joint space. Originally, a white latex balloon was proposed for the capsule, but it ripped when punctured with the instruments. The final design (Figure 3.11) was a thin layer of white silicone reinforced with nylon, which was cut and sewn into the correct shape. Velcro was also sewn to the capsule to allow it to anchor onto the bones on either side of the joint.

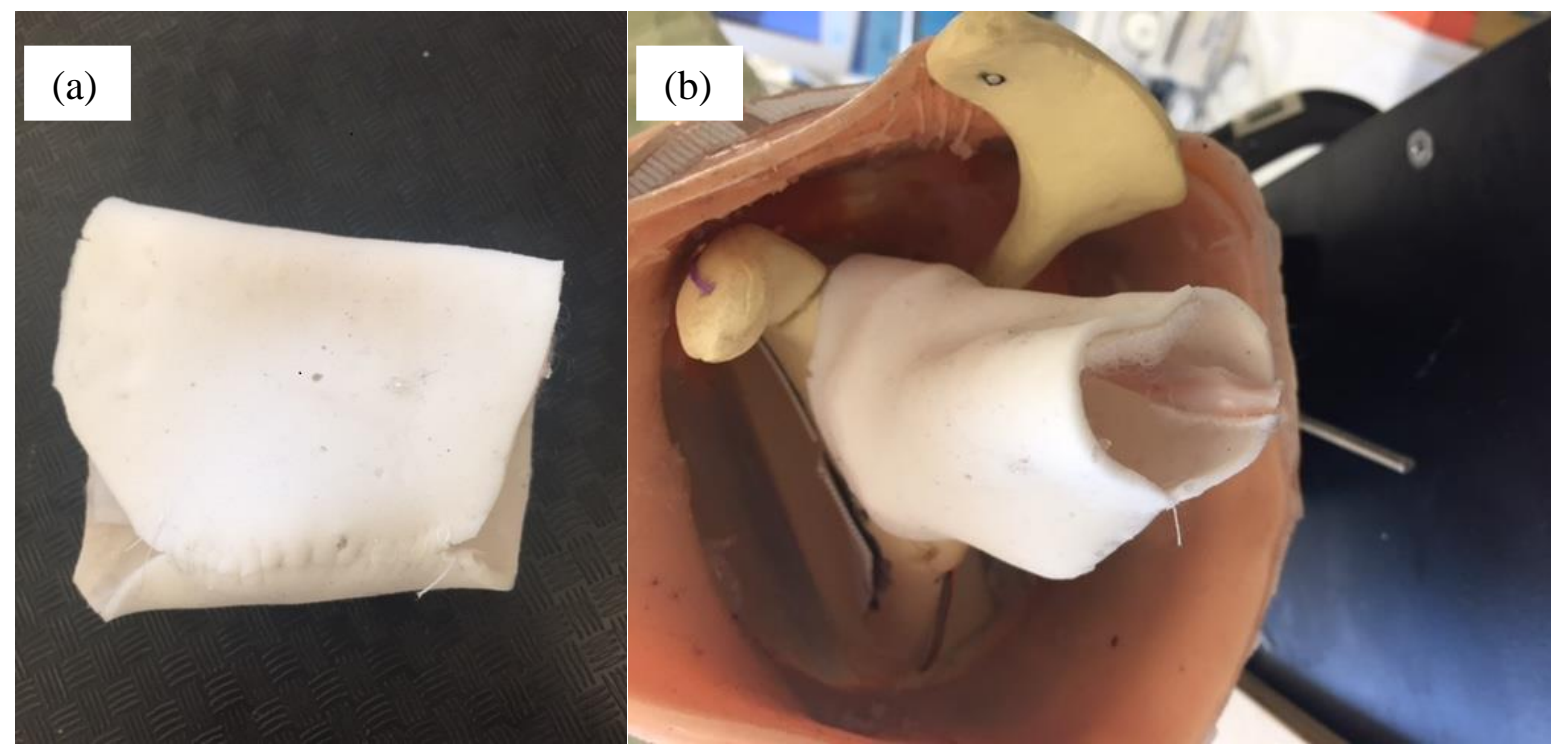

Figure 3.11: (a) Synthetic joint capsule (b) Capsule attached to glenoid with velcro. 


\subsubsection{Body, Skin, Fat and Arm}

In order to have a cosmetically appealing and realistic simulator, an arm was purchased from the Dapper Cadaver prop fabrication shop (Sun Valley, CA). The arm was made from lightweight foam, and was not waterproof. A layer of red Ecoflex 00-30 siliconewas used to waterproof the proximal end of the arm, and to secure the humerus bone in place, Figure 3.12.
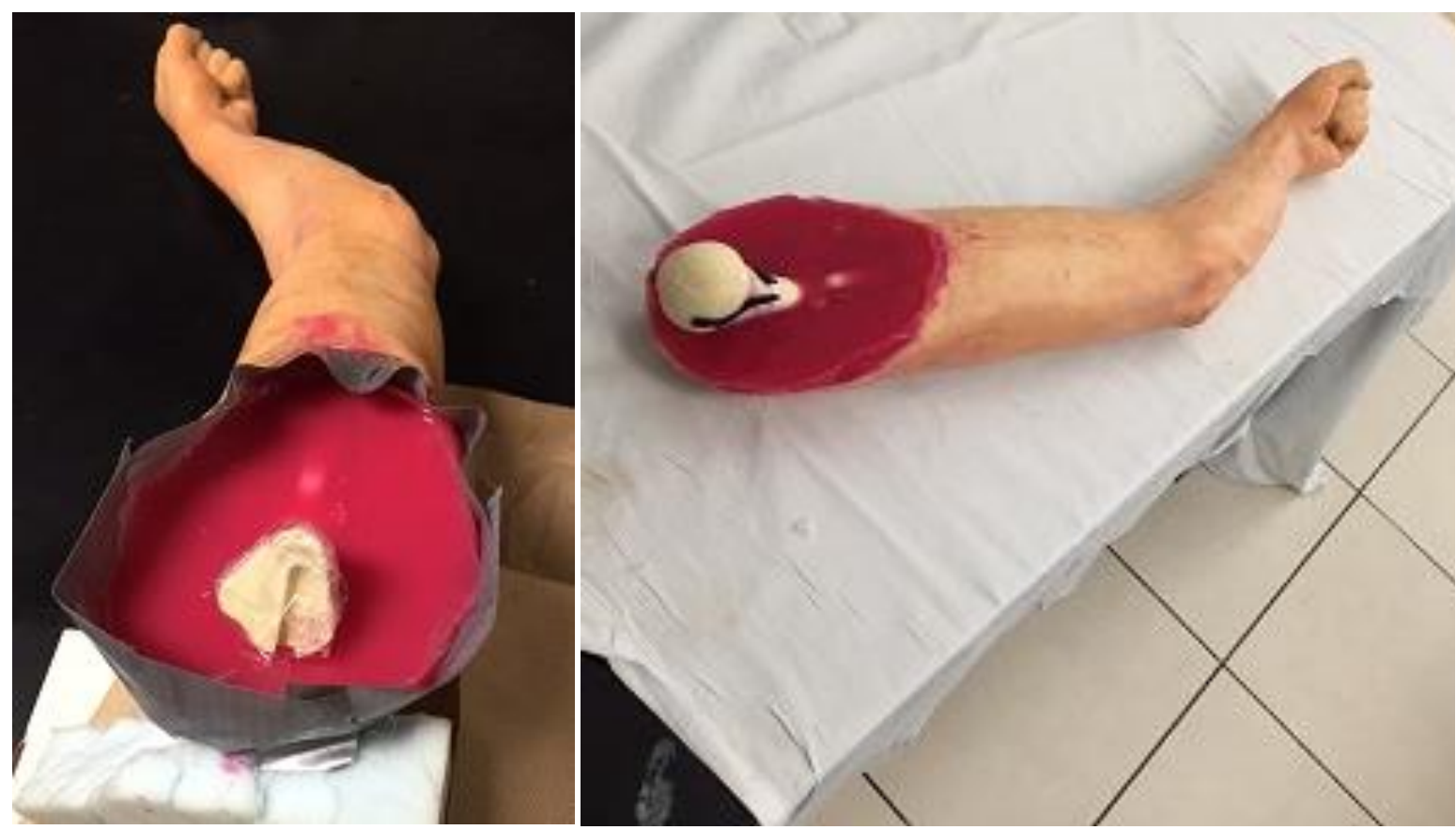

Figure 3.12: Arm with humerus inserted and sealed using silicone.

The body of the simulator was sculpted from a block of foam (Part 2565FR and 2545FR, The Foam Store, Kitchener, ON), Figure 3.13 (a). The foam has a density of 2.5 pounds per cubic foot, and was ordered in two compression ratings: $65 \mathrm{lb}_{\mathrm{f}}$ and $45 \mathrm{lb}_{\mathrm{f}}$. The firmer $65 \mathrm{lb}_{\mathrm{f}}$ compression grade was selected to give a firmer feel to the body. Initially it was proposed to cover the body in a skin layer, however as the chest is often draped during surgery, a simple surgical cloth was used to cover the foam, Figure 3.13 (b). The cloth had the added benefit of not adding much weight or cost to the construction. The body would not be exposed to water from the joint area, so there was no need to waterproof the foam. The foam was hollowed out to create a space for the scapula bone. 

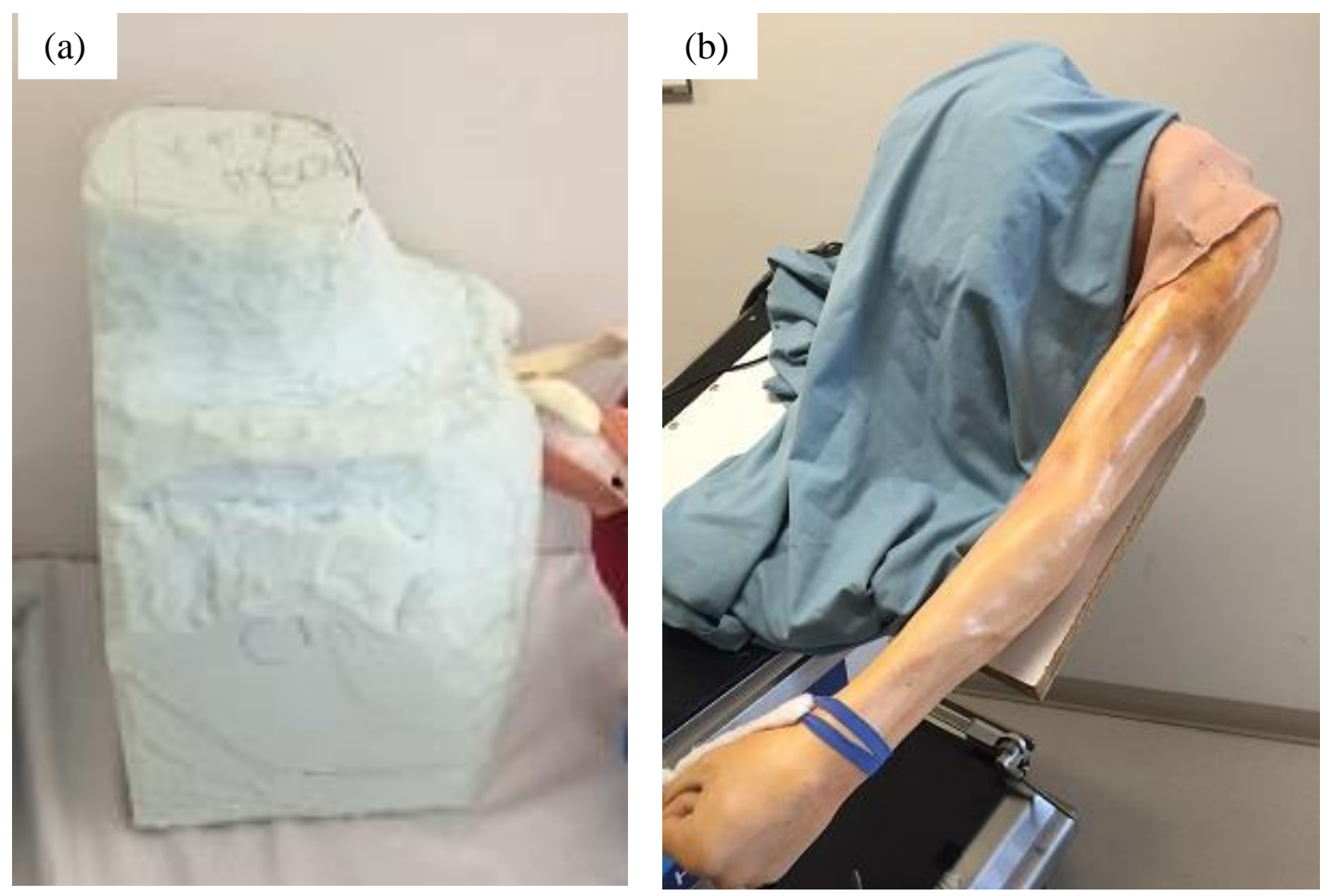

Figure 3.13: (a) Sculpted foam torso. (b) Torso covered by drape.

A layer of skin was created to attach the arm to the body, covering the joint. Ecoflex 0030 was used for the skin, reinforced with nylon, so that it would not rip when the portals were cut, Figure 3.13. The nylon also allowed Velcro strips to be sewn onto the skin. The Velcro allows for opening and closing the joint to provide access inside. A thin layer of subcutaneous fat was included in the region covering the top of the joint in order to create a more realistic feel when palpating the joint externally. 


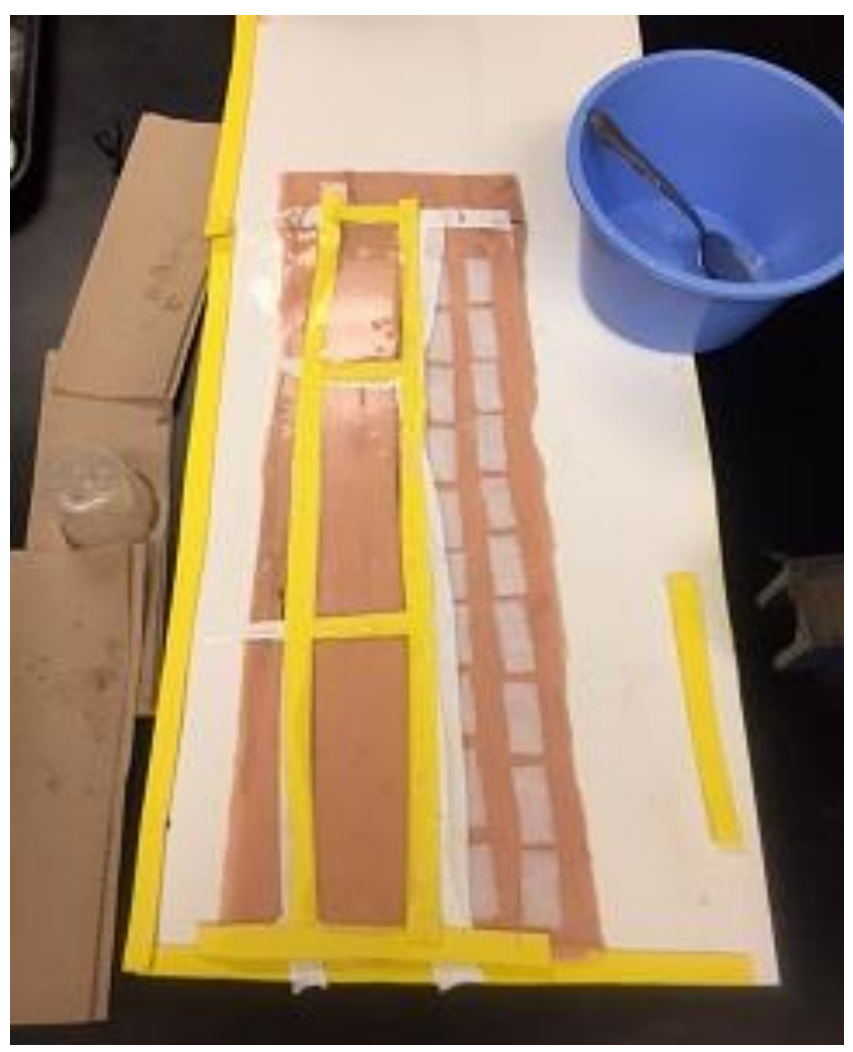

Figure 3.14: Silicone skin with fat layer curing.

To create the fat, various formulations of two Smooth-On products, Ecoflex GEL and Slacker, were investigated. The fat formulations were sandwiched between layers of Ecoflex 00-30 as suggested by the manufacturer, as shown in Figure 3.15.

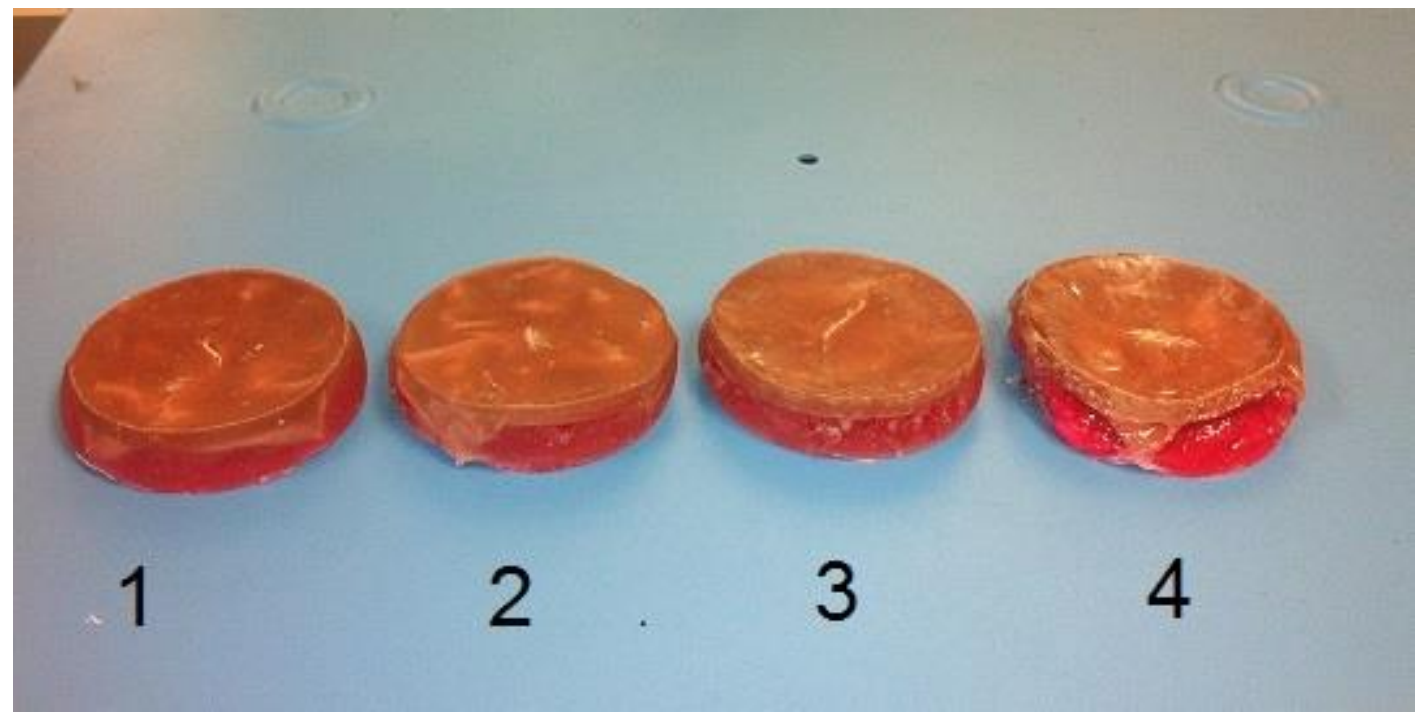

Figure 3.15: Tested fat formulations. 
The sample fat formulations were palpated by an orthopaedic surgeon in order to determine which one was the most realistic. The formulations and observations are presented in Table 3.4. It was found that the addition of the Slacker created a softer fat layer that more easily allowed for palpation of the bones. However, the Slacker also made the fat layer stickier and runnier, which were undesired properties for surgical instruments to pass through this layer. Talc powder was used to prevent the instruments from sticking. For the $0.5 \mathrm{~cm}$ fat layer tested, formula \#3 was selected as the most realistic. For thinner layers of fat, less Slacker would need to be added to the Ecoflex GEL to allow for adequate palpation.

The skin was sewn to the arm and sealed with Ecoflex 00-30 silicone as shown in Figure 3.16 .

Table 3.4: Tested fat formulations.

\begin{tabular}{llll}
\hline$\#$ & Skin Layer $(20 \mathrm{cc})$ & Fat Layer $(50 \mathrm{cc})$ & Results \\
\hline 1 & Ecoflex 00-30 & $\begin{array}{l}\text { Ecoflex GEL } \\
(\text { no Slacker })\end{array}$ & $\begin{array}{l}\text { Firm, harder to palpate the bone and } \\
\text { more difficult to discern edges through } \\
\text { palpation. Does not stick to the } \\
\text { instrument after talc powder is applied. }\end{array}$ \\
\hline 2 Ecoflex 00-30 & $\begin{array}{l}\text { Ecoflex GEL : Slacker } \\
(2.8: 1)\end{array}$ & $\begin{array}{l}\text { A little firmer than \#3. Can barely feel } \\
\text { edges while palpating bone. Does not } \\
\text { stick to the instrument after talc powder } \\
\text { is applied. }\end{array}$ \\
\hline 3 & Ecoflex 00-30 & $\begin{array}{l}\text { Ecoflex GEL : Slacker } \\
(2: 1)\end{array}$ & $\begin{array}{l}\text { Softer than \#1 and \#2. Can feel edges } \\
\text { while palpating bone. Still holds shape. } \\
\text { Does not stick to the instrument after talc } \\
\text { powder is applied. }\end{array}$ \\
\hline 4 & Ecoflex 00-30 & $\begin{array}{l}\text { Ecoflex GEL : Slacker } \\
(1: 1)\end{array}$ & $\begin{array}{l}\text { Very sticky, a little runny, does not hold } \\
\text { shape, easy to palpate edges of bone } \\
\text { through sample. Sticks to instrument } \\
\text { after talc powder is applied. }\end{array}$ \\
\hline
\end{tabular}




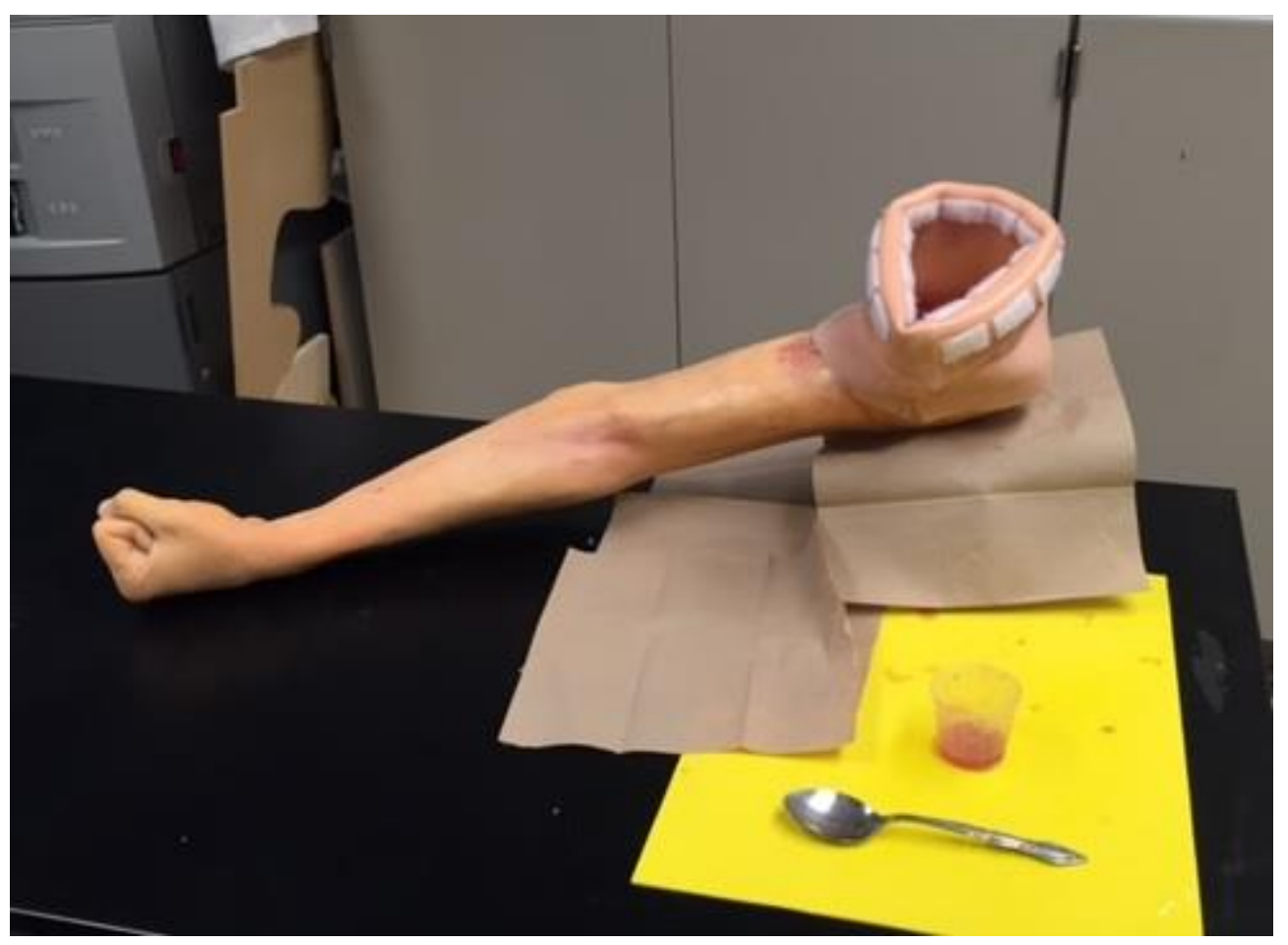

Figure 3.16: Arm with skin attached.

\subsection{Waterproof Connection}

In order to create a waterproof seal around the joint between the arm and the torso, a silicone sock was made for the scapula. First, the scapula was cast in plaster, and then silicone was poured between the mould and bone. A connective skin section was attached to the silicone sock and was reinforced with an ABS printed plastic part to provide structure.

The arm was then attached to the simulator, with the capsule, muscles and Velcro on the skin holding the two pieces together. In order to complete the water-tight seal, a zip-tie was pulled around the two layers of Velcro-attached skin, tightening them around the plastic support. This process is shown in Figure 3.17. 

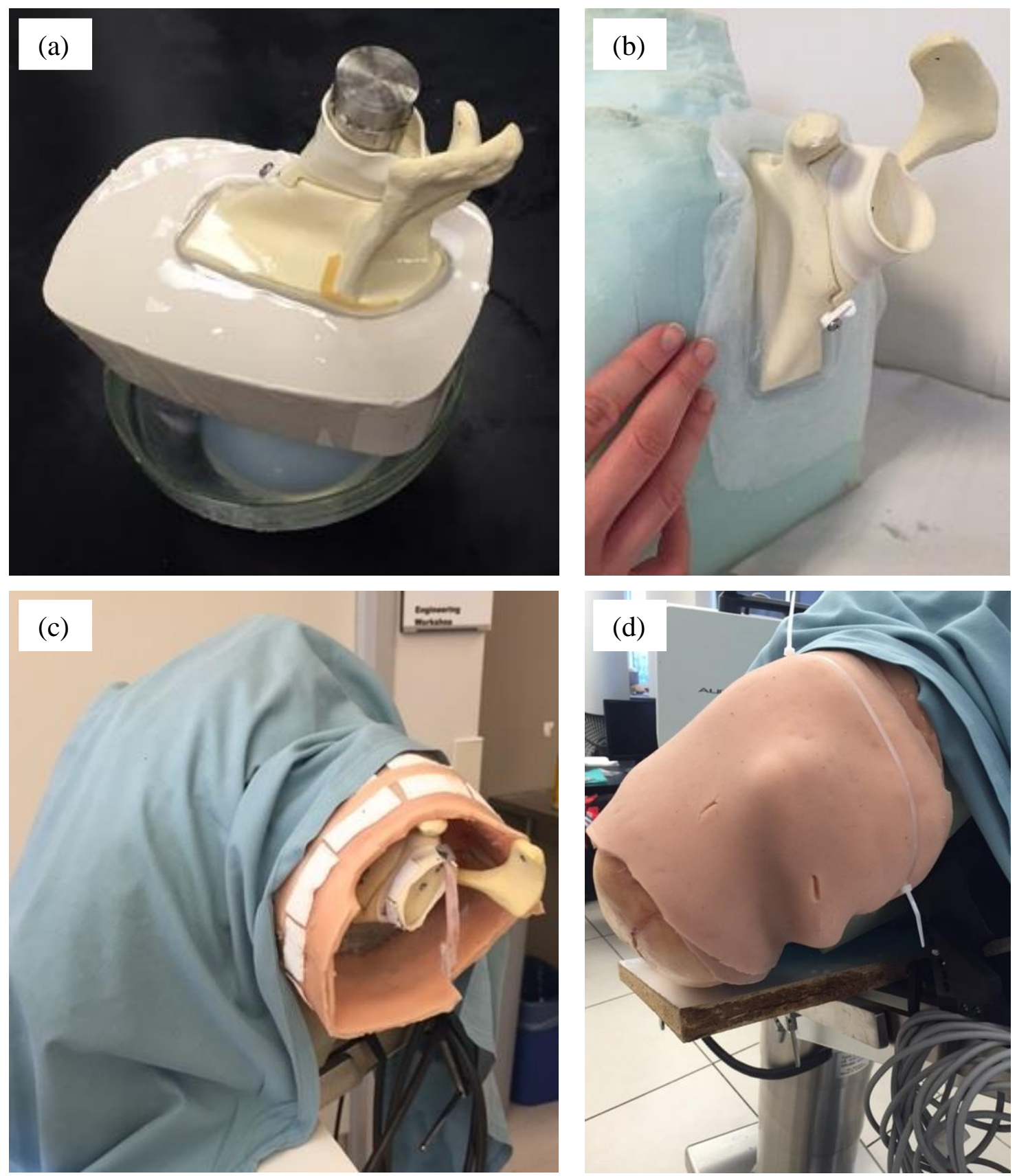

Figure 3.17: Creating of the silicone sock and skin. (a) Silicone being moulded. (b) Silicone sock around scapula. (c) Silicone skin attached to sock. (d) Skins attached and sealed with a cable tie. 
Once assembled, the posterior, anterior and lateral subacromial portals were cut in the correct locations, under the direction of an orthopaedic surgeon, as seen in Figure 3.18.

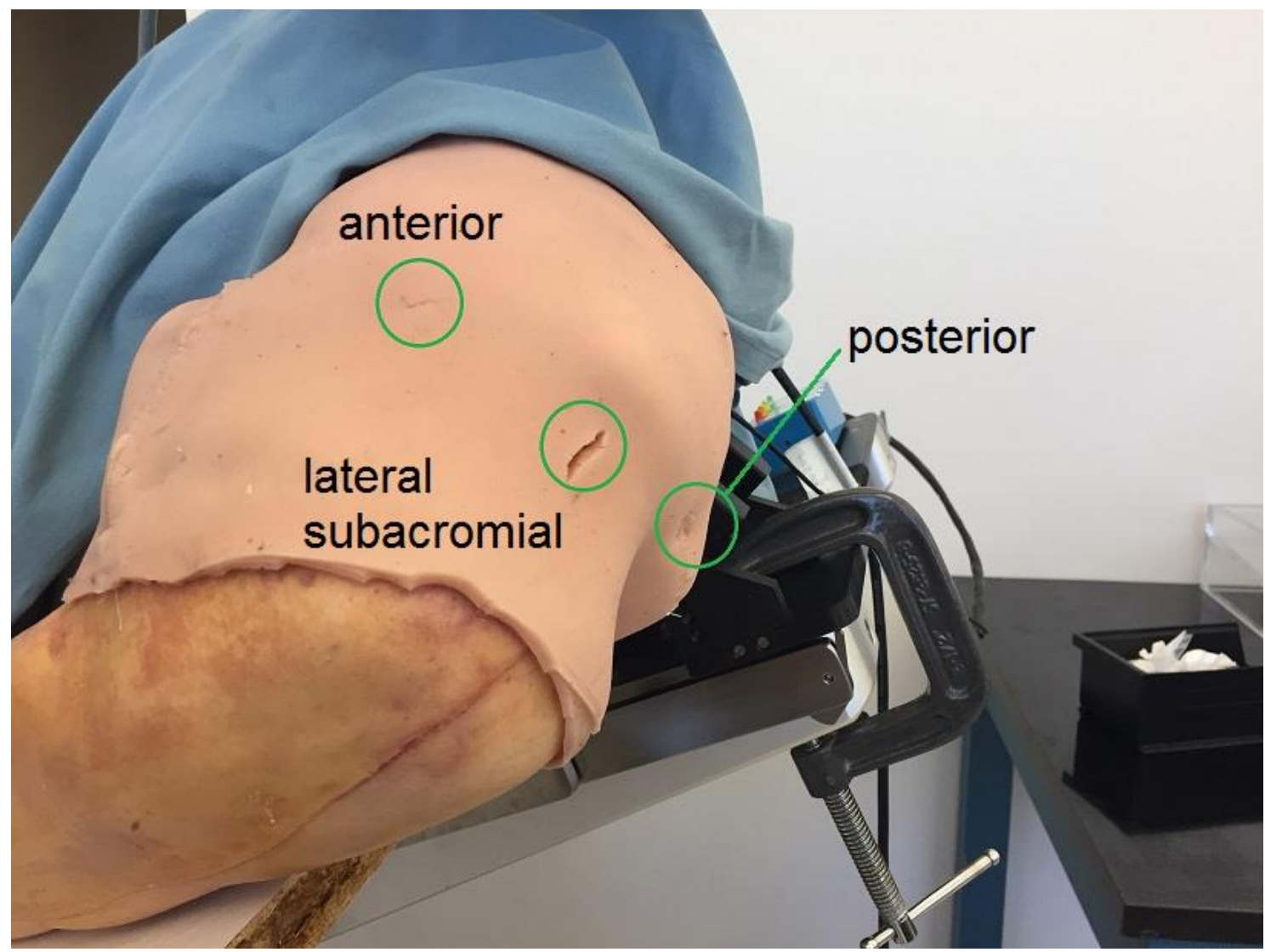

Figure 3.18: Locations of the three portals.

After filling the simulator with water, it was found that the portals leaked substantially with the instruments inserted and being moved around. To reduce leakage through the portals, a silicone seal was sewn to the inside of the skin (Figure 3.19). The addition of the seal reduced the volume of water loss by providing a greater surface area to seal around the arthroscope. 

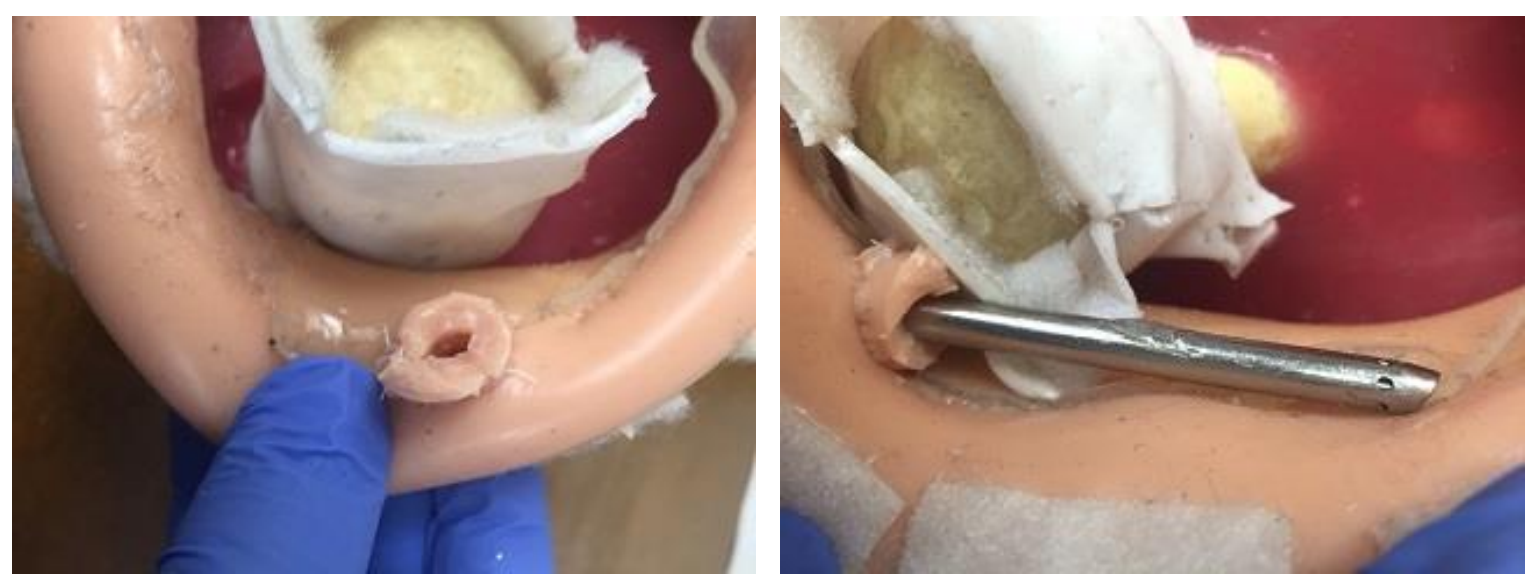

Figure 3.19: Seal around portal.

\subsection{Switches for Objective Assessment of Probing Tasks}

Measurement of trainee performance was considered to be an important requirement for the simulator. In order to provide objective results for measuring the completion of the surgical probing tasks, small switches were embedded in strategic locations of the anatomy. The overall system consists of a sensor, an indicator, a graphical user interface, and a data logger.

\subsubsection{Sensor}

The sensing system consists of a KMT Series Nano-Miniature SMT Top Actuated Switch (CKN10288CT-ND, C\&K Components, Newton, MA) soldered with two leads of thirtygauge coated wire (Figure 3.20.a). The switches are single-pole, single-throw (SPST), normally open (NO), and rated as "dust tight" and protected against complete, continuous submersion in water. The switches are available in operating forces between $100 \mathrm{gf}$ and 340 gf. As the purpose was to measure a simple probing task, the minimum available operating force of $100 \mathrm{gf}$ was selected for use in the simulator. The required travel for the switch is $0.15 \mathrm{~mm}$, which was considered to be an acceptable travel for the tip of the instrument. The switches were surface mounted onto the polyurethane foam Sawbones (Pacific Research Laboratories, Vachon Island, WA). The locations were selected using recommendations by the arthroscopic surgeon, who is familiar with surgical training methods. The locations were selected to teach residents the requisite anatomy and to allow for the practice of diagnostic arthroscopy and probing within the joint. Placement 
of the switches was intended to avoid areas used for destructive tasks, such as shaving and burring. Ink dots were used to mark the desired switch locations on the underside of the acromion, the underside of the coracoid process, the centre of the glenoid and top of the glenoid beneath the biceps tendon. Channels were drilled through the bone and the wires were threaded through so that the trainee is not able follow the wires as an aid to locating the switch. The switches were secured to the bone's surface with cyanoacrylate glue (Figure 3.20).

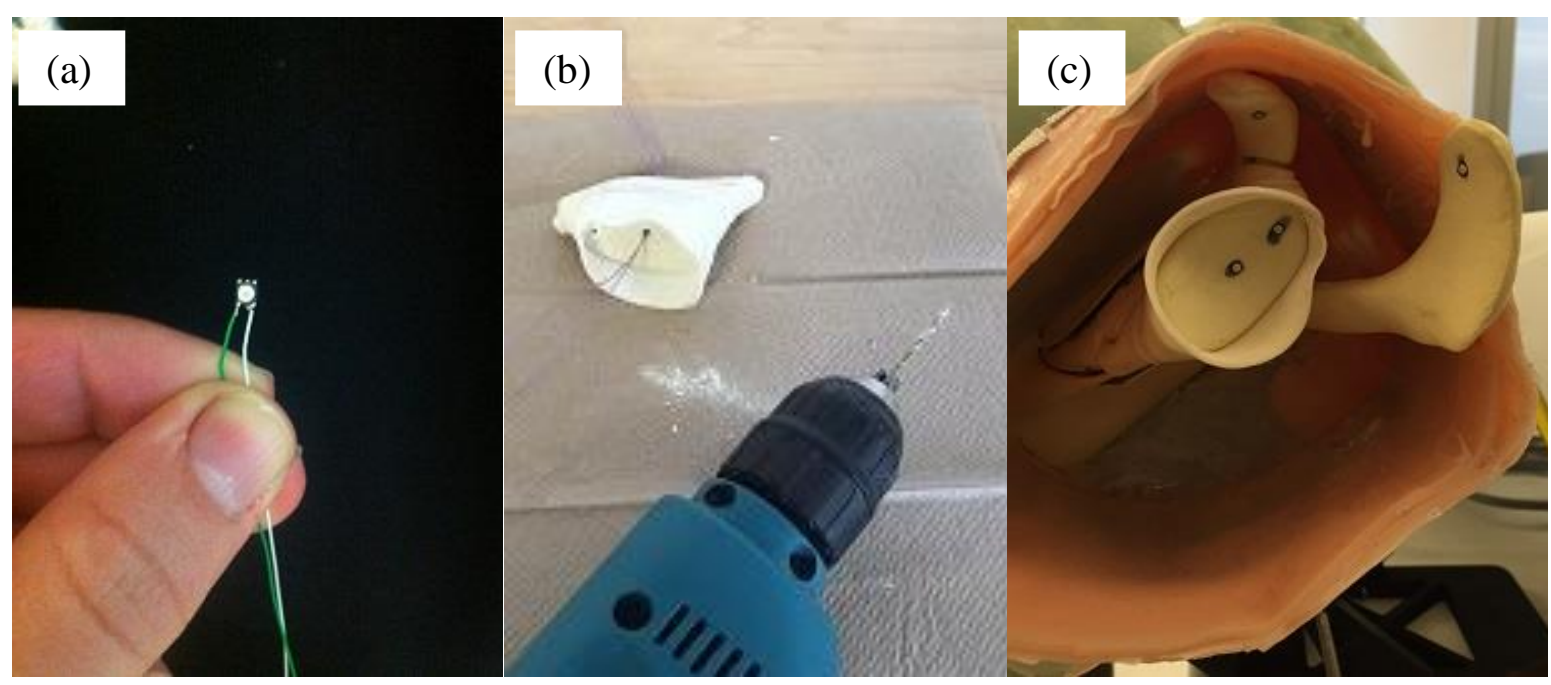

Figure 3.20: (a) Switches for probing task. (b) Wires for switches threaded through the bone. (c) Switches installed on the bones.

To confirm waterproof operation, a switch was connected to a 5 VDC power supply (E3620A, Agilent Technologies), and it was able to toggle an LED without creating a short circuit (Figure 3.21). 

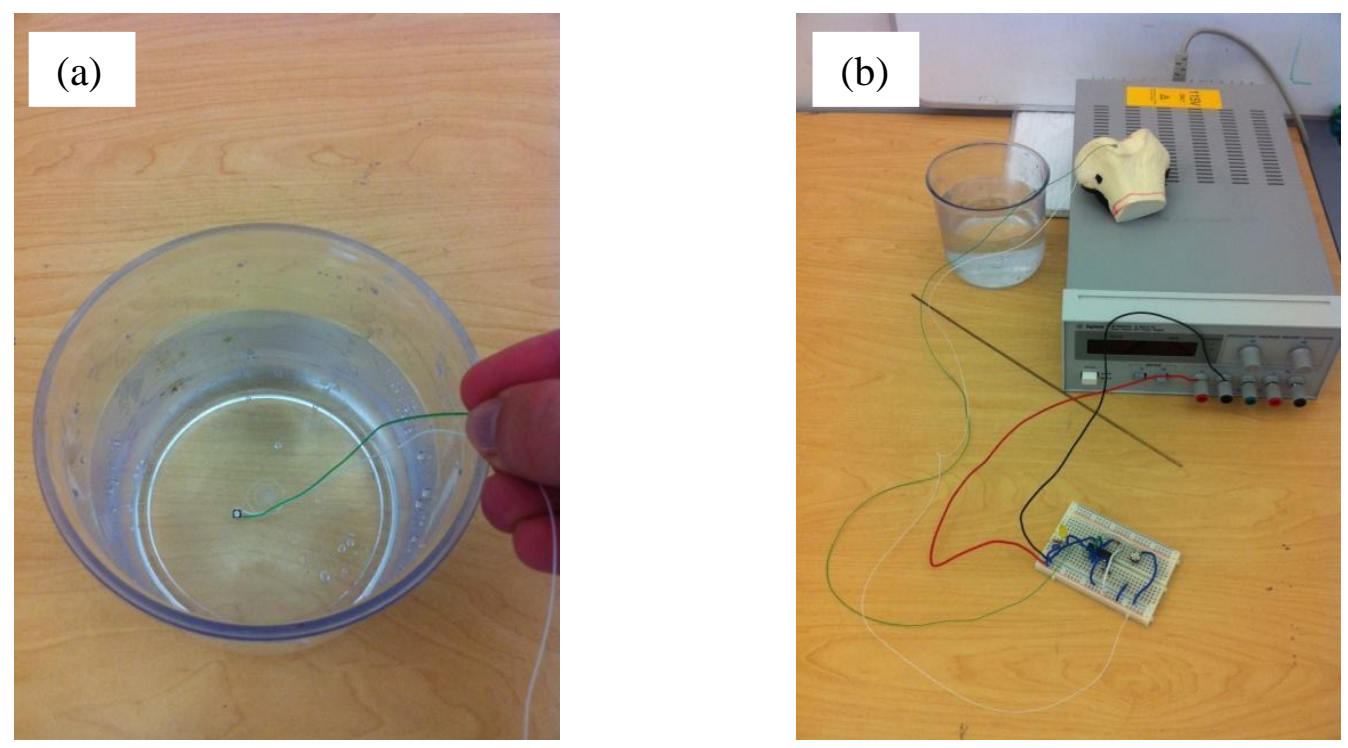

Figure 3.21: (a) Switch submerged in water. (b) Circuit with 5 VDC power supply.

\subsubsection{Data Recording and Graphical User Interface}

The electronic recording system consists of a desktop computer connected to a microcontroller (Arduino Nano, Ivrea, Italy) using serial communication over USB. The microcontroller is wired to four inputs (buttons) and four outputs (LED lights) using a breadboard (Figure 3.2). The microcontroller receives a discrete signal when a button is momentarily depressed. The signals are sent to the computer, which returns a signal to latch on the discrete output for the corresponding LED. The computer software maintains a $\log$ of the time when a button is depressed, as well as the corresponding button number.

A graphical user interface (GUI) was created in QT to provide communication and testing functionality as well as an additional visual indication (Figure 3.2 and Figure 3.3). 


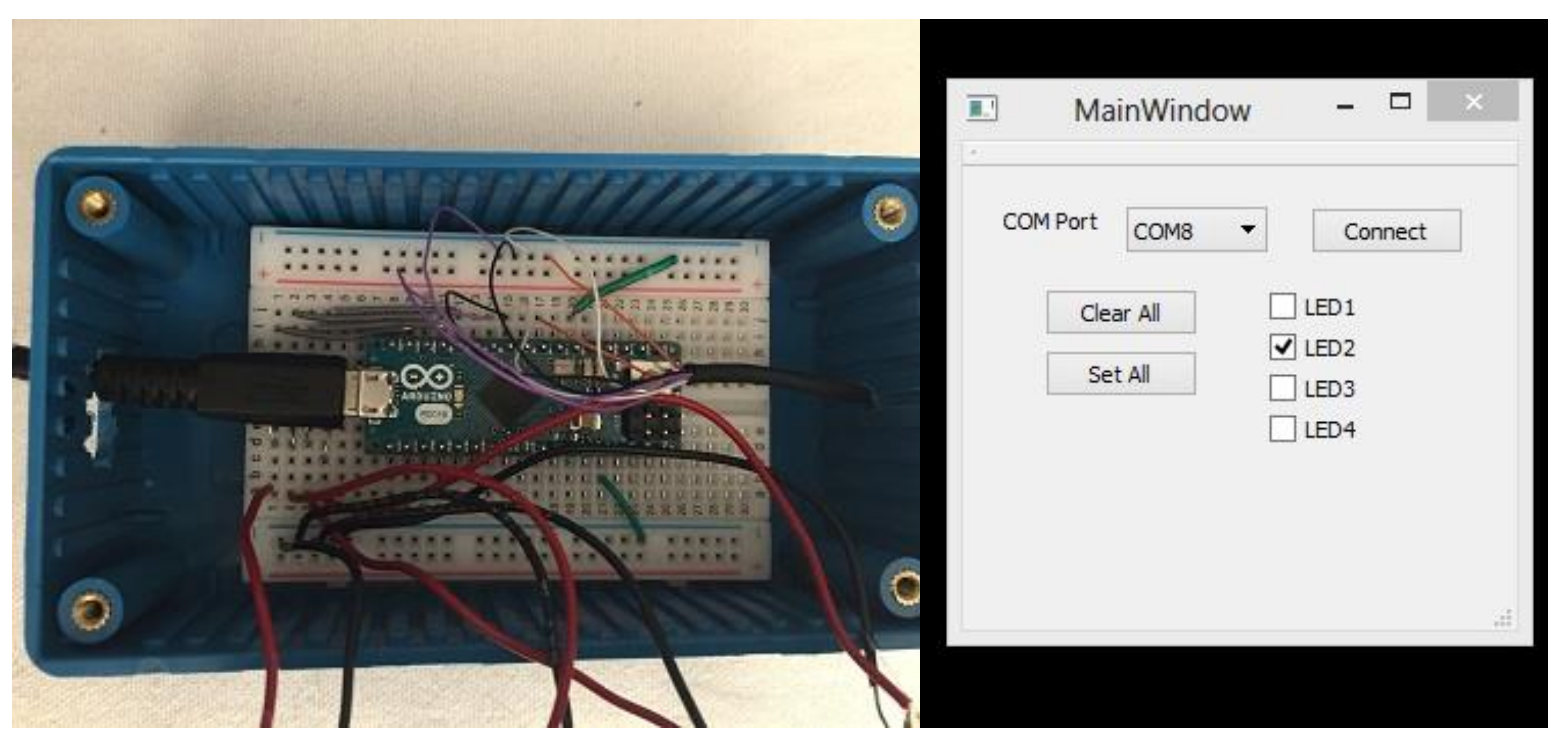

Figure 3.22: Microcontroller and wiring.

Figure 3.23: GUI.

\subsubsection{Visual Indication}

To provide feedback to the trainee, an LED display with lights corresponding to each button was provided. The lights were labelled with the corresponding anatomical location. For good visibility, $5 \mathrm{~mm}$ LED lights were used (Figure 3.4).

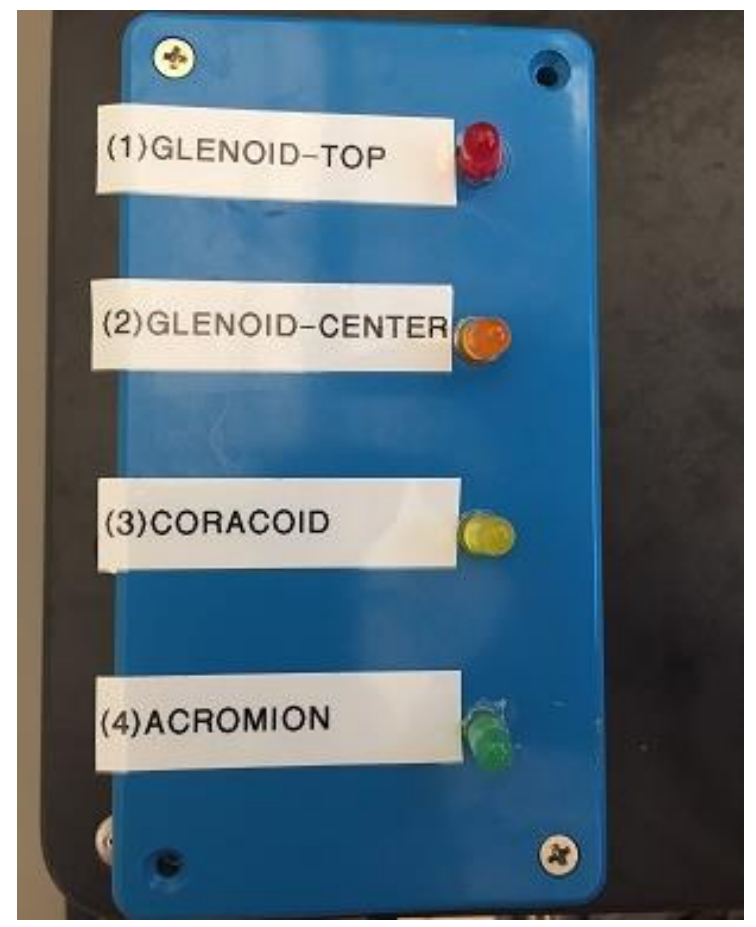

Figure 3.24: LED indicators. 


\subsection{Simulator Base and Integrated Force/Torque Sensor}

A base was required for the simulator in order to support the torso, shoulder and arm. The design criteria for the base were as follows:

- The base must be strong enough to withstand the forces applied to the simulator.

- The base must have room to accommodate the clamp used to attach the simulator to the table.

- The base design must facilitate switching between the beach chair and lateral decubitus positions.

- The design must incorporate a force/torque sensor (9105-TIF-GAMMA-IP68, ATI, Apex, NC) in order to capture forces applied to the simulator by the trainees.

The simulator base was designed in SolidWorks and constructed using a combination of purchased parts and components that were custom printed in ABS plastic. The components of the base are shown in Figure 3.5 and Figure 3.6.

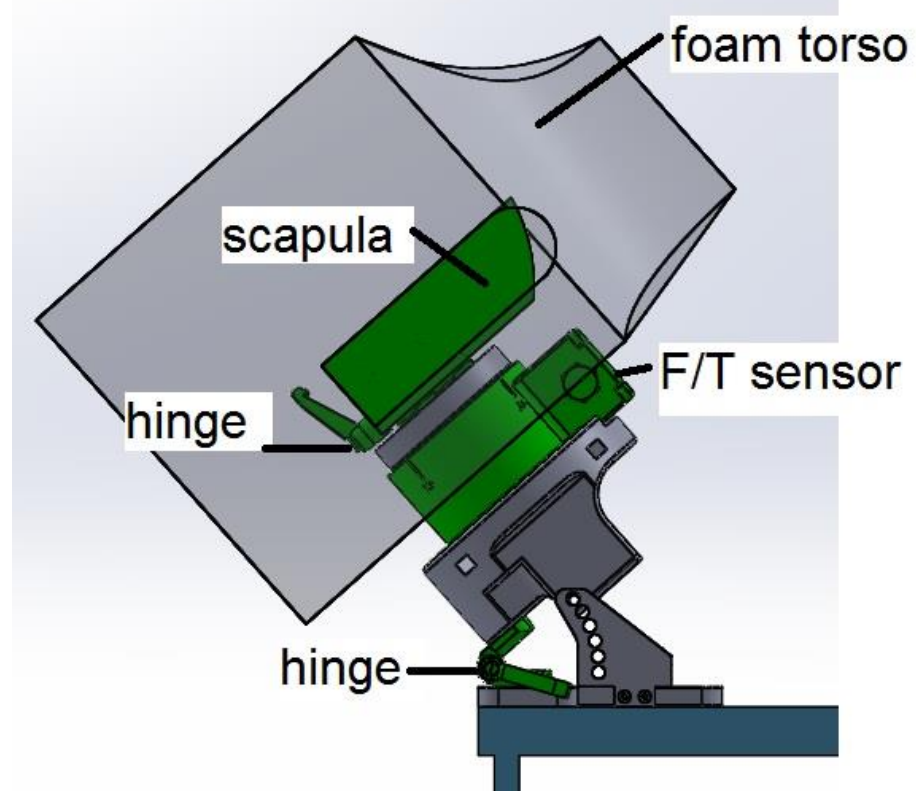

Figure 3.25: Non-ABS parts of torso and support base. 


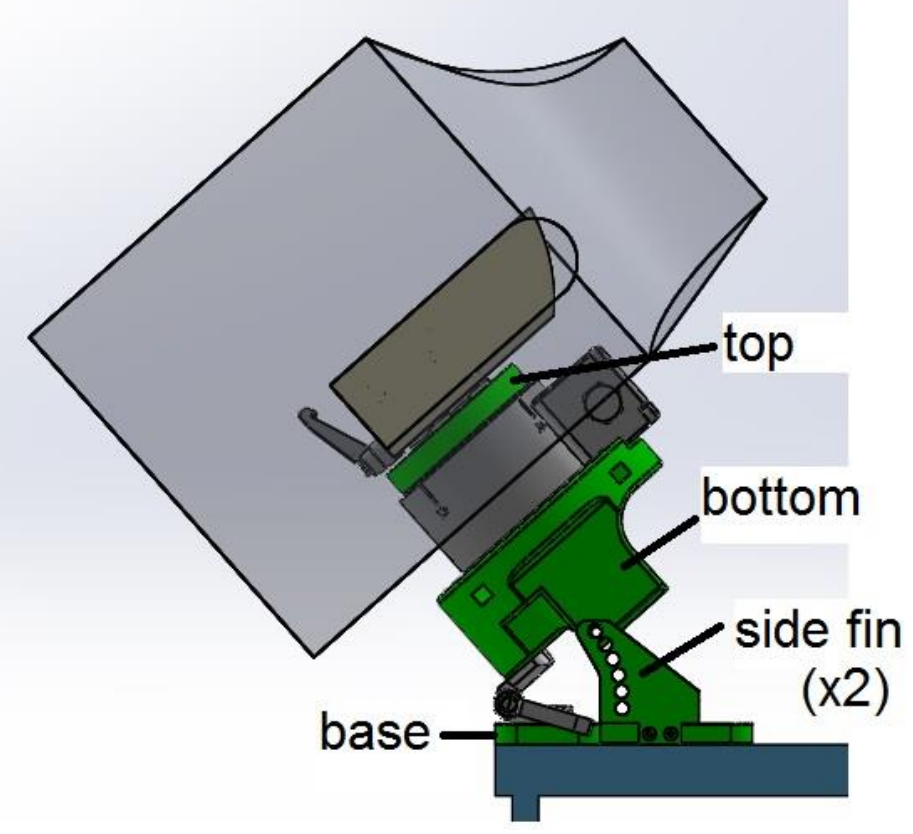

Figure 3.26: ABS printed parts of support base.

To ensure that the base would be strong enough, a stress analysis was performed for each ABS component part before printing. The total weight of the simulator was anticipated to be approximately $4 \mathrm{~kg}$, with the heaviest components being the F/T sensor (1.98 kg) and the arm with the silicone seal $(1.48 \mathrm{~kg})$. The force applied by the trainees was assumed to be a maximum of $40 \mathrm{~N}$ based on a previous knee arthroscopy simulator study [72]. Therefore, a maximum total force of $80 \mathrm{~N}$ is anticipated as being applied to the simulator. This value was used to complete a stress analysis of each of the parts, in order to ensure that they would withstand the maximum forces. The analysis was repeated in both the beach chair and lateral decubitus orientations. Selected results are presented below for the side fins and the bottom F/T sensor support in the beach chair position (Table 3.1). The ABS material has a Yield Stress of $4.2 \times 10^{7} \mathrm{~N} / \mathrm{m}^{2}$, leaving a safety factor of over 100 for each part. 
Table 3.5: Stress analysis for select parts in lateral decubitus position.

\begin{tabular}{|c|c|c|}
\hline Description & von Mises stress & von Mises scale \\
\hline $\begin{array}{l}\text { Side fin in } \\
\text { beach chair } \\
\text { position. }\end{array}$ & & $\begin{array}{r}\text { von Mises }\left(\mathrm{N} / \mathrm{m}^{\wedge} 2\right] \\
3.552 \mathrm{e}+006 \\
3.257 \mathrm{e}+006 \\
-2.962 \mathrm{e}+006 \\
-2.666 \mathrm{e}+006 \\
-2.371 \mathrm{e}+006 \\
-2.075 \mathrm{e}+006 \\
-1.780 \mathrm{e}+006 \\
-1.485 \mathrm{e}+006 \\
-1.189 \mathrm{e}+006 \\
-8.941 \mathrm{e}+005 \\
-5.987 \mathrm{e}+005 \\
3.034 \mathrm{e}+005 \\
8.007 \mathrm{e}+003\end{array}$ \\
\hline $\begin{array}{l}\text { Bottom } F / T \\
\text { sensor } \\
\text { support in } \\
\text { beach chair } \\
\text { position. }\end{array}$ & & $\begin{array}{r}\text { von Mises }\left(\mathrm{N} / \mathrm{m}^{\wedge} 2\right) \\
1.547 \mathrm{e}+005 \\
1.419 \mathrm{e}+005 \\
1.290 \mathrm{e}+005 \\
-1.161 \mathrm{e}+005 \\
-1.033 \mathrm{e}+005 \\
-9.038 \mathrm{e}+004 \\
7.751 \mathrm{e}+004 \\
6.464 \mathrm{e}+004 \\
5.177 \mathrm{e}+004 \\
3.890 \mathrm{e}+004 \\
2.603 \mathrm{e}+004 \\
1.316 \mathrm{e}+004 \\
2.865 \mathrm{e}+002\end{array}$ \\
\hline
\end{tabular}

The support base of the simulator allows the user to switch between beach chair and lateral decubitus by manipulating two lever-lock hinges (095KF3030F08, Fath, Germany), which are integrated into the support and alter the orientation of the torso. The hinges are rated for a maximum force of $400 \mathrm{~N}$ (axial) and $700 \mathrm{~N}$ (radial), which exceeds the requirements. Adjustable side supports comprising fins with a series of holes and a 
rod are used to reinforce the lower hinge angle during beach chair, as the locking mechanism force rating was not published (Figure 3.6).

In the beach chair position both hinges are open, the bottom hinge at 45 degrees and the top hinge at 90 degrees, as depicted in Figure 3.7. For the lateral decubitus position, both hinges are closed as depicted in Figure 3.8.
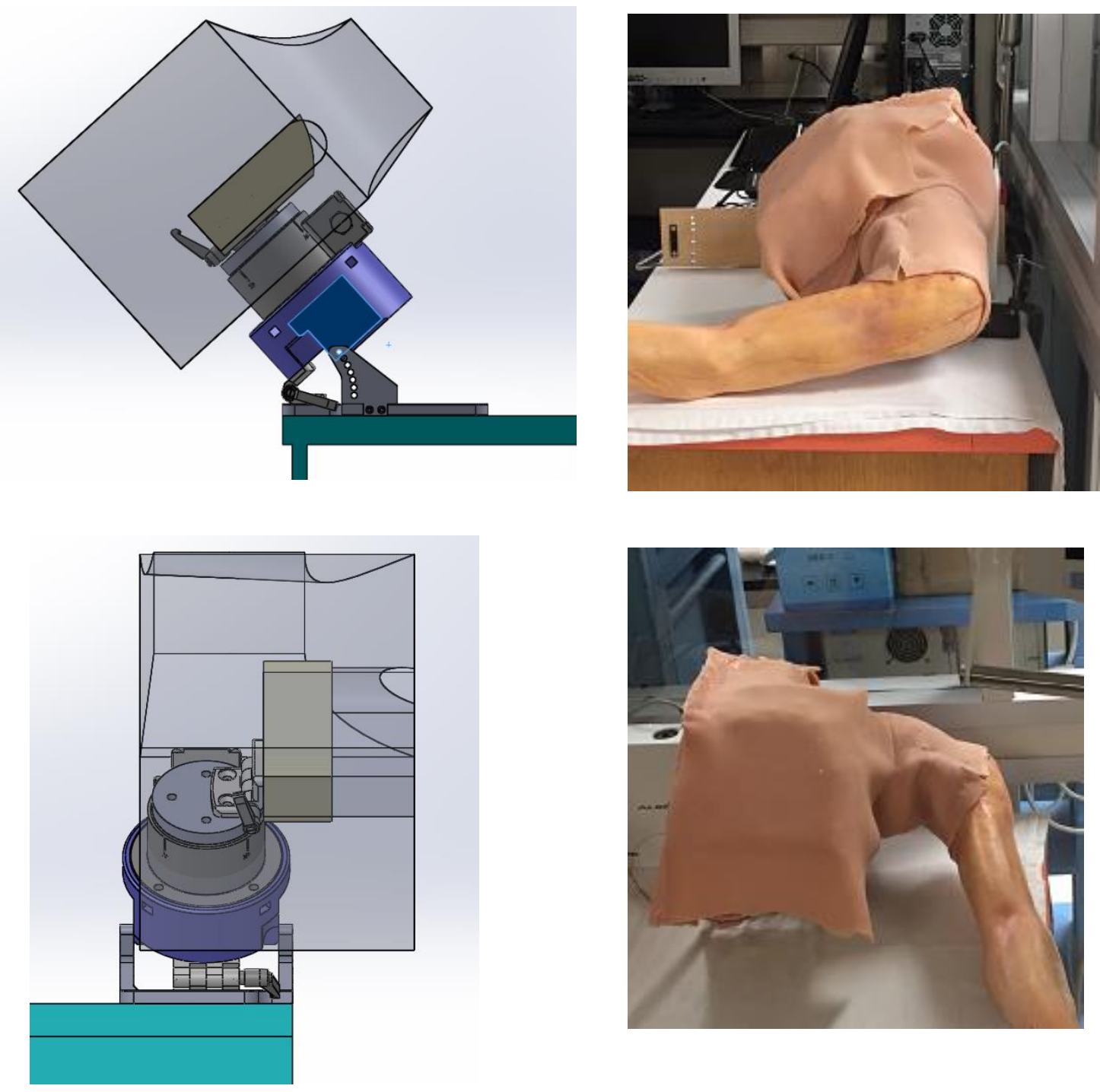

Figure 3.27: Simulator in the beach chair position. 

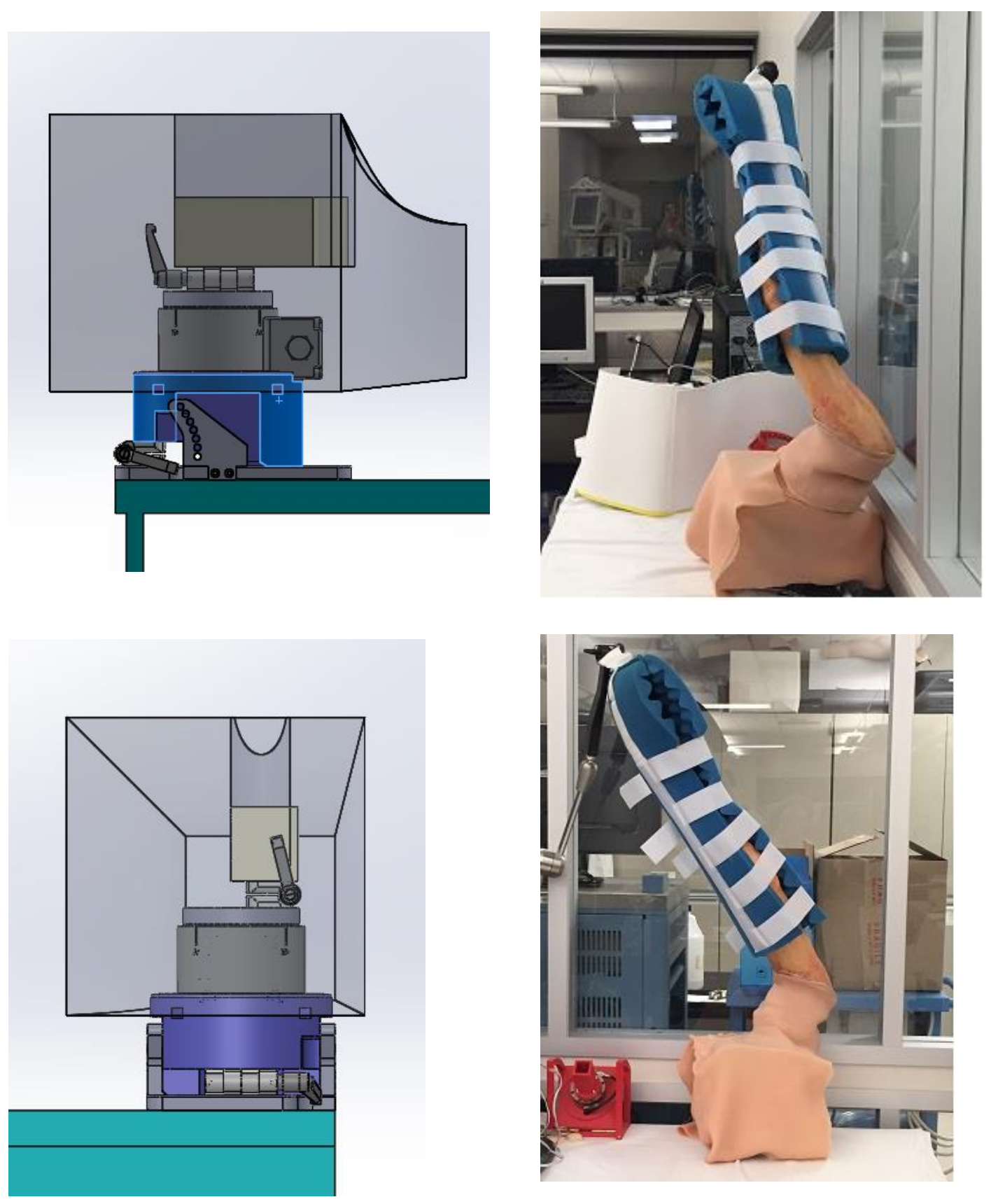

Figure 3.28: Simulator in the lateral decubitus position. 


\subsection{Summary}

The presented design of the shoulder simulator meets the requirements set out at the beginning of this chapter. The simulator includes basic anatomic structures of the shoulder, and permits realistic arthroscopic surgical actions. With the exception of the force-torque sensor, the parts are economical and modular to allow for quick and easy replacement of damaged components. The simulator is able to facilitate either wet or dry practice and can be oriented in either the beach chair or lateral decubitus operating position.

The posterior, anterior and lateral subacromial portals are pre-cut to allow access to the joint. The integrated buttons and force torque sensor allow for measurement of the actions of trainees. Additional equipment for external performance measurement will be introduced in the following chapter.

An external view of the completed simulator is shown in Figure 3.9. Figure 3.10 depicts the simulator in use by one of the expert surgeons. Design challenges and recommended changes will be discussed in Chapter 5. The following chapter describes the methods used to test and validate the simulator. 


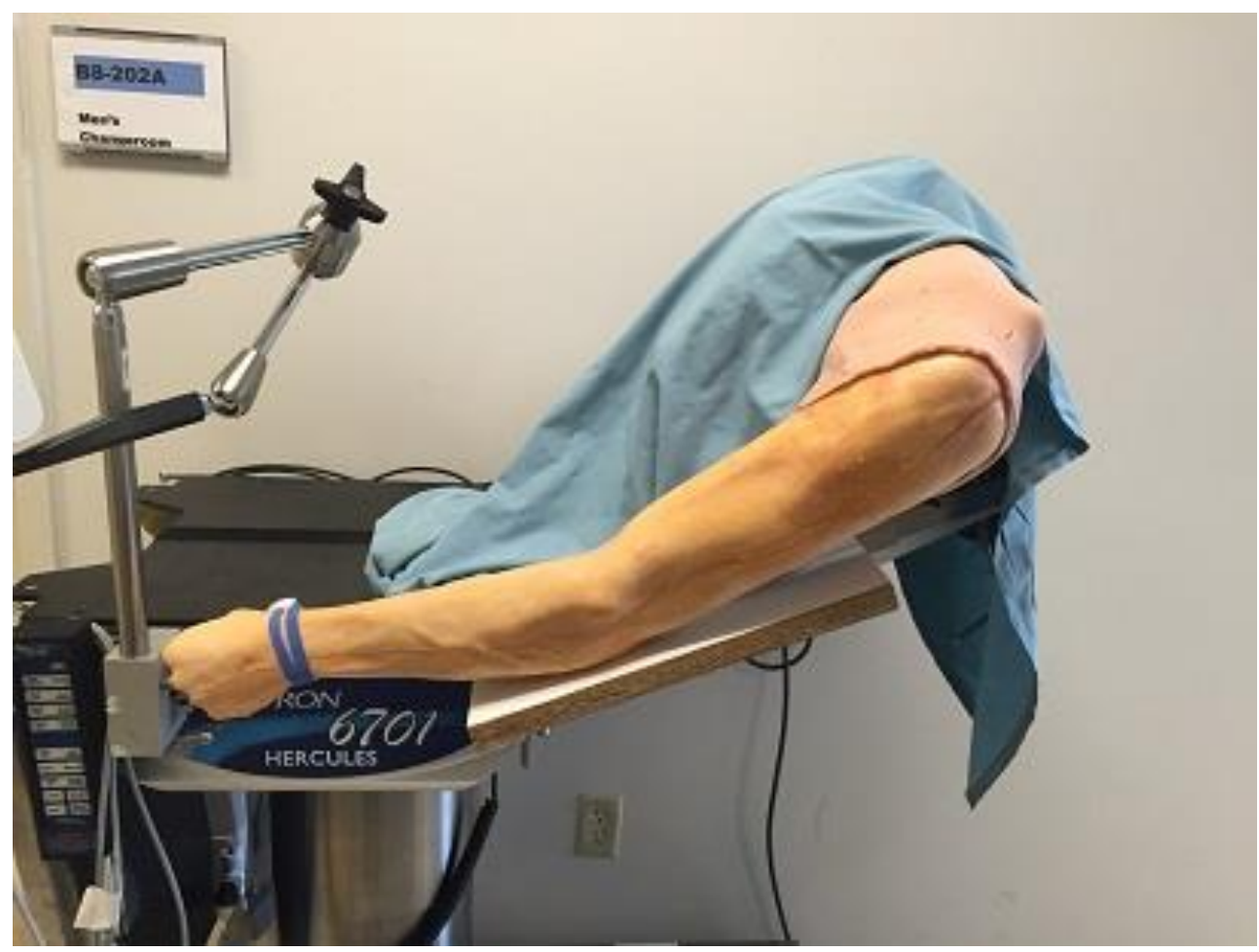

Figure 3.29: Completed simulator.

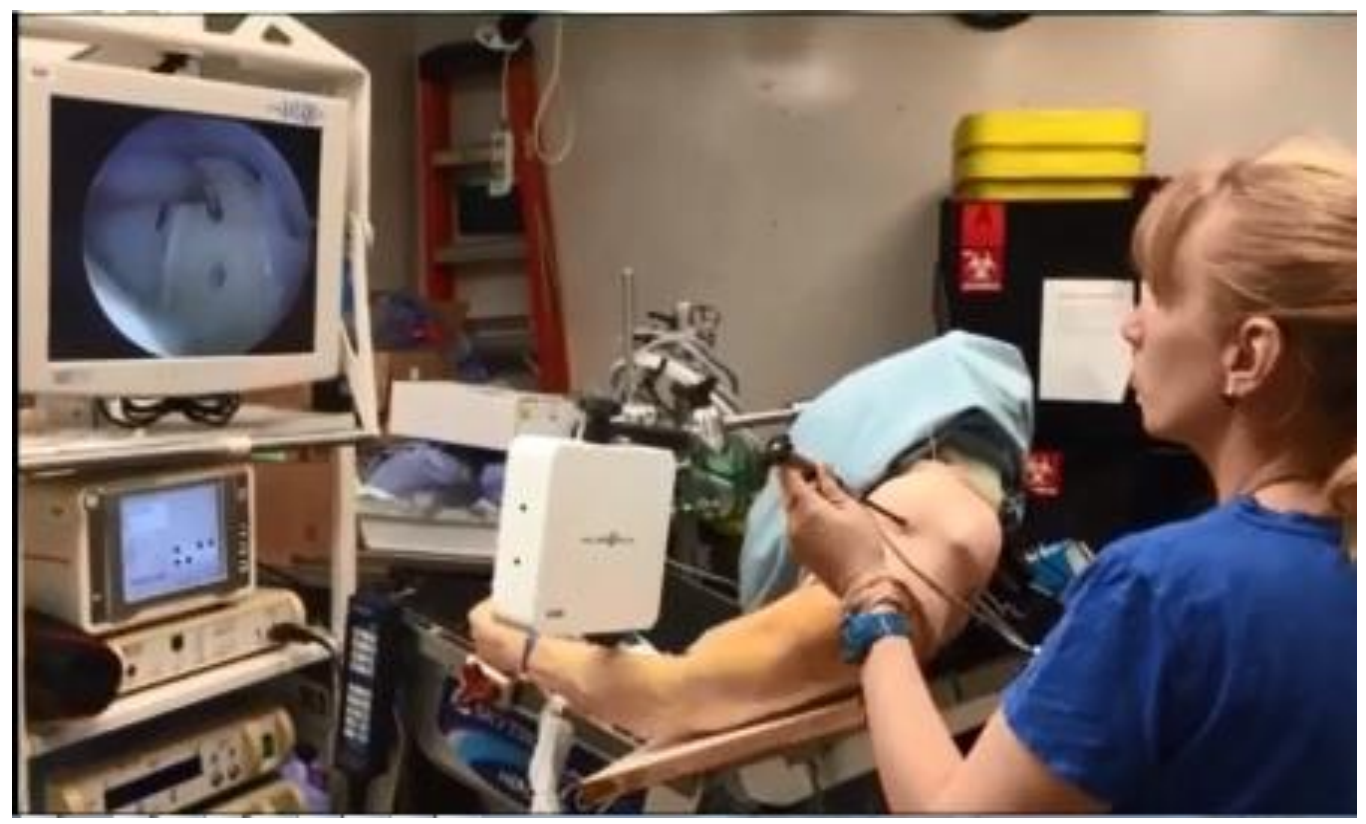

Figure 3.30: Simulator in use by an expert surgeon. 


\section{Chapter 4}

\section{Experimental Evaluation}

As described in the previous chapter, the shoulder simulator was designed to help novice surgeons improve their psychomotor performance by facilitating the practice of basic arthroscopic skills. The simulator allows trainees to practice basic skills such as triangulation, orientation, navigation of the anatomy, probing and grasping. These skills have been previously identified as important for surgical residents to be comfortable with before entering the $\mathrm{OR}[18,19]$. The study presented in this chapter was designed to evaluate the effectiveness of the shoulder simulator. The study involved collecting time, force and position data while subjects completed simple arthroscopy tasks. The performance of novice subjects was compared before and after practice, and also compared to that of expert surgeons.

\subsection{Recruitment and Ethics}

Subjects were recruited via academic email lists affiliated with Western University, following approval by the Research Ethics Board at Western. An email was distributed with an attached information letter that outlined details of the study (Appendix A). Participation in the study was entirely voluntary, and all candidates who expressed interest in taking part were included. Novices were identified as subjects with no medical background, medical students with no surgical training, and junior orthopaedic residents and non-orthopaedic surgeons with no scoping experience. The intermediate group incorporated senior orthopaedic residents, orthopaedic fellows, and non-orthopaedic surgeons with scoping experience. The expert group consisted of fellowship trained orthopaedic surgeons who have a clinical practice focused on arthroscopy.

Upon arrival for the study, subjects were asked to initial and sign the letter of consent. A total of 25 subjects (17 novices, 2 intermediates, and 6 experts) were recruited to participate in the study. Further details of the ethics protocol (FileNo. 106105) can be found in Appendix B. 


\subsection{Equipment}

The study was conducted in a surgical prep-room at CSTAR (Canadian Surgical Technologies and Advanced Robotics) in University Hospital. The equipment used in the study is shown in Figure 4.1 and described in detail below.

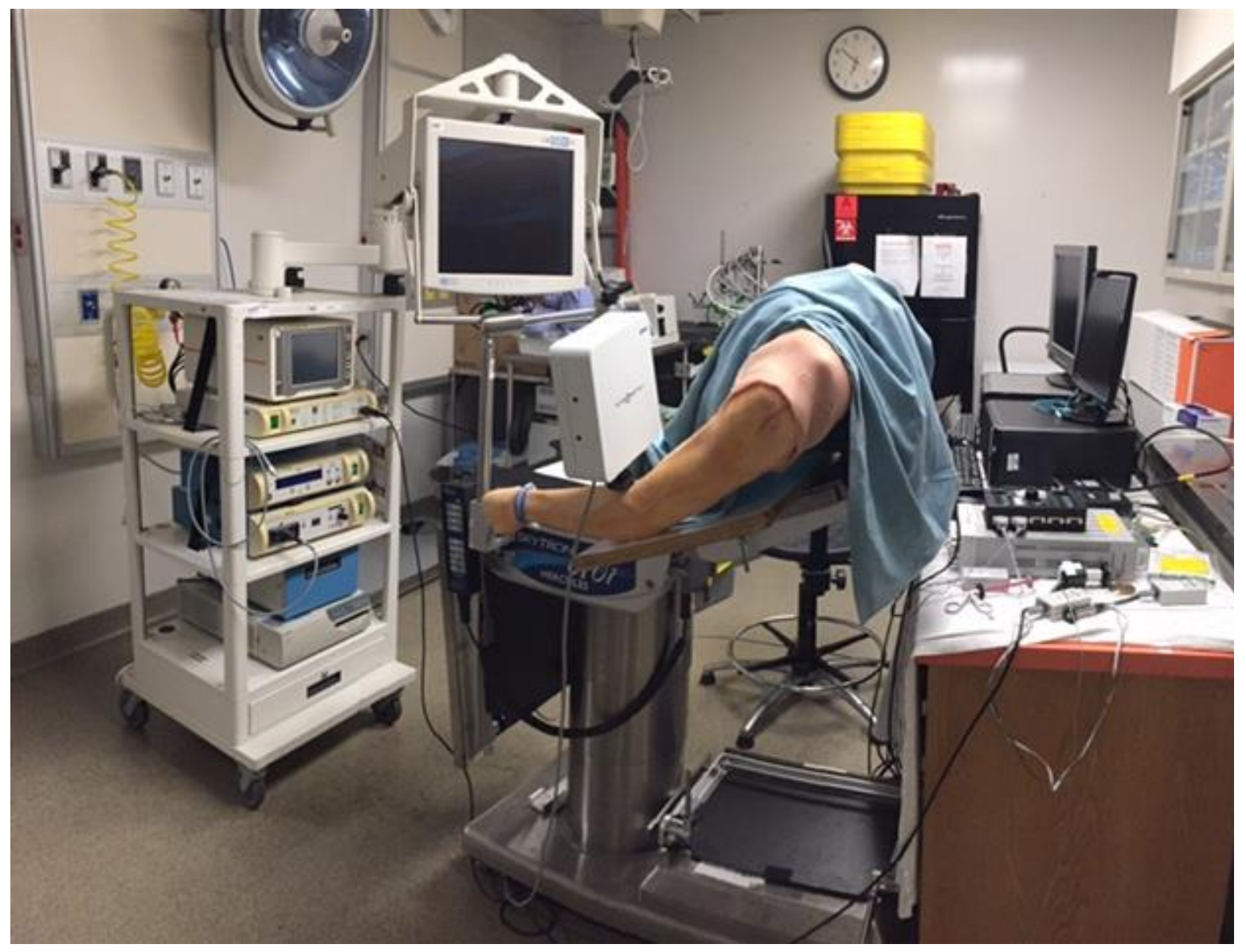

Figure 4.1: Equipment setup for simulator study.

\section{Data collection equipment:}

1) Simulator: The simulator was a custom-built sensorized physical shoulder simulator as described in detail in Chapter 3. The embedded F/T sensor measures 6 DOF with forces in the $x, y$ and $z$ directions, as well as torques around the $x, y$ and $z$ axes. Embedded switches provide a discrete digital signal when depressed. 
2) Surgical Tools: An arthroscopy probe and grasper that had been previously developed at CSTAR were the surgical tools used in the study (Figure 4.2 and Figure 4.3). Each instrument has been sensorized with four strain gauges arranged at 90 degrees around the shaft in order to measure forces in both the $x$ and $y$ directions. The gauges are connected to a 5 VDC power supply (E3620A, Agilent, Santa Clara, CA) through an amplifier (Quanser, Markham, ON) and communicate with the computer via a data acquisition card (Keithley, Cleveland, $\mathrm{OH})$. A sensor for position tracking is also affixed to the shaft of each instrument, described in Item 4 below.

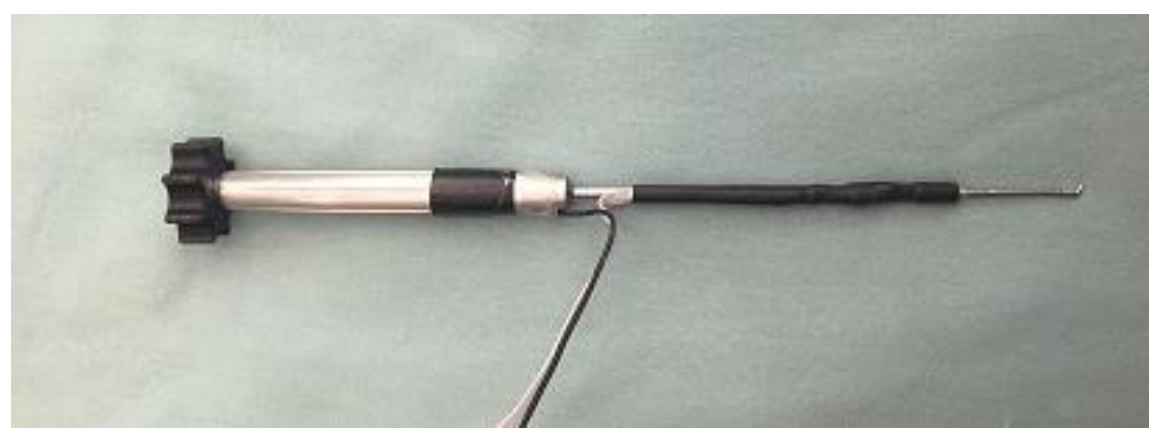

Figure 4.2: The sensorized arthroscopy probe tool.

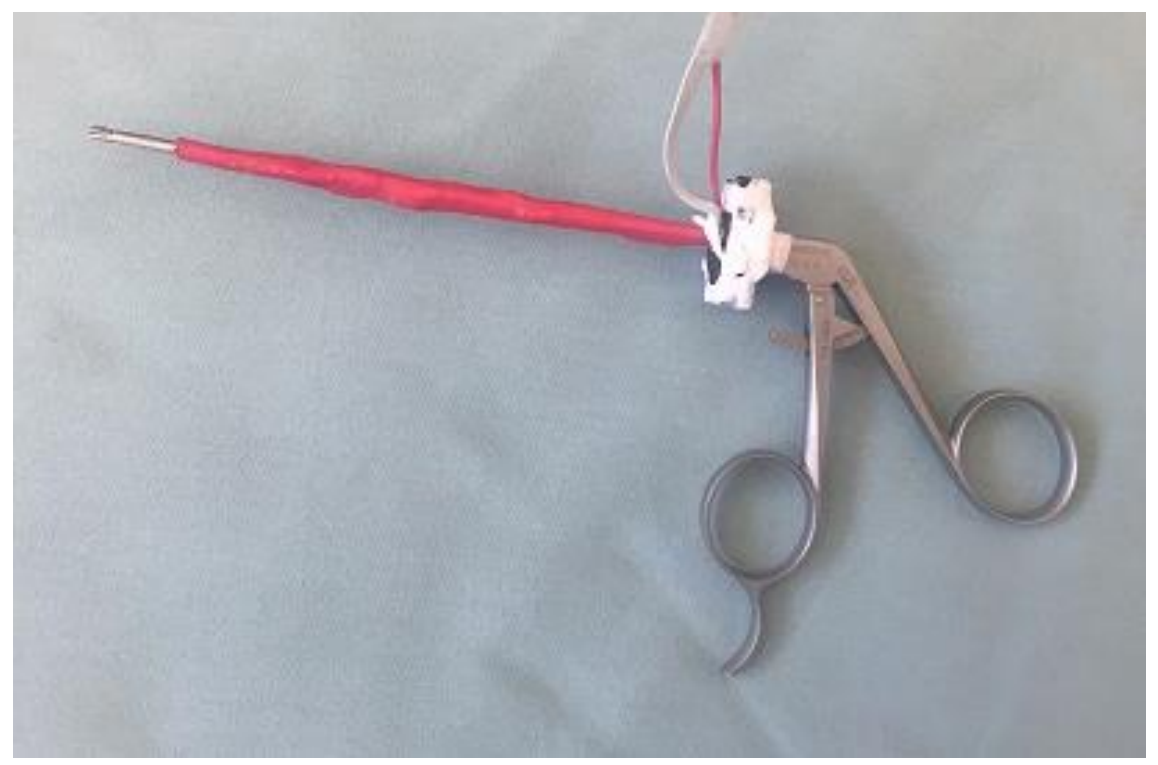

Figure 4.3: The sensorized arthroscopy grasper tool. 
3) Video Tower, Arthroscope and Camera: The arthroscope is a long slender instrument that incorporates a 30-degree lens (Smith \& Nephew, London, UK) and attachment points for a light source and water supply. The arthroscope is mounted to a camera head that attaches via a cable to a video tower. The video tower from Smith \& Nephew (London, UK) consists of an adjustable flat panel monitor, light source (model Dyonics 300XL), camera control unit (model 460P 3-CCD), and video recording system (model 660HD).

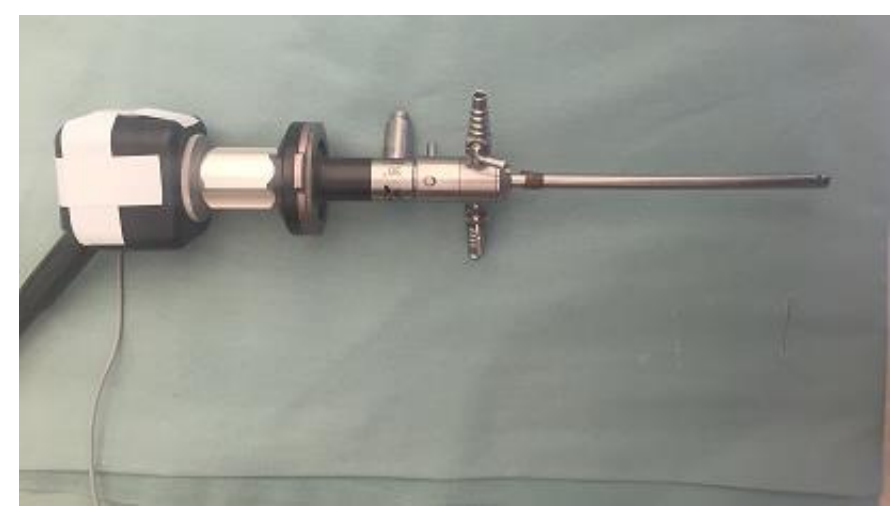

Figure 4.4: Arthroscope and camera with position sensor attached.

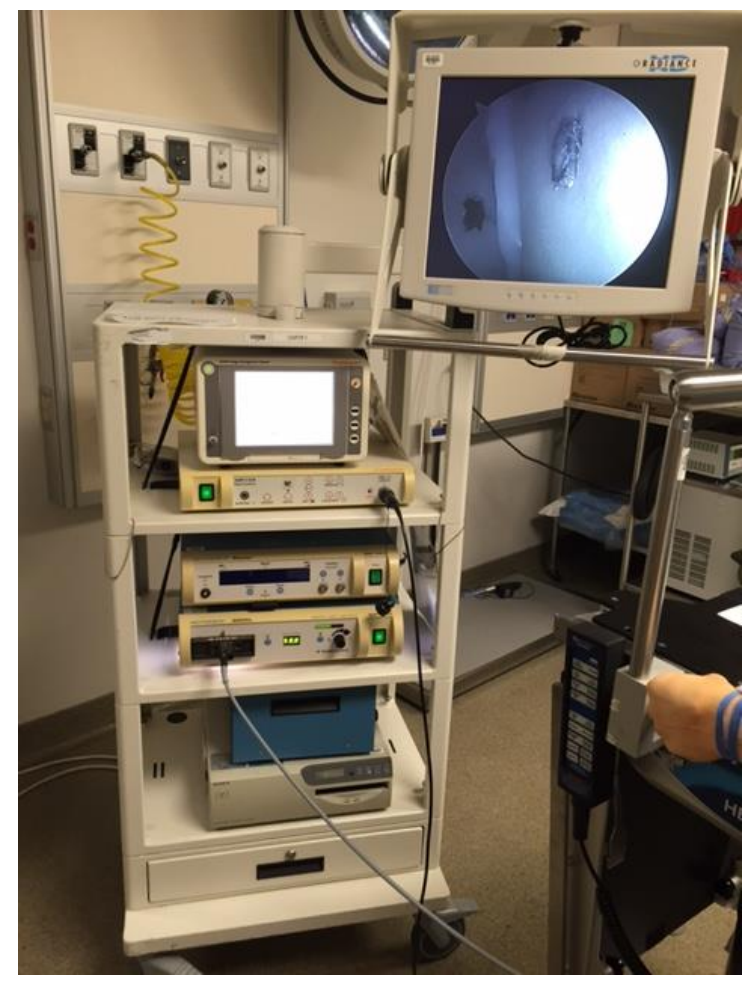

Figure 4.5: Video tower. 
4) Position Sensing System: Position data was collected using an Aurora electromagnetic tracking system from Northern Digital Inc. Medical (Waterloo, ON). The system consists of a Planar Field Generator, System Control Unit, Sensor Interface Units (3), and 5DOF Sensors (3). The three sensors are used to track the probe, grasper and arthroscope. Each tool was calibrated within the position system to produce transformations for locating the tips of the instruments.

The Aurora works by creating a series of magnetic fields and known volume of varying magnetic flux. Sensors placed inside the measurement volume will have a voltage induced in them. The characteristics of the voltage depend on the sensor position and orientation and the strength and phase of the varying magnetic fields. The voltages are converted into digital data and analyzed to produce position and orientation. The system measures in 5 DOF: the three translation values for the $x$, $y$, and $z$ directions and two of the three rotation values (pitch and yaw).

5) Personal Computers: The position, force and switch data was captured using custom designed software on two personal computers (Dell, Round Rock, TX).

\subsection{Instructions to Novice and Intermediate Trainees}

Subjects were provided with a handout containing basic information on the shoulder anatomy, the surgical instruments, and a brief description of the tasks. Subjects were recruited from diverse academic backgrounds, and with varying prior exposure to the information in the anatomy section. They were permitted to review the handout at their leisure. A copy of the handout has been included in Appendix C.

Immediately before each task, subjects were shown a video of an expert completing the task. A video of the surgeon using the simulator, taken from an external viewpoint, was followed by an internal view of the surgeon's instruments completing the task, taken from the endoscope. The video was shown once, without rewind or fast-forwarding. The video demonstrated the task and use of the instruments but did not provide any specific tips on completing the tasks. 
Before beginning Task 1, subjects were given up to five minutes to familiarize themselves with the arthroscope, tool and simulator. Subjects were then asked to complete a "Pre-test" which comprised the three tasks. They were then given the opportunity to practice for up to 30 minutes. The subjects then completed a "Post-test". Each subject was scheduled for a maximum of 2 hours. Their time was approximately allocated as shown in Table 4.1.

Table 4.1: Agenda for novice subjects.

\begin{tabular}{ll}
\hline Welcome and instructions & 15 minutes \\
Time for familiarization with the equipment & 5 minutes \\
Pre-test (attempt all three tasks) & 30 minutes \\
Practice & 30 minutes maximum \\
Post-test (repeat all three tasks) & 30 minutes
\end{tabular}

\subsection{Instructions to Expert Subjects}

Expert subjects were shown the informational printout so that they could later provide feedback. The task videos were shown before each task to explain what was required. The experts were given time to familiarize themselves with the simulator before completing the tasks. Although experts were permitted to repeat the tasks, there was no practice period or post-test.

\subsection{Tasks}

Three tasks were selected based on a review of the literature and after consultation with an expert surgeon. The selected tasks consist of probing anatomical points and grasping loose bodies for removal. A shaving task was not selected for this study as it is a destructive task, and would require frequent parts replacement. The tasks were performed in a dry simulator and in the beach chair position. 


\subsubsection{Task 1: Intra-articular Probing}

- Before starting Task 1, the arthroscope was inserted into the capsule for novice subjects through the posterior portal. Intermediate and expert subjects inserted the arthroscope themselves. The probe tool was positioned outside of the simulator, next to the anterior portal.

- At the start of the task, the subject entered the simulator with the probing tool through the portal.

- The subject entered the joint capsule, visualized and probed the two anatomical markers located in the centre of the glenoid, and at the top of the glenoid under the biceps tendon (Table 4.2).

- Each anatomical marker consisted of a microswitch, as described in Section 3.4. When the switch was depressed, an LED light turned on indicating that this marker was successfully probed.

- The task ended when both indicator lights had turned on.
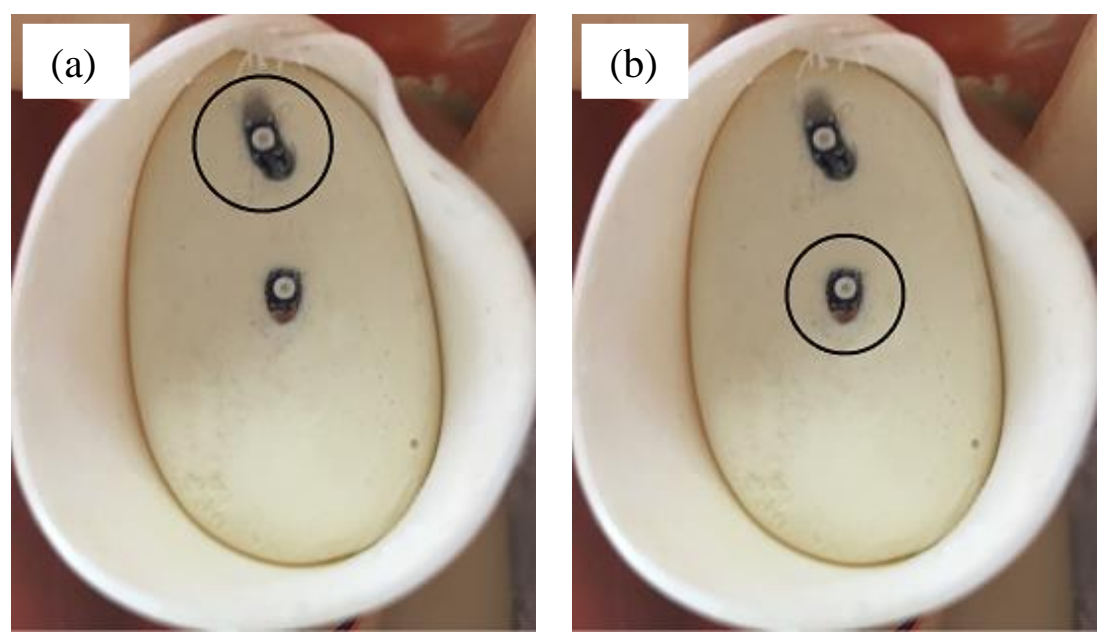

Figure 4.6: Switch locations for task one. (a) Top of the glenoid underneath the biceps tendon. (b) Centre of the glenoid. 


\subsubsection{Task 2: Subacromial Probing}

- Before starting Task 2, the arthroscope was inserted into the subacromial space for novice subjects through the posterior portal. Intermediate and expert subjects inserted the arthroscope themselves before the start of the task. The probe tool was positioned outside of the simulator, next to the lateral subacromial portal.

- At the start of the task the subject entered the simulator with the probing tool through the portal.

- The subject entered the subacromial space, visualized and probed the two anatomical markers located underneath the acromion, and underneath the coracoid process (Table 4.3). As in the previous task, each anatomical marker consisted of a microswitch. When the switch was depressed, an LED light turned on indicating that this marker was successfully probed.

- The task ended when both indicator lights have been turned on.
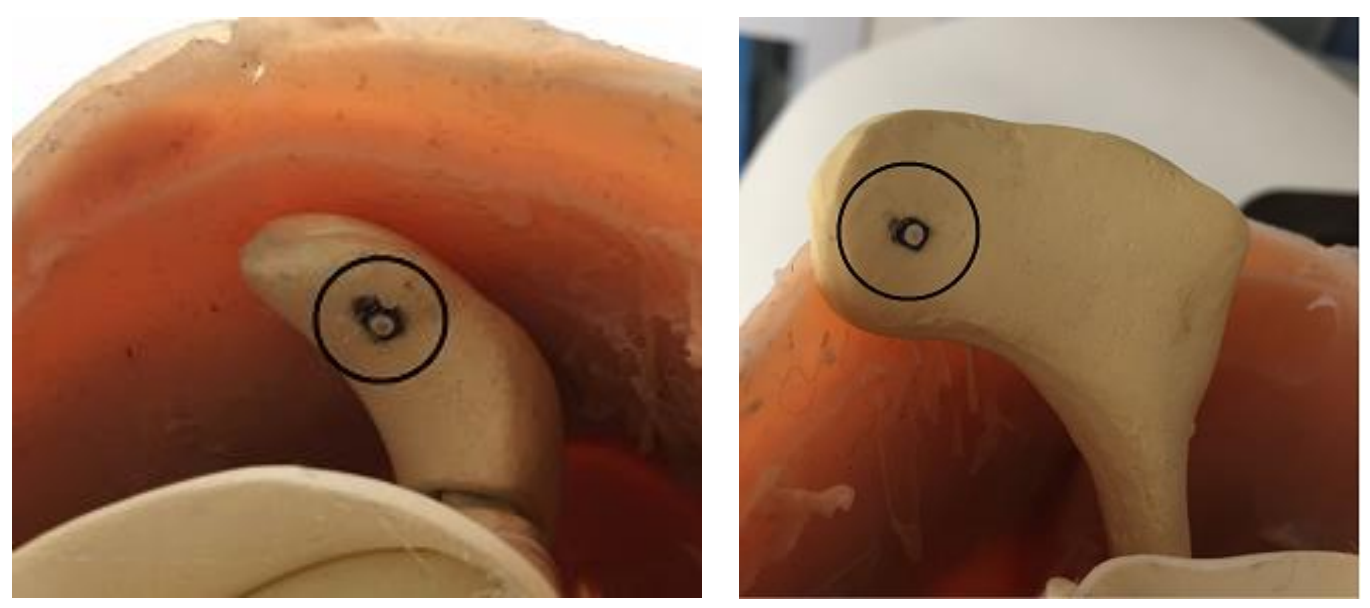

Figure 4.7: Switch locations for task two. (a)Underneath the coracoid process. (b) Underneath the acromion. 


\subsubsection{Task 3: Intra-articular Grasping}

- Before starting Task 3, the arthroscope was inserted into the capsule for novice subjects through the posterior portal. Intermediate and expert subjects inserted the arthroscope themselves before the start of the task. The grasper tool was positioned outside of the simulator next to the anterior portal.

- At the start of the task, the subject entered the simulator with the grasping tool through the portal.

- The subject entered the joint capsule, visualized the loose body, grasped the loose body, and removed the loose body from the simulator (Figure 4.7). The loose bodies are made from sections of spare synthetic biceps tendons as described in chapter 3 and were sized with consultation with an orthopaedic surgeon.

- The task ended when the loose body has been removed from the simulator.

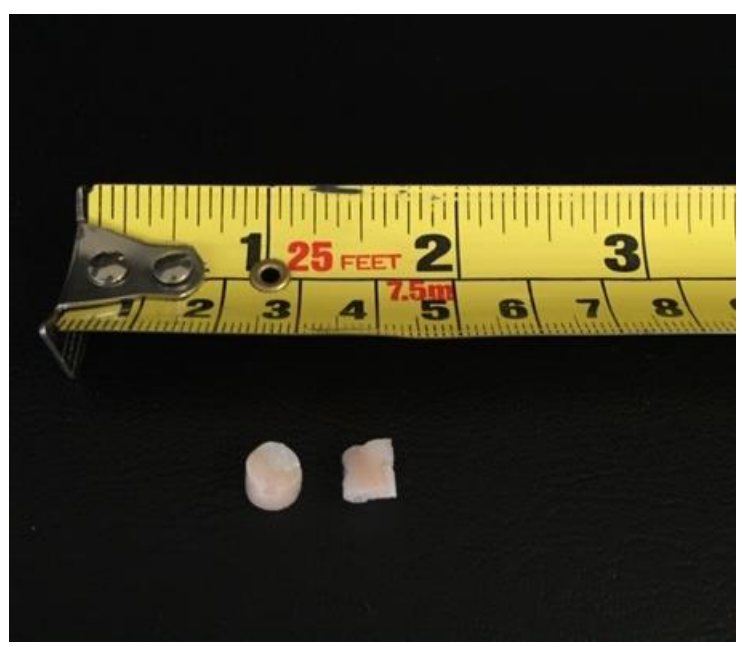

Figure 4.8: Loose bodies used in grasping task.

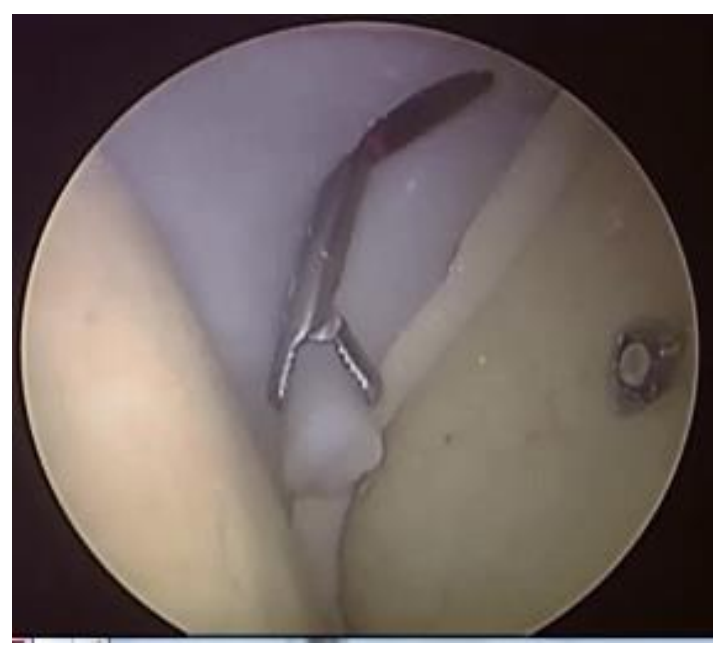

Figure 4.9: Grasper reaching for loose body. 


\subsection{Data Analysis}

Position, force, and time data were collected for each subject. Performance metrics were computed from the collected data, and were selected based on a review of the literature.

Total task time was calculated from the start of Tasks 1 and 2 to the moment the second switch was successfully pushed. For the grasping task, total time was calculated from the start of Task 3 until the subject successfully removed the loose body from the simulator.

The force and position data was post-processed using MATLAB (MathWorks, Natick, MA). Force data from the instruments and from the embedded F/T sensor were used to calculate average and maximum forces. Position data from the instruments and arthroscope were used to calculate path length, velocity, and jerk.

A single factor ANOVA was performed using Microsoft Excel (Microsoft, Redmond, WA) to evaluate statistical significance. The results from the study are presented in the following section.

\subsection{Performance Metrics}

Performance metrics were processed from the collected time, force and position data using MATLAB and analyzed using a single factor ANOVA in Microsoft Excel.

Two novice subjects failed to complete the pre-test for Task 1, and three novice subjects failed to complete the pre-test for Task 2. The subjects who failed to complete the tasks cited muscle fatigue and frustration as reasons for quitting. All subjects completed the pre-test for Task 3. After practicing on the simulator, all subjects were able to complete the three tasks on the post-test. Subjects who failed to complete the pre-test for Tasks 1 and 2 were removed completely from the analysis of those tasks. The results of the intermediate subject are not presented as there was only one subject in the group.

The task completion time was calculated for Tasks 1 and 2 from the start of the task until the second button was depressed. For Task 3, the completion time was calculated from the start of the task until the loose body was removed from the simulator. The results show that the expert group completed the tasks more quickly than the novices, and the 
novices completed the tasks more quickly after practice with the simulator as presented in Table 4.2. The difference in task time between the novice pre-test and expert was found to be statistically significant for all three tasks while the difference in task time between novice pre- and post-test was significant for Task 1 only.

Table 4.2: Task completion time.

\begin{tabular}{|l|l|l|l|l|l|l|}
\hline & $\begin{array}{l}\text { Novice } \\
\text { Subjects } \\
(n)\end{array}$ & $\begin{array}{l}\text { Expert } \\
\text { Subjects } \\
(n)\end{array}$ & $\begin{array}{l}\text { Novice } \\
\text { Pre-Test } \\
(\mathrm{s})\end{array}$ & $\begin{array}{l}\text { Novice } \\
\text { Post-Test } \\
(\mathrm{s})\end{array}$ & $\begin{array}{l}\text { Expert } \\
(\mathrm{s})\end{array}$ & $p$ values* \\
\hline Task 1 & 14 & 6 & 228.7 & 100.7 & 29.2 & $\mathbf{0 . 0 1 3 , 0 . 0 2 9}, \mathbf{0 . 0 1 7}$ \\
\hline Task 2 & 13 & 6 & 320.9 & 203.1 & 64.8 & $\mathbf{0 . 0 0 8 , 0 . 0 3 5}, 0.102$ \\
\hline Task 3 & 16 & 6 & 91.3 & 53.9 & 21.5 & $\mathbf{0 . 0 4 0}, 0.087,0.093$ \\
\hline
\end{tabular}

Instrument position data was collected from the probe in Tasks 1 and 2, and from the grasper tool in Task 3. The path length (P) metric was computed using Equation 4.1:

$$
P=\sum_{i=1}^{n} \sqrt{\left(x_{i}-x_{i-1}\right)^{2}+\left(y_{i}-y_{i-1}\right)^{2}+\left(z_{i}-z_{i-1}\right)^{2}}
$$

As expected, the path length results followed a decreasing trend (Table 4.3). For all three tasks, the experts' path length was shorter compared to the novices. The novices also showed a reducing trend in path length from the pre- to the post-test. The difference in task time between the novice pre-test and expert was found to be statistically significant for Tasks 1 and 2. The number of novice subjects was reduced by one to a total of thirteen for Task 1 due to a data collection error.

*p values from single-ANOVA of: novice pre-test vs. expert, novice post-test vs. expert, novice pre-test vs. novice post-test. Bolded values indicate statistically significant results. 
Table 4.3: Instrument path length.

\begin{tabular}{|l|l|l|l|l|l|l|}
\hline & $\begin{array}{l}\text { Novice } \\
\text { Subjects } \\
(n)\end{array}$ & $\begin{array}{l}\text { Expert } \\
\text { Subjects } \\
(n)\end{array}$ & $\begin{array}{l}\text { Novice } \\
\text { Pre-Test } \\
(\mathrm{m})\end{array}$ & $\begin{array}{l}\text { Novice } \\
\text { Post-Test } \\
(\mathrm{m})\end{array}$ & $\begin{array}{l}\text { Expert } \\
(\mathrm{m})\end{array}$ & $p$ values $^{*}$ \\
\hline Task 1 & 13 & 6 & 7.55 & 4.01 & 1.019 & $\mathbf{0 . 0 1 4 , 0 . 0 3 3 , 0 . 0 6 0}$ \\
\hline Task 2 & 13 & 6 & 7.97 & 4.67 & 2.790 & $\mathbf{0 . 0 4 8 , 0 . 3 2 1 , 0 . 1 0 7}$ \\
\hline Task 3 & 16 & 6 & 4.62 & 2.40 & 1.033 & $0.080,0.056,0.094$ \\
\hline
\end{tabular}

Force data was collected from a force-torque sensor that was embedded in the simulator, as well as from strain gauges on the shafts of the probe and grasper tools. The anticipated trend was a decrease in applied force corresponding to greater surgical skill. An analysis of average instrument force did not demonstrate a strong or consistent trend between the applied instrument forces and level of experience. The maximum or peak forces were also examined (Table 4.4, Table 4.5) but no prominent trend was shown.

Table 4.4: Average instrument force.

\begin{tabular}{|l|l|l|l|l|l|l|}
\hline & $\begin{array}{l}\text { Novice } \\
\text { Subjects } \\
(n)\end{array}$ & $\begin{array}{l}\text { Expert } \\
\text { Subjects } \\
(n)\end{array}$ & $\begin{array}{l}\text { Novice } \\
\text { Pre-Test } \\
(\mathrm{N})\end{array}$ & $\begin{array}{l}\text { Novice } \\
\text { Post-Test } \\
(\mathrm{N})\end{array}$ & $\begin{array}{l}\text { Expert } \\
(\mathrm{N})\end{array}$ & $p$ values* \\
\hline Task 1 & 14 & 6 & 1.38 & 0.85 & 1.33 & $0.933,0.111,0.125$ \\
\hline Task 2 & 13 & 6 & 0.94 & 0.88 & 0.94 & $0.991,0.758,0.695$ \\
\hline Task 3 & 16 & 6 & 1.67 & 1.26 & 3.01 & $0.325,0.130,0.463$ \\
\hline
\end{tabular}

*p values from single-ANOVA of: novice pre-test vs. expert, novice post-test vs. expert, novice pre-test vs. novice post-test. Bolded values indicate statistically significant results. 
Table 4.5: Maximum instrument force.

\begin{tabular}{|l|l|l|l|l|l|l|}
\hline & $\begin{array}{l}\text { Novice } \\
\text { Subjects } \\
(n)\end{array}$ & $\begin{array}{l}\text { Expert } \\
\text { Subjects } \\
(n)\end{array}$ & $\begin{array}{l}\text { Novice } \\
\text { Pre-Test } \\
(\mathrm{N})\end{array}$ & $\begin{array}{l}\text { Novice } \\
\text { Post-Test } \\
(\mathrm{N})\end{array}$ & $\begin{array}{l}\text { Expert } \\
(\mathrm{N})\end{array}$ & $p$ values $*$ \\
\hline Task 1 & 14 & 6 & 8.81 & 8.17 & 6.29 & $0.149,0.296,0.596$ \\
\hline Task 2 & 13 & 6 & 9.34 & 8.09 & 7.36 & $0.213,0.705,0.396$ \\
\hline Task 3 & 16 & 6 & 24.17 & 27.52 & 5.39 & $0.189,0.135,0.780$ \\
\hline
\end{tabular}

The results from the force-torque sensor for the average and maximum force are presented below in Table 4.6 and Table 4.7. There was no clear trend for the average force data. For the maximum force, there is a decreasing trend for all three tasks, both between novices and experts and for novices from pre- to post-practice.

Table 4.6: F/T sensor average force.

\begin{tabular}{|l|l|l|l|l|l|l|}
\hline & $\begin{array}{l}\text { Novice } \\
\text { Subjects } \\
(n)\end{array}$ & $\begin{array}{l}\text { Expert } \\
\text { Subjects } \\
(n)\end{array}$ & $\begin{array}{l}\text { Novice } \\
\text { Pre-Test } \\
(\mathrm{N})\end{array}$ & $\begin{array}{l}\text { Novice } \\
\text { Post-Test } \\
(\mathrm{N})\end{array}$ & $\begin{array}{l}\text { Expert } \\
(\mathrm{N})\end{array}$ & p values $*$ \\
\hline Task 1 & 14 & 6 & 2.6 & 2.01 & 2.41 & $0.786,0.901,0.178$ \\
\hline Task 2 & 13 & 6 & 2.17 & 1.93 & 2.62 & $0.245,0.075,0.361$ \\
\hline Task 3 & 16 & 6 & 1.98 & 1.76 & 7.01 & $0.109,0.096,0.351$ \\
\hline
\end{tabular}

Table 4.7: F/T sensor maximum force.

\begin{tabular}{|l|l|l|l|l|l|l|}
\hline & $\begin{array}{l}\text { Novice } \\
\text { Subjects } \\
(n)\end{array}$ & $\begin{array}{l}\text { Expert } \\
\text { Subjects } \\
(n)\end{array}$ & $\begin{array}{l}\text { Novice } \\
\text { Pre-Test } \\
(\mathrm{N})\end{array}$ & $\begin{array}{l}\text { Novice } \\
\text { Post-Test } \\
(\mathrm{N})\end{array}$ & $\begin{array}{l}\text { Expert } \\
(\mathrm{N})\end{array}$ & $p$ values ${ }^{*}$ \\
\hline Task 1 & 14 & 6 & 7.39 & 6.05 & 12.27 & $0.204,0.080,0.289$ \\
\hline Task 2 & 13 & 6 & 10.51 & 8.57 & 10.89 & $0.810,0.195,0.079$ \\
\hline Task 3 & 16 & 6 & 5.09 & 4.56 & 9.70 & $0.126,0.095,0.395$ \\
\hline
\end{tabular}

*p values from single-ANOVA of: novice pre-test vs. expert, novice post-test vs. expert, novice pre-test vs. novice post-test. Bolded values indicate statistically significant results. 
At the end of their trial, the experienced subjects were given a questionnaire regarding their impressions of the simulator (Appendix D). The response from the six subjects in the expert and intermediate categories were grouped together as they are all surgeons with arthroscopy experience. The expert surgeon who consulted on the project was not asked to participate in the questionnaire due to a conflict of interest. The average scores are presented in Table 4.8. The questionnaire uses a Likert scale where $5=$ strongly agree, 3 = neutral, and $1=$ strongly disagree.

Table 4.8: Results of questionnaire from expert and intermediate respondents.

\begin{tabular}{ll}
\multicolumn{1}{c}{ Statement } & Mean Score \\
\hline $\begin{array}{l}\text { The system is beneficial to the introduction of basic skills (e.g., triangulation, } \\
\text { navigation and orientation within the joint) }\end{array}$ & 5.0 \\
The visual representation of the joint provides sufficient realism for the training & 4.3 \\
of basic skills & 4.0 \\
The physical limb model provides sufficient realism for the training of basic & \\
skills & 4.7 \\
The instruments feel realistic & 4.7 \\
I would use the system for training (or recommend its use) if it were available & \\
\hline
\end{tabular}

There was also a section at the bottom of the questionnaire for participants to share their comments. The comments provided were: "Great simulation!”, “Works well!", and "Glenohumeral anatomy is sufficient. Subacromial anatomy is not very realistic".

Novices were also given the questionnaire, in particular to answer the last question, and provide an opportunity for comment. The mean score for the last question was 4.8 (standard deviation 0.4), indicating that they would use the simulator for training. The comments received from novices were: "By the end of the session I felt much more comfortable with the navigation of using both the probe and scope together"; " "Skin" was stretchier (sic) than normal skin would be, but visual representations were accurate."; "Combination of training videos and being able to practice on the simulator would be a 
beneficial tool for surgeons". Overall, novices seemed to enjoy their time using the simulator.

\subsection{Discussion}

The purpose of this study was to assess the effectiveness of the simulator as a learning tool and to determine if it improves performance of novice trainees in basic arthroscopy tasks. Practice on the simulator should familiarize trainees with the shoulder anatomy, the use of the tools and the hand-eye coordination required in arthroscopy.

Task completion time has been previously shown in the literature to decrease with experience [8], [47], [57], [58], [73]. An analysis of the task completion time shows that experts completed the tasks more quickly than the novices, and that novices improved their task time after practice. Task time should not be the only indicator of improved performance as it lacks information as to the quality of the completed task. Instrument path length was also analyzed. The literature has previously shown that the path length, also called distance travelled, decreases with experience [57], [61]. For the path length metric, experts completed the task using a shorter path, as expected, for all tasks. Novices decreased the path length from the pre-test to the post-test. The results from the task completion time and path length support construct validity for the simulator in terms of distinguishing between novices and experts and achieving the goal of helping novices improve through practice.

Force based metrics for arthroscopy and laparoscopy have been presented in the literature [61], [74], suggesting that experienced surgeons use less force than novices. The results for average and maximum forces did not show differences between novice and expert groups. While time and path length are measures of efficiency, and show a decreasing trend with experience, the trend for force is less intuitive. A surgeon may want to avoid excessive force application to tissues that are easily damaged, while other tasks may require a firmer touch. However, for the probing and grasping tasks, which mostly consist of navigating the anatomy and precise movements, a lower force was anticipated from the expert surgeons. This trend was not seen. In the future, a more involved analysis of force based metrics and larger samples sizes should be considered. 
An interesting result was the excessive force used by novices in Task 3 . For Task 3 , the mean maximum force was influenced by four of the sixteen subjects applying excessive forces greater than $60 \mathrm{~N}$ during the pre-task, and five applying forces greater than $60 \mathrm{~N}$ during the post-task. The maximum force applied by an expert during Task 3 was $2.5 \mathrm{~N}$. The highest maximum force applied at any time by an expert was $13 \mathrm{~N}$, which occurred during Task 1, while the highest maximum force applied by a novice in Task 1 was 14.4 $\mathrm{N}$ and was $15.7 \mathrm{~N}$ in Task 2. One reason for the high forces during the grasping task (Task 3) could be that novice subjects often used the grasper at awkward angles, applying pressure as they leveraged it through the portals, which acted as a fulcrum, in order to reach the loose body inside the capsule. Defining which metrics to use is outside the scope of this thesis but may be considered during future work.

The experts and the intermediate level surgeon who came to use the simulator, all rated it highly in terms of realism, supporting the face validity of the simulator. The simulator was also rated highly as being beneficial for the introduction of basic skills, and it was agreed that they would use the simulator for training. These results support the construct validity of the simulator.

The shoulder was a left shoulder which required holding the instrument being manipulated in the left hand. With the majority of the population being right-handed this increases the difficulty especially among novice trainees. More experienced surgeons have better ambidextrous performance [16] and this may have been a factor in elucidating difference between novices and experts.

The study had several limitations. First, it explored only two basic tasks, probing and grasping and the results are limited to these two tasks. Additional training tasks must be studied before assuming practice with the simulator improves performance. The small number of expert surgeons meant that the study lacked sufficient power to distinguish between novice and expert groups. It was challenging to recruit expert arthroscopy surgeons with the limited pool locally available. Perhaps recruiting experts to use the simulator during a local arthroscopy surgical event would be an effective way to collect more expert data. The novice subjects who participated in the study came from diverse 
educational backgrounds ranging from undergraduate and graduate students in engineering and kinesiology, to undergraduate medical students. It was observed that some novice subjects were more motivated than others to complete the tasks and to practice in between tests. Perhaps limiting recruitment to students who were interested in medicine and surgery would improve novice engagement in future studies.

The study put the simulator through many hours of use by untrained novice subjects. The physical simulator held up well to the heavy usage with only a few indications of damage. Two of the microswitches had to be replaced during the course of the study as the plastic coating was damaged due to rigorous probing. Also, the two portals allowing access to the joint capsule were reinforced with stitches to prevent tearing, after it became apparent that rigorous use could rip the thin silicone, despite the nylon reinforcement. These repairs were inexpensive and simple to make.

The study tested the simulator with twenty subjects performing three tasks, and putting the simulator through many hours of use. The task completion time and path length metrics were able to indicate a difference in skill level. Novice subjects who used the simulator rated it highly as something they would use for training. Expert subjects found the simulator realistic and considered it to be a useful training tool. 


\section{Chapter 5}

\section{Conclusions and Future Work}

The work presented in this thesis fills a void within existing shoulder simulators by combining the physical nature of a human cadaver with the feedback capabilities of VR simulators. Unlike the knee joint, the human shoulder joint is not well represented by available animal models. Cadavers require continual replacement, and limit practice locations. VR simulators provide limited tactile feedback and carry high initial costs. The physical shoulder simulator will allow residents to practice using real instruments with tactile feedback, in accessible locations, while receiving feedback.

The design requirements set out at the beginning of chapter three have been met. The simulator can facilitate wet or dry practice, and can be oriented in either the beach chair or the lateral decubitus positions. The micro switches embedded in the simulator objectively capture the exact time when a probing task is complete. An embedded force torque sensor captures force data and presents the opportunity to explore more complex force-based metrics in the future.

The study that was conducted showed that the simulator helped novices improve their arthroscopic skills on probing and grasping tasks. Improvements were seen in task completion time and path length metrics after novices used the simulator to practice, indicating improved psychomotor skills. Experienced surgeons who used the simulator rated it highly in terms of realism, and indicated that they would use it as a training tool if it were available.

Due to innate differences in psychomotor ability, surgical residents need varying amounts of practice in order to achieve proficiency in basic arthroscopic skills. By using the physical shoulder simulator to practice residents could improve their basic arthroscopic skills prior to entering the OR, resulting in improved patient safety and saving valuable OR time. 


\subsection{Contributions}

This thesis contributes the design of a novel sensorized physical shoulder simulator for training basic arthroscopic skills. The specific contributions of the thesis can be summarized as follows:

- Design and implementation of a novel method for quantitatively timing a probing task using embedded micro switches which function in both wet and dry practice environments.

- Design and implementation of a novel mechanism to accommodate both beach chair and lateral decubitus surgical positions, while incorporating a force-torque sensor, and facilitating wet or dry practice.

\subsection{Future Work}

Based on the testing and use of the shoulder simulator design, suggestions for future improvements were identified.

The simulator design could be improved for realism and functionality.

- A better fat encapsulation method should be investigated as some synthetic fat escaped from the outer silicone layer and stuck to the scope during subacromial manipulation.

- For improved realism during subacromial tasks, future versions of the simulator could include the clavicle, arcromioclavicular joint, and coraco-acromial ligament. The clavicle would have to be bisected or a method would be required to seal the transition between the waterproof compartment and the torso.

- More resilient switches constructed from hard plastic should be evaluated for inclusion in the simulator to prevent destruction after rigorous probing by novice trainees. 
- A design to allow the practice of port placement could be incorporated into the simulator. The design would likely require being able to switch the shoulder skin from a skin with pre-cut waterproof portals to an uncut shoulder skin for practicing port placement.

- The project could be expanded to construct a right hand shoulder simulator and shoulder simulators representing different patient sizes.

Further to design improvements, more rigorous validation studies could be completed, as follows:

- Future trials could be expanded to collect data from a higher number of novice and expert subjects. It was challenging to recruit local expert arthroscopy surgeons with the limited pool available. Perhaps recruiting experts to use the simulator during an arthroscopy surgical event or conference would be an effective way to collect more extensive expert data. Future studies might consider limiting novice recruitment to medical school students to help ensure high engagement. A future study could use a survey created specifically for novices about the utility of the simulator to help understand what novices found difficult and beneficial.

- Future studies could include additional tasks such as burring or shaving.

- Future data analysis could examine and develop different force based metrics for the shoulder. Force based metrics, or metrics that combine force and position data, could be developed that are unique to each task.

- A future study could examine transfer validity from the simulator to the OR. This study would examine if orthopaedic residents perform better in the OR after having used the simulator to learn and practice basic skills. Another possible future transfer validity study could be conducted for intermediates. Other professions which rely on psychomotor skill proficiency often prepare their muscles and cerebellar function with warm-up activities and there is some 
evidence supporting "preoperative warm-up" as a means of improving surgical skills proficiency in subsequent tasks [63].

With additional work towards design improvement and validation, future commercialization of the simulator may be possible. 


\section{References}

[1] R. J. Koehler, S. Amsdell, E. a Arendt, L. J. Bisson, J. P. Braman, J. P. Bramen, A. Butler, A. J. Cosgarea, C. D. Harner, W. E. Garrett, T. Olson, W. J. Warme, and G. T. Nicandri, "The Arthroscopic Surgical Skill Evaluation Tool (ASSET)," Am. J. Sports Med., vol. 41, no. 6, pp. 1229-37, Jun. 2013.

[2] X. Li, J. K. Eichinger, T. Harshorn, H. Zhou, E. G. Matzkin, and J. P. Warner, “A Comparison of the Lateral Decubitus and Beach-Chair Positions for Shoulder Surgery: Advantages and Complications," J. Am. Acad. Orthop. Surg., vol. 23, pp. 18-28, 2015.

[3] J. E. Tibone, F. H. Savoie, and B. S. Shaffer, Shoulder Arthroscopy. New York: Springer-Verlag, 2003.

[4] ESSKA, Effective Training of Arthroscopic Skills. Berlin, Heidelberg: Springer, 2015.

[5] M. P. Hall, K. M. Kaplan, C. T. Gorczynski, J. D. Zuckerman, and J. E. Rosen, "Assessment of arthroscopic training in U.S. orthopaedic surgery residency programs: A resident self-assessment," Bull. NYU Hosp. Jt. Dis., vol. 68, no. 1, pp. 5-10, 2010.

[6] R. M. Frank, B. Erickson, J. M. Frank, C. a. Bush-Joseph, B. R. Bach, B. J. Cole, A. a. Romeo, M. T. Provencher, and N. N. Verma, "Utility of modern arthroscopic simulator training models," Arthrosc. - J. Arthrosc. Relat. Surg., vol. 30, no. 1, pp. 121-133, Jan. 2014.

[7] K. S. N. Akhtar, A. Chen, N. J. Standfield, and C. M. Gupte, "The role of simulation in developing surgical skills," Curr. Rev. Musculoskelet. Med., vol. 7, no. 2 , pp. 155-160, 2014. 
[8] G. J. M. Tuijthof, M. N. van Sterkenburg, I. N. Sierevelt, J. van Oldenrijk, C. N. Van Dijk, and G. M. M. J. Kerkhoffs, "First validation of the PASSPORT training environment for arthroscopic skills.," Knee Surg. Sports Traumatol. Arthrosc., vol. 18, no. 2, pp. 218-224, Mar. 2010.

[9] R. M. Satava, "Historical review of surgical simulation - A personal perspective," World J. Surg., vol. 32, no. 2, pp. 141-148, 2008.

[10] H. Kaufman, R. Wiegand, and R. Tunick, "Teaching surgeons to operate --Principles of psychomotor skills training," Acta Neurochir. (Wien)., vol. 87, no. 1, pp. 1-7, 1987.

[11] R. Treuting, "Minimally invasive orthopedic surgery: arthroscopy," Ochsner J., vol. 2, no. 3, pp. 158-163, 2000.

[12] M. Karahan, P. C. Unalan, S. Bozkurt, I. Odabaş, U. Akgun, S. Cifcili, P. Lobenhoffer, and A. T. Aydin, "Correlation of basic motor skills with arthroscopic experience," Acta Orthop. Traumatol. Turc., vol. 43, no. 1, pp. 49-53, 2009.

[13] OED Online, "psychomotor, adj.," Oxford University Press, 2015. [Online]. Available:

http://www.oed.com./view/Entry/153915?redirectedFrom=psychomotor. [Accessed: 23-May-2015].

[14] P. M. Fitts and M. I. Posner, Human Performance. Belmont, California: Brooks/Cole, 1967.

[15] J. Mckee, ““ Rebooting' Orthopaedic Resident Education: AAOS sponsors second summit on orthopaedic surgery training through simulation," American Academy of Orthopaedic Surgeons: Now, Illinois, Feb-2014.

[16] K. Rose and R. Pedowitz, "Fundamental Arthroscopic Skill Differentiation With Virtual Reality Simulation,” Arthrosc. J. Arthrosc. Relat. Surg., vol. 31, no. 2, pp. 299-305, 2015. 
[17] M. Karahan and G. Tuijthof, "ESSKA Instructional Course Lecture Book," Berlin Heidelberg: Springer, 2014.

[18] O. Safir, A. Dubrowski, L. Mirsky, C. Lin, D. Backstein, and H. Carnahan, "What skills should simulation training in arthroscopy teach residents? A focus on resident input," Int. J. Comput. Assist. Radiol. Surg., vol. 8, no. 3, pp. 433-437, 2008.

[19] Y. Hui, O. Safir, A. Dubrowski, and H. Carnahan, "What skills should simulation training in arthroscopy teach residents?," Int. J. Comput. Assist. Radiol. Surg., vol. 3, no. 5, pp. 945-953, Nov. 2013.

[20] S. Bayona, J. M. Fernández-Arroyo, I. Martín, and P. Bayona, “Assessment study of insight ARTHRO VR $®$ arthroscopy virtual training simulator: Face, content, and construct validities," J. Robot. Surg., vol. 2, no. 3, pp. 151-158, 2008.

[21] G. Norman, K. Dore, and L. Grierson, "The minimal relationship between simulation fidelity and transfer of learning.," Med. Educ., vol. 46, no. 7, pp. 63647, Jul. 2012.

[22] M. Leahy, "Using Simulation, Metrics to Improve Orthopaedic Surgical Skills: Newer training methods begin with the basics," American Academy of Orthopaedic Surgeons: Now, Illinois, Feb-2012.

[23] J. a. Martin, G. Regehr, R. Reznick, H. Macrae, J. Murnaghan, C. Hutchison, and M. Brown, "Objective structured assessment of technical skills (OSATS) for surgical residents,” Br. J. Surg., vol. 84, pp. 273-278, 1997.

[24] P. C. Unalan, K. Akan, H. Orhun, U. Akgun, O. Poyanli, A. Baykan, Y. Yavuz, T. Beyzadeoglu, R. Nuran, B. Kocaoglu, N. Topsakal, M. Akman, and M. Karahan, "A basic arthroscopy course based on motor skill training.," Knee Surg. Sports Traumatol. Arthrosc., vol. 18, no. 10, pp. 1395-1399, Oct. 2010.

[25] ESSKA, "European Basic Arthroscopy Course," 2015. [Online]. Available: http://www.europeanarthroscopycourse.eu/. [Accessed: 08-Jun-2015]. 
[26] A. M. M. A. Sherman, K.P., Ward,J.W. , Willis,D.P.M.,Mohsen, “Surgical Trainee Assessment Using a VE Knee Arthrscopy Training System (VE-KATS): Experimental Results.pdf.” 2001.

[27] P. Heng, C. Cheng, T. Wong, Y. Xu, Y. Chui, K. Chan, S. Tso, and S. Member, “A Virtual-Reality Training System for Knee Arthroscopic Surgery,” vol. 8, no. 2, pp. 217-227, 2004.

[28] S. Srivastava, P. L. Youngblood, C. Rawn, S. Hariri, W. L. Heinrichs, and A. L. Ladd, "Initial evaluation of a shoulder arthroscopy simulator: Establishing construct validity," J. Shoulder Elb. Surg., vol. 13, no. 2, pp. 196-205, Mar. 2004.

[29] R. Riener, M. Frey, T. Pröll, F. Regenfelder, and R. Burgkart, "Phantom-Based Multimodal Interactions for Medical Education and Training: The Munich Knee Joint Simulator," IEEE Trans. Inf. Technol. Biomed. vol. 8, no. 2, pp. 208-216, 2004.

[30] A. D. McCarthy, L. Moody, A. R. Waterworth, and D. R. Bickerstaff, "Passive Haptics in a Knee Arthroscopy Simulator," Clin. Orthop. Relat. Res., vol. 442, pp. 13-20, Jan. 2006.

[31] S. Bayona, M. Garcia, C. Mendoza, J. M. Ferniindez, and R. Juan, "Shoulder Arthroscopy Training System with Force Feedback," Proc. Int. Conf. Med. Inf. Vis., pp. 4-9, 2006.

[32] “Arthro Mentor,” Simbionix USA Corporation, 2014. [Online]. Available: http://simbionix.com/simulators/arthro-mentor/. [Accessed: 29-Jan-2015].

[33] S. F. Fucentese, S. Rahm, K. Wieser, J. Spillmann, M. Harders, and P. P. Koch, "Evaluation of a virtual-reality-based simulator using passive haptic feedback for knee arthroscopy,” Knee Surgery, Sport. Traumatol. Arthrosc., pp. 1-9, 2014.

[34] "Medical Training Simulators," VirtaMed AG, 2014. [Online]. Available: http://www.virtamed.com/en/medical-training-simulators/arthros/ . [Accessed: 29Jan-2015]. 
[35] R. D. Meyer, J. R. Tamarapalli, and J. E. Lemons, "Arthroscopy Training Using a Black-Box Technique,” Arthroscopy, vol. 9, no. 3, pp. 338-340, 1993.

[36] A. Alvand, S. Auplish, H. Gill, and J. Rees, "Topics in Training: Innate Arthroscopic Skills in Medical Students and Variation in Learning Curves," $J$. Bone Jt. Surg., vol. 93, no. e115, pp. 1-9, 2011.

[37] A. Escoto, F. Le Ber, A. L. Trejos, M. D. Naish, R. V Patel, and M.-E. Lebel, “A knee arthroscopy simulator: Design and validation.," Conf. Proc. IEEE Eng. Med. Biol. Soc., vol. 2013, pp. 5715-5718, 2013.

[38] J. J. Stunt, G. M. M. J. Kerkhoffs, T. Horeman, C. N. van Dijk, and G. J. M. Tuijthof, "Validation of the PASSPORT V2 training environment for arthroscopic skills.," Knee Surg. Sports Traumatol. Arthrosc., Aug. 2014.

[39] “Arthroscopy," Pacific Research Laboratories, 2014. [Online]. Available: http://www.sawbones.com/Catalog/Skills Training/Arthroscopy. [Accessed: 23Jan-2015].

[40] "Product Details," Adam Rouilly, 2010. [Online]. Available: http://www.adamrouilly.co.uk/productdetails.aspx?pid=2348\&cid=330. [Accessed: 23-Jan-2015].

[41] "Product details," Coburger Lehrmittelanstalt Media for Health Education. [Online]. Available: http://www.coburgerlehrmittelanstalt.de/wbc.php?sid=4620d84eb7\&tpl=produktdetail.html\&pid=628\& recno=7. [Accessed: 23-Jan-2015].

[42] “Shoulder Joint Arthroscopy Model," China Medicine Device. [Online]. Available: http://www.chinamedevice.com/ChinaSuppliers/8599/Shoulder-Joint-ArthroscopyModel-475387.htm. [Accessed: 23-Jan-2015].

[43] G. J. M. Tuijthof, P. Visser, I. N. Sierevelt, C. N. Van Dijk, and G. M. M. J. Kerkhoffs, "Does perception of usefulness of arthroscopic simulators differ with levels of experience?," Clin. Orthop. Relat. Res., vol. 469, no. 6, pp. 1701-1708, 2011. 
[44] A. H. Gomoll, R. V O’Toole, J. Czarnecki, and J. J. P. Warner, "Surgical experience correlates with performance on a virtual reality simulator for shoulder arthroscopy,” Am. J. Sports Med., vol. 35, no. 6, pp. 883-888, 2007.

[45] K. D. Martin, "Arthroscopic Basic Task Performance in Shoulder Simulator Model Correlates with Similar Task Performance in Cadavers," J. Bone Jt. Surg., vol. 93, no. 21, p. e127 1, 2011.

[46] N. E. Seymour, A. G. Gallagher, S. a Roman, M. K. O’Brien, V. K. Bansal, D. K. Andersen, and R. M. Satava, "Virtual reality training improves operating room performance: results of a randomized, double-blinded study.," Ann. Surg., vol. 236, no. 4, pp. 458-463; discussion 463-464, 2002.

[47] G. M. Fried, L. S. Feldman, M. C. Vassiliou, S. a Fraser, D. Stanbridge, G. Ghitulescu, and C. G. Andrew, "Proving the value of simulation in laparoscopic surgery.," Ann. Surg., vol. 240, no. 3, pp. 518-525; discussion 525-528, 2004.

[48] A. G. Gallagher, N. E. Seymour, J.-A. Jordan-Black, B. P. Bunting, K. McGlade, and R. M. Satava, "Prospective, randomized assessment of transfer of training (ToT) and transfer effectiveness ratio (TER) of virtual reality simulation training for laparoscopic skill acquisition.," Ann. Surg., vol. 257, no. 6, pp. 1025-31, Jun. 2013.

[49] N. R. Howells, H. S. Gill, a J. Carr, a J. Price, and J. L. Rees, “Transferring simulated arthroscopic skills to the operating theatre: a randomised blinded study.," J. Bone Joint Surg. Br., vol. 90, no. 4, pp. 494-499, Apr. 2008.

[50] D. W. Cannon, W. E. Garrett, R. E. Hunter, D. G. Eckhoff, G. T. Nicandri, M. R. Hutchinson, and D. D. Johnson, "Improving Residency Training in Arthroscopic Knee Surgery with Use of a Virtual-Reality Simulator," J. Bone Jt. Surg., no. 96, pp. 1798-1806, 2014.

[51] R. F. Henn, N. Shah, J. J. P. Warner, and A. H. Gomoll, "Shoulder arthroscopy simulator training improves shoulder arthroscopy performance in a cadaveric 
model," Arthrosc. - J. Arthrosc. Relat. Surg., vol. 29, no. 6, pp. 982-985, Jun. 2013.

[52] A. Butler, T. Olson, R. J. Koehler, and G. T. Nicandri, "Topics in Training: Do the Skills Acquired by Novice Surgeons Using Anatomic Dry Models Transfer Effectively to the Task of Diagnostic Knee Arthroscopy Performed on Cadaveric Specimens?," J. Bone Jt. Surg., vol. 107, no. 1, pp. 1-10, 2013.

[53] A. A. Gumbs, N. J. Hogle, and D. L. Fowler, "Evaluation of resident laparoscopic performance using global operative assessment of laparoscopic skills," J Am Coll Surg, vol. 204, no. 2, pp. 308-313, 2007.

[54] A. Insel, B. Carofino, R. Leger, R. Arciero, and A. D. Mazzocca, "The development of an objective model to assess arthroscopic performance.," J. Bone Joint Surg. Am., vol. 91, no. 9, pp. 2287-95, Sep. 2009.

[55] A. C. Hoyle, C. Whelton, R. Umaar, and L. Funk, "Validation of a global rating scale for shoulder arthroscopy: a pilot study," Shoulder Elb., vol. 4, no. 1, pp. 1621, 2012.

[56] S. Bayona, K. Akhtar, F. Tr, A. L. Dodds, and F. Bello, "Topics in Training: Assessing Performance in Shoulder Arthroscopy: The Imperial Global Arthroscopy Rating Scale (IGARS),” J. Bone Jt. Surg., vol. 96, no. 13, pp. 1-7, 2014.

[57] N. R. Howells, M. D. Brinsden, R. S. Gill, A. J. Carr, and J. L. Rees, "Motion analysis: a validated method for showing skill levels in arthroscopy.," Arthroscopy, vol. 24, no. 3, pp. 335-42, Mar. 2008.

[58] R. A. Pedowitz, J. Esch, and S. Snyder, "Evaluation of a virtual reality simulator for arthroscopy skills development," Arthrosc. J. Arthrosc. Relat. Surg., vol. 18, no. 6, pp. 1-6, Jul. 2002. 
[59] A. H. Gomoll, G. Pappas, B. Forsythe, and J. J. P. Warner, "Individual skill progression on a virtual reality simulator for shoulder arthroscopy: a 3-year follow-up study.” Am. J. Sports Med., vol. 36, pp. 1139-1142, 2008.

[60] M. C. Vassiliou, G. a Ghitulescu, L. S. Feldman, D. Stanbridge, K. Leffondré, H. H. Sigman, and G. M. Fried, "The MISTELS program to measure technical skill in laparoscopic surgery: evidence for reliability.," Surg. Endosc., vol. 20, no. 5, pp. 744-747, May 2006.

[61] Y. Tashiro, H. Miura, Y. Nakanishi, K. Okazaki, and Y. Iwamoto, "Evaluation of skills in arthroscopic training based on trajectory and force data.," Clin. Orthop. Relat. Res., vol. 467, no. 2, pp. 546-52, Feb. 2009.

[62] I. Oropesa, M. K. Chmarra, P. Sanchez-Gonzalez, P. Lamata, S. P. Rodrigues, S. Enciso, F. M. Sanchez-Margallo, F.-W. Jansen, J. Dankelman, and E. J. Gomez, "Relevance of Motion-Related Assessment Metrics in Laparoscopic Surgery," Surg. Innov., 2012.

[63] K. Kahol, R. M. Satava, J. Ferrara, and M. L. Smith, "Effect of Short-Term Pretrial Practice on Surgical Proficiency in Simulated Environments: A Randomized Trial of the 'Preoperative Warm-Up' Effect," J. Am. Coll. Surg., vol. 208, no. 2, pp. 255-268, Mar. 2009.

[64] H. Gray, Anatomy of the Human Body, 20th ed. Philidelphia: Lea \& Febiger, 1918.

[65] J. a Szivek, M. Thomas, and J. B. Benjamin, "Characterization of a synthetic foam as a model for human cancellous bone.," J. Appl. Biomater., vol. 4, no. 3, pp. 26972, Jan. 1993.

[66] ASTM Standard F1839-08, "Standard Specification for Rigid Polyurethane Foam for Use as a Standard Material for Testing Orthopaedic Devices and Instruments," 2008.

[67] ASTM Standard D5023-07, "Standard Test Method for Plastics: Dynamic Mechanical Properties: In Flexure (Three-Point Bending )," 2007. 
[68] V. Shim, J. Boheme, C. Josten, and I. Anderson, "Use of Polyurethane Foam in Orthopaedic Biomechanical Experimentation and Simulation,” 2012.

[69] M. S. Thompson, I. D. McCarthy, L. Lidgren, and L. Ryd, "Compressive and Shear Properties of Commercially Available Polyurethane Foams," J. Biomech. Eng., vol. 125, no. 5, p. 732, 2003.

[70] C. H. Turner and D. B. Burr, "Basic biomechanical measurements of bone: a tutorial.,"Bone, vol. 14, no. 4, pp. 595-608, 2015.

[71] J. D. Currey, "Mechanical properties of vertebrate hard tissues.," Proc. Inst. Mech. Eng. H., vol. 212, no. 6, pp. 399-411, 1998.

[72] A. Escoto, A. Luisa, M. D. Naish, R. V Patel, and M.-E. Lebel, "Force Sensingbased Simulator for Arthroscopic Skills Assessment in Orthopaedic Knee Surgery,” Stud. Heal. Technol. Inform., 2012.

[73] A. H. Gomoll, G. Pappas, B. Forsythe, and J. J. P. Warner, "Individual skill progression on a virtual reality simulator for shoulder arthroscopy: a 3-year follow-up study.," Am. J. Sports Med., vol. 36, no. 6, pp. 1139-1142, 2008.

[74] A. L. Trejos, R. V. Patel, R. a. Malthaner, and C. M. Schlachta, "Development of force-based metrics for skills assessment in minimally invasive surgery," Surg. Endosc. Other Interv. Tech., vol. 28, no. 7, pp. 2106-2119, 2014. 


\section{Appendices}

\section{Appendix A: Letter of Information and Consent}

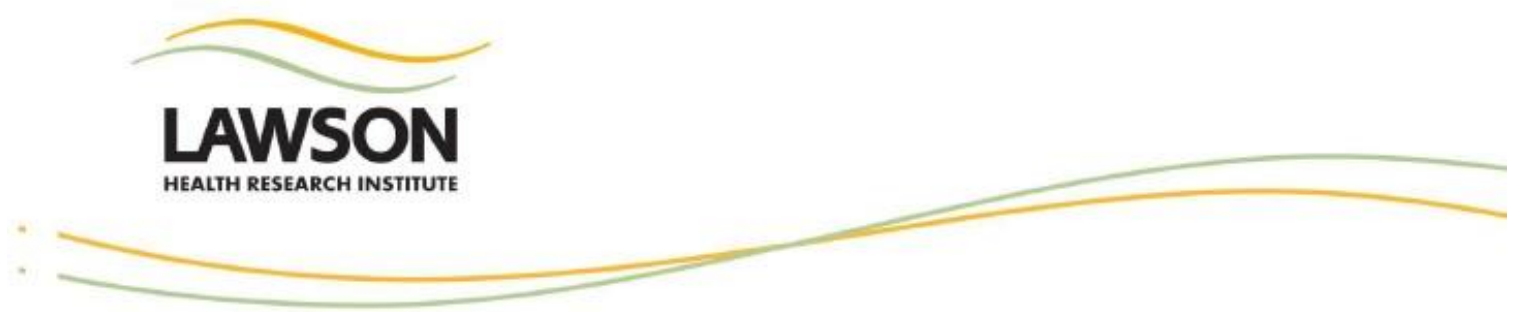

Project Title: Motor Learning in Arthroscopic Surgery

Principal Investigator:

Dr. Ana Luisa Trejos, Ph.D.

Assistant Professor,

Departm ent of Electrical and Computer Engineering, Western University

Associate Scientist, Canadian Surgical Technologies and Advanced Robotics,

Law son Health Research Institute

\section{Letter of Information}

\section{Invitation to $P$ articipate}

You are invited to participate in a research study that aims to develop a system for the training and assessment of arthroscopic skills in knee and shoulder surgery.

\section{Purpose of the Letter}

The pumose of this letter is to provide you with information required for you to make an informed decision regarding participation in this research.

\section{Purpose of this Study}

The purpose of this study is to develop a system for the training and assessment of arthroscopic skills in knee and shoulder surgery. The system will assess skill level based on hand movements, the force profiles of the tools used and signals that measure muscle activity while performing surgical tasks.

\section{Inclusion Criteria}

Participants from different skills levels, including individuals with no prior experience on surgic al simulators, junior and senior orthopaedic residents, orthopaedic fellows, and expert surgeons, with minimum age of 18 years can be included in the study.

\section{Exclusion Criteria}

There is no exclusion criteria.

$\vee 2.0-25 / \mathrm{Feb} / 2015$

The researd insthte of Lond on Health Sciences centre and St woeph's Hea bh Care, London.
Page 1 of 6

London Health Sciences Centre
Participant Initials:

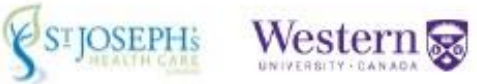




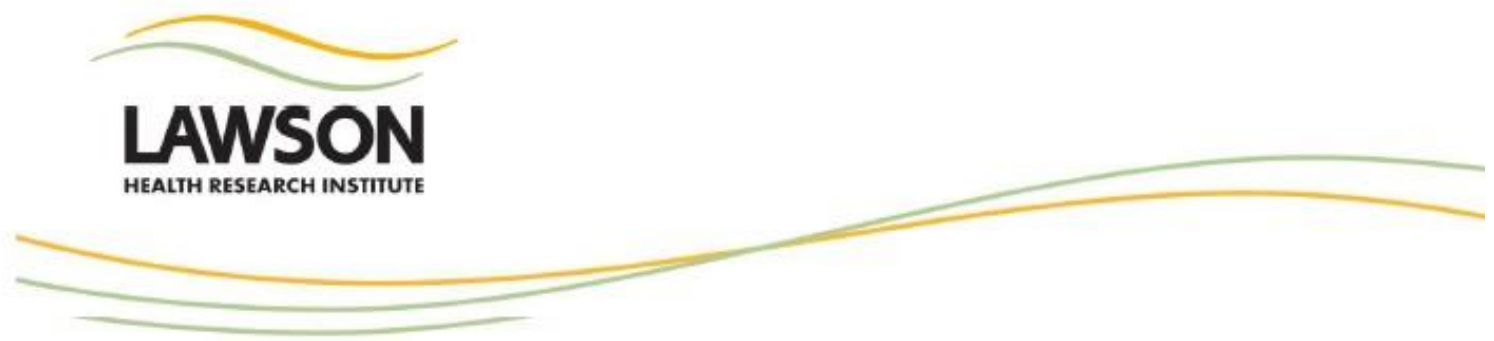

\section{Study Procedures}

The experiments will commence by showing you 10 basic arthroscopic tasks that we expect you to perform. You will then be asked to perform 3 trials for each task. While you perform the tasks, software will be used to record your hand movements and force profiles of the instruments to directly link each of the steps required to accomplish each task. Surface electromyography electrodes will be placed on your hands, arms and shoulders to record EMG signals during the tasks. A video of the arthroscopic view that only shows the inside of the simulator will also be recorded for further analysis.

The database resulting from these experiments will be used to perform a thorough statistical analysis to model the force profiles corresponding to each of the tasks, to correlate the data to the skill level of the subjects and to determ ine the most effective way of guiding a trainee when leaming a task.

The experiment is expected to take a maximum of 2 hours for the first session. As a participant, you may be asked to retum at a later date for a re-test session. Up to 105 subjects will be asked to perform these experiments. The experiments will be conducted in CSTAR's Engineering Laboratory located on the $8^{\text {th }}$ Ievel of U niversity Hospital.

\section{Possible Risks and Harms}

There are no known risks, harmful effects or discomforts expected to arise from your participation in this study.

\section{Possible Benefits}

There are no benefits to the participants. However, there are benefits for the society. It is expected that the availability of a training environment that allows residents to become proficient and confident in arthroscopic surgical techniques without any risk to patients will be of great benefit. The residents will be able to get as much exposure as they want with the training system and this will allow them to follow their own progress and improvement over time. With better-prepared and safer residents, surgeons will be able to focus on more advanced skills and the finer aspects of the procedures instead of demonstrating and teaching basic skills. In addition, the outcomes of this project will have a direct and almost immediate benefit to the Ontario population through the improvement of patient safety, 


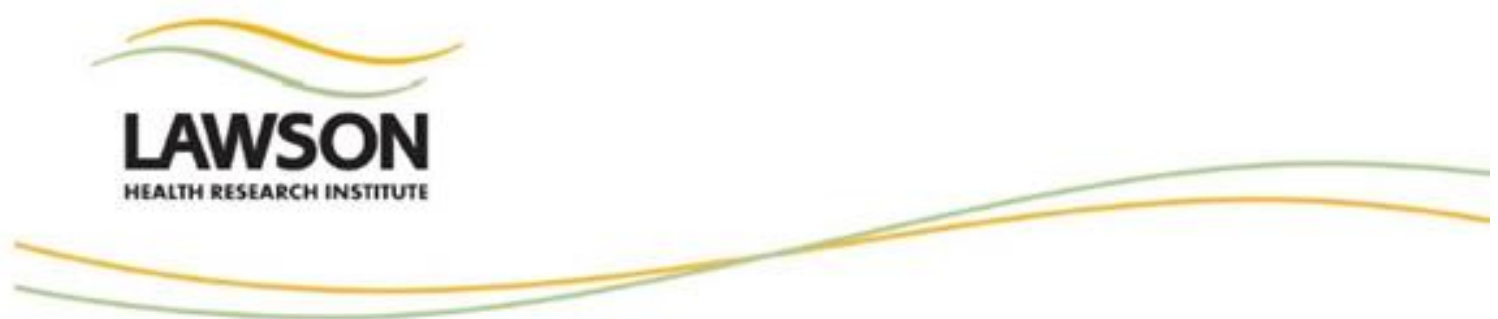

shortening of wait times, alleviating anticipated shortages in health human resources, and by the development and commercialization of the next generation of simulators.

\section{Compensation}

There will be no compensation provided to the participants.

\section{Voluntary P articipation}

Participation in this study is voluntary. You may refuse to participate, or withdraw from the study at any time with no effect on your current training or employment status. Strict confidentiality will be maintained throughout the study.

\section{Confidentiality}

The only personal information that will be collected during the trials will be your level of expertise in arthroscopic surgery. The participants with a career relevant to arthroscopic surgery should be advised that their performance as a surgeon, resident, fellow, etc. will not be evaluated and no assessment of your skill level will be perfomed during the trials. However, prior to the experiments, you will be asked to report your current year of training. This information will help us to determine your level of experience. All data collected will remain confidential and accessible only to the investigators of this study.

\section{Publication}

As it is mentioned in section 11, the only personal information that will be collected during the trials will be your level of expertise in arthroscopic surgery. Thus, if the results of the study are published, your narne will not be used. If you would like to receive a copv of any potential study results, please contact

at

or

\section{Contacts for Further Inform ation}

If you have any questions or concerns regarding participation in our study, please contact 


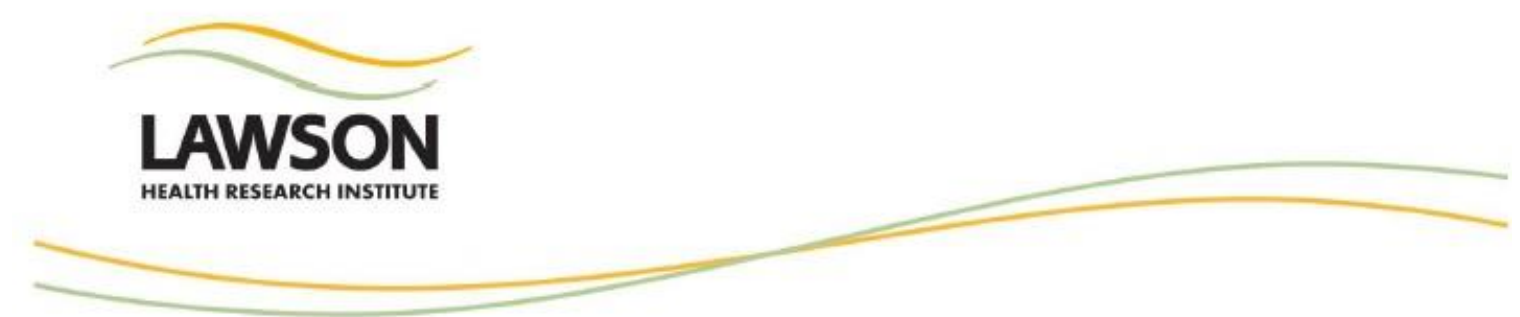

This research is supported by the Ontario Research Fund and is being conducted by the following researchers:

Dr. Ana Luisa Trejos, Ph.D. (Principal Investigator)

Assistant Professor,

Department of Electrical and Computer Engineering, Western University

Associate Scientist, Canadian Surgical Technologies and Advanced Robotics,

Lawson Health Research Institute

Dr. Marie-Eve LeBel, MD, MHPE, FRCSC (Co-Investigator)

Orthopaedic Surgeon and Associate Professor

Department of Surgery, Division of Orthopaedic Surgery

Roth-McFarlane $\mathrm{H}$ and and Upper Limb Centre

The University of Westem Ontario

\section{Dr. Michael Naish, Ph.D. (Co-investigator)}

Assistant Professor,

Departments of Mechanical and Materials Engineering \& Electrical and Computer Engineering, Western University

Scientist, Canadian Surgic al Technologies and Advanced Robotics Institute

\section{Dr. Rajnikant Patel, Ph.D., P.Eng. (Co-investigator)}

Distinguished University Professor and Tier 1

Canada Research Chair, Department of Electrical and Computer Engineering and Department of Sungery, Western University

Director of Engineering, Canadian Surgic al Technologies and Advanced Robotics

\section{Behnaz P oursartip, Ph.D. Student}

Research Assistant, Western University

Canadian Surgical Technologies and Advanced Robotics

Laura Mccracken, M.E.Sc Student

Research Assistant, Western University

Canadian Surgical Technologies and Advanced Robotics

$\vee 2.0-25 / F e b / 2015$

The research insthte of Lond on Heatth Sciences centre and St bseph's Heath Care, London.
Page 4 of 6

London Health Sciences Centre
Participant Initials:

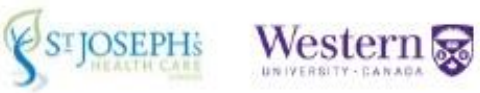




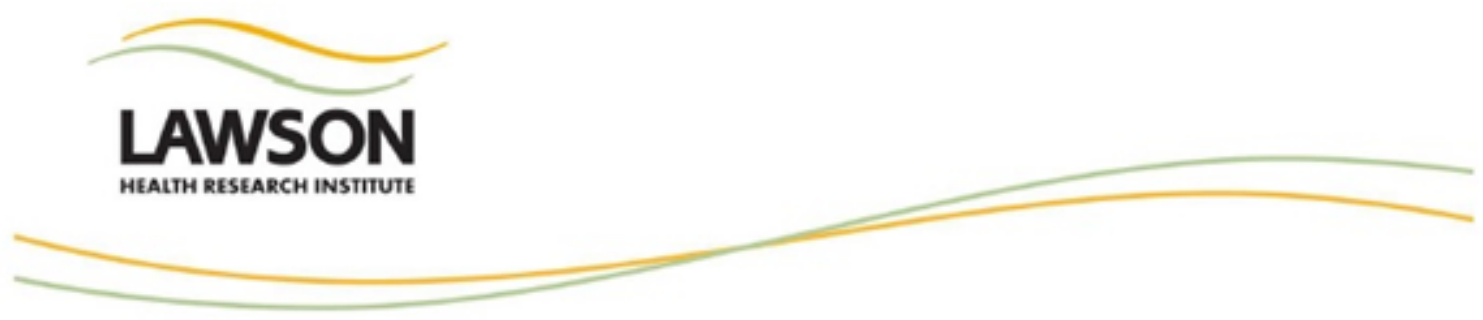

Abelardo Escoto, M.E.Sc. (Research Support Staff)

Research Assistant

Canadian Surgical Technologies and Advanced Robotics, Lawson Health Research Institute

If you have any questions about the conduct of this study or your rights as a research subject you may contact Scientific Director, Lawson Health Research Institute at

A copy of this information package is yours to keep for your personal records. 


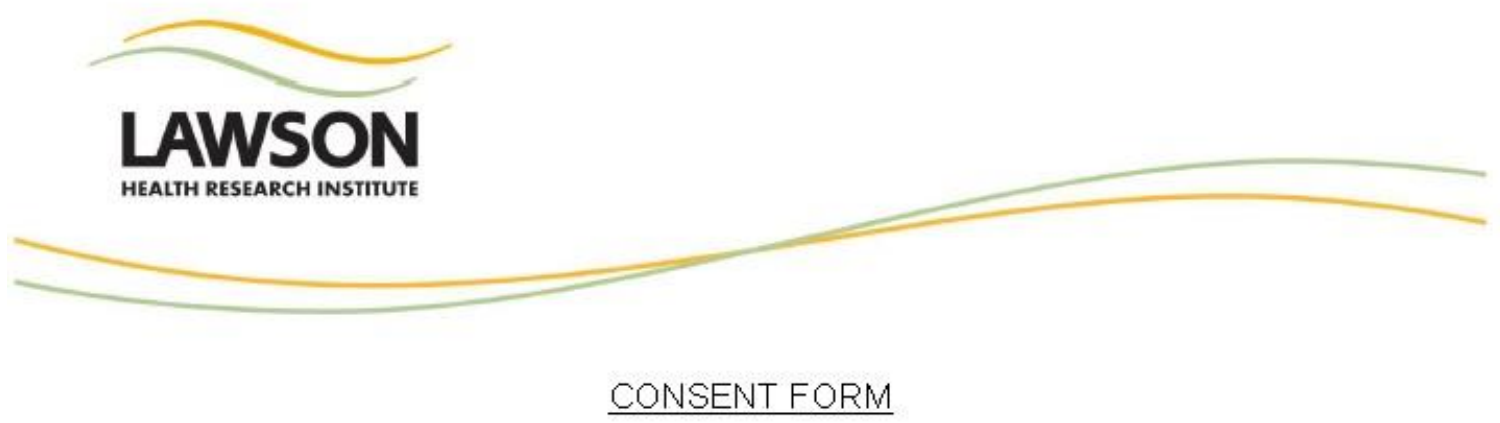

Title of Research: Motor Learning in Arthroscopic Surgery

Principal Investigator: Dr. Ana Luisa Trejos,

Co-Investigators: $\quad$ Dr. Marie-Eve LeBel, Dr. Michael Naish, Dr. Rajni Patel

Students: Behnaz Poursartip, Laura Mccracken

Research Support Staff: Abelardo Escoto

For the Participant:

I have read the Information/Consent document, have had the nature of the study explained to $\mathrm{me}$, and I agree to participate in this research study. All questions have been answered to my satisfaction.

Name of Participant - Please Print Signature of Participant Date

Name of Person Obtaining

Signature of Person Obtaining

Date Informed Consent Informed Consent

$\vee 2.0-25 / F e b / 2015$

The research institute of London Heabl Sciences Centre and St wseph's Health Care, London.
Page 6 of 6

London Health Sciences Centre
Participant Initials:

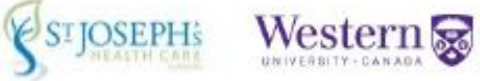




\section{Appendix B: Ethics Approval}

\section{estern University Health Science Research Ethics Board HSREB Delegated Initial Approval Notice}

Principal Investigator: Dr. Ana Luisa Trejos

Department \& Institution: Unknown,London Health Sciences Centre

HSREB File Number: 106105

Study Title: Motor Learning in Arthroscopic Surgery

Sponsor: Ontario Centres of Excellence Ine.

HSREB Initial Approval Date: March 03, 2015

HSREB Expiry Date: March 03, 2016

Documents Approved and/or Received for Information:

\begin{tabular}{|l|l|l|}
\hline Document Name & Comments & Version Date \\
\hline Western University Protocol & & $2015 / 02 / 25$ \\
\hline Recruitment Items & Email & $2015 / 02 / 25$ \\
\hline Letter of Information \& Consent & & $2015 / 02 / 25$ \\
\hline
\end{tabular}

The Western University Health Science Research Ethics Board (HSREB) has reviewed and approved the above named study, as of the HSREB Initial Approval Date noted above.

HSREB approval for this study remains valid until the HSREB Expiry Date noted above, conditional to timely submission and acceptance of HSREB Continuing Ethics Review. If an Updated Approval Notice is required prior to the HSREB Expiry Date, the Principal Investigator is responsible for completing and submitting an HSREB Updated Approval Form in a timely fashion.

The Western University HSREB operates in compliance with the Tri-Council Policy Statement Ethical Conduct for Research Involving Humans (TCPS2), the International Conference on Harmonization of Technical Requirements for Registration of Pharmaceuticals for Human Use Guideline for Good Clinical Practice (ICH E6 RI), the Ontario Personal Health Information Protection Act (PHIPA, 2004), Part 4 of the Natural Health Product Regulations, Health Canada Medical Device Regulations and Part C, Division 5, of the Food and Drug Regulations of Health Canada.

Members of the HSREB who are named as Investigators in research studies do not participate in discussions related to, nor vote on such studies when they are presented to the REB.

The HSREB is registered with the U.S. Department of Health \& Human Services under the IRB registration number IRB 00000940.

Ethics Officer to Contact for Further Information 
Appendix C: Novice Informational Handout

\section{Basic Shoulder Anatomy}

The following bones are included in the shoulder simulator.
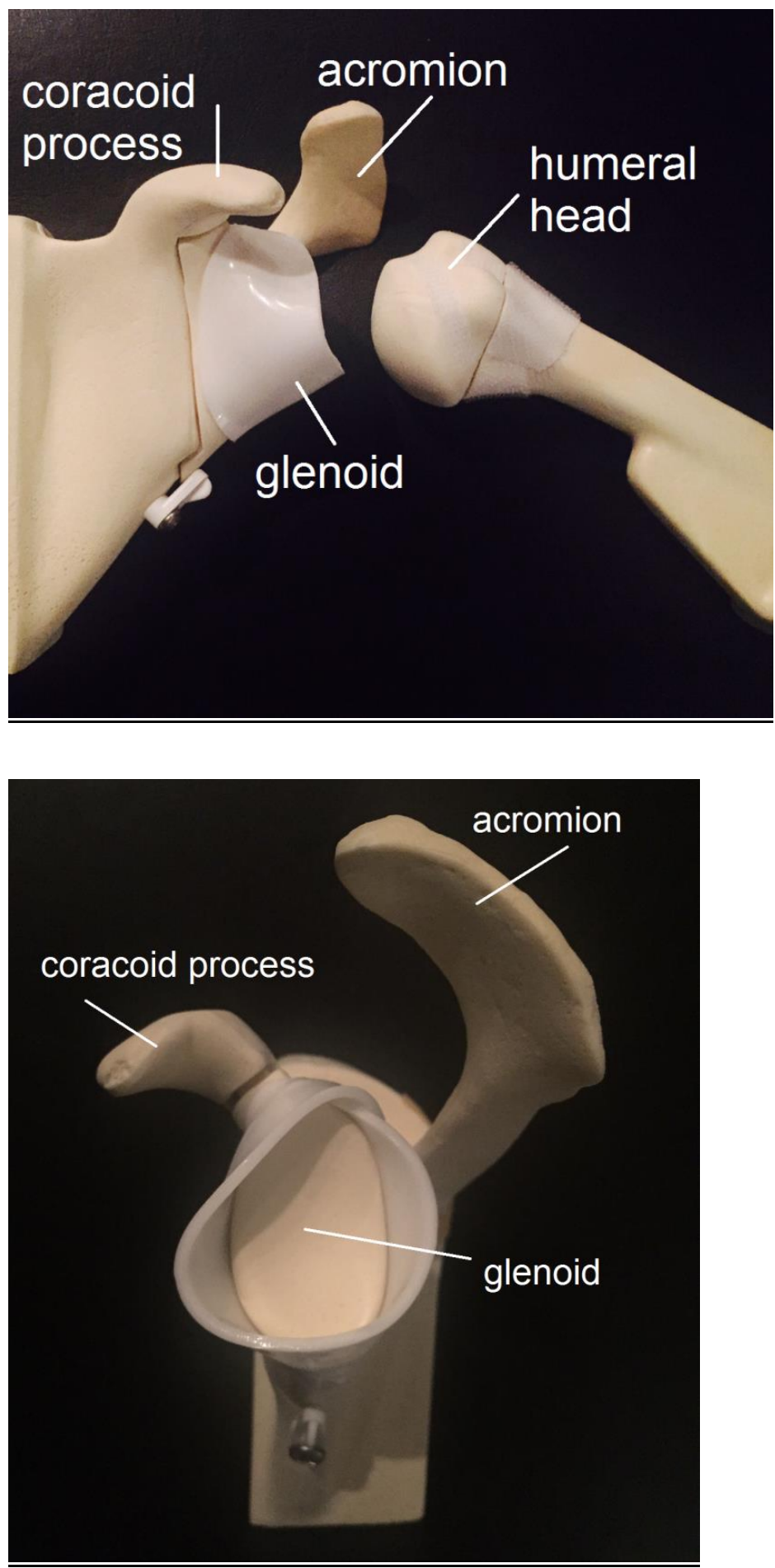
The following soft tissues are included in the simulator:

(1) The joint capsule encapsulates the humeral head and the glenoid.

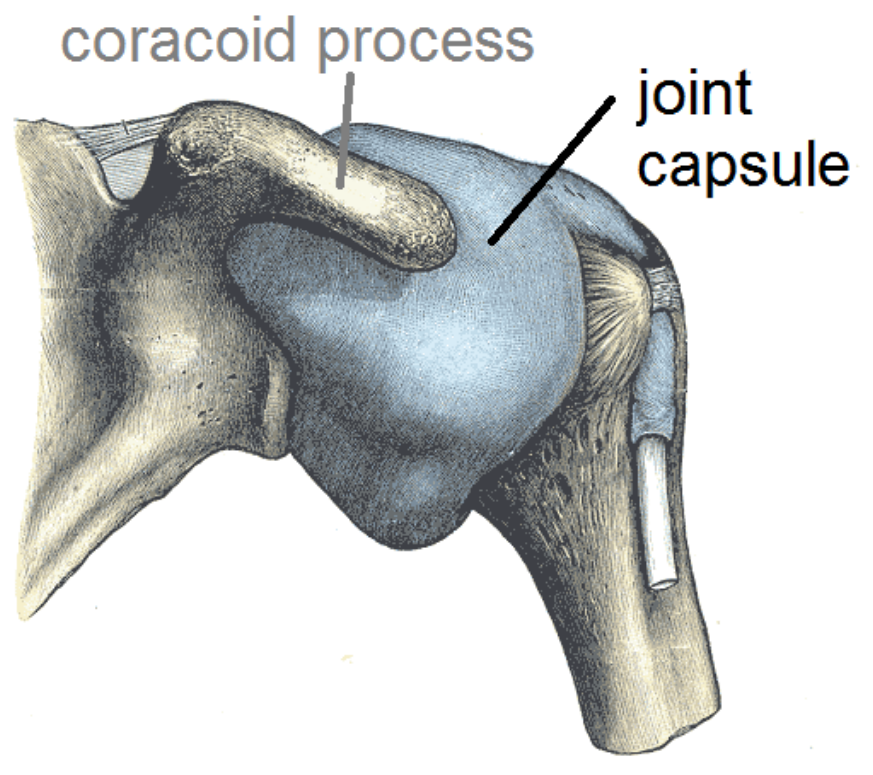

(2) The muscles of the rotator cuff cover the joint capsule.

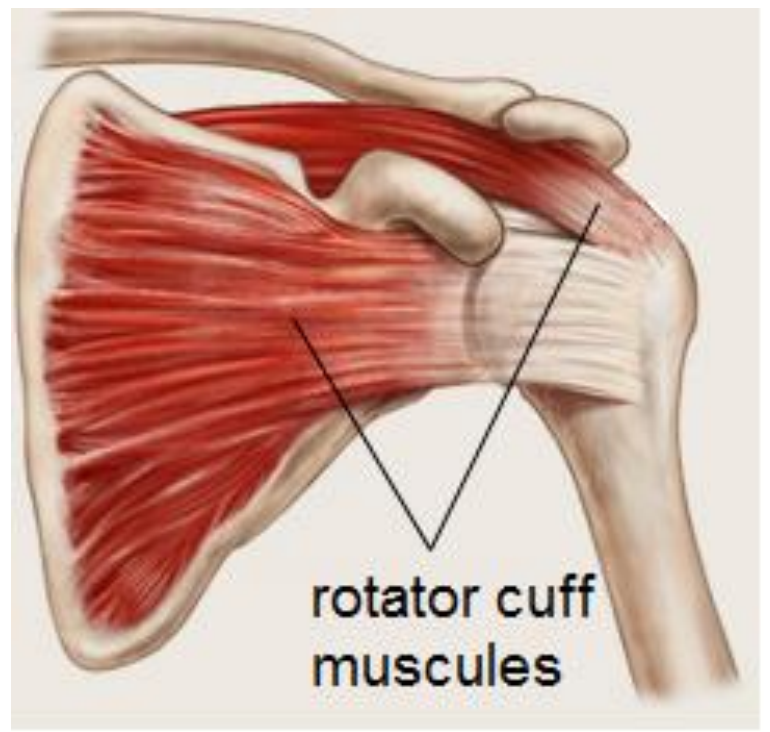


These are the surgical tools you will be using today:

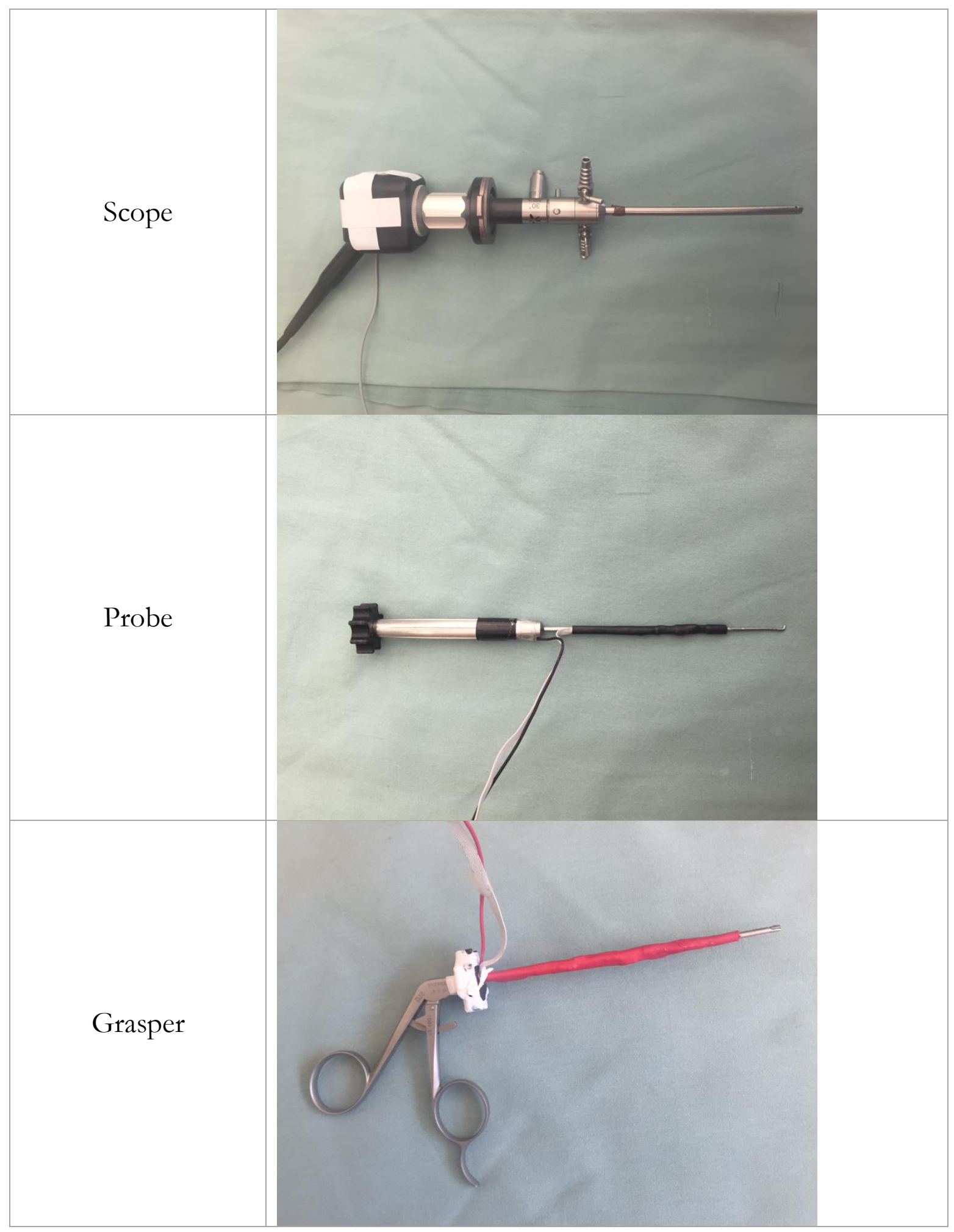


You will be completing the following tasks: There are three tasks for you to complete. A video will be shown before each task to explain what to do.

Task 1: You will probe (push) two small buttons located on the glenoid inside the joint capsule.

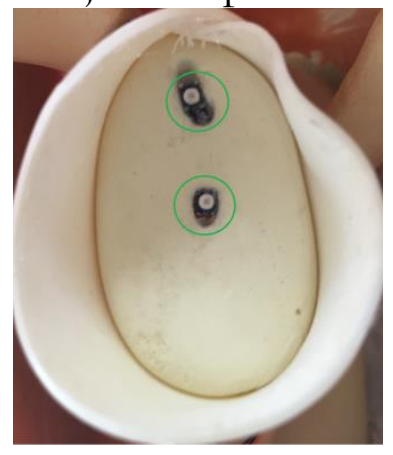

Task 2: You will probe (push) two small buttons located on the acromion and the coracoid process, outside of the joint capsule.

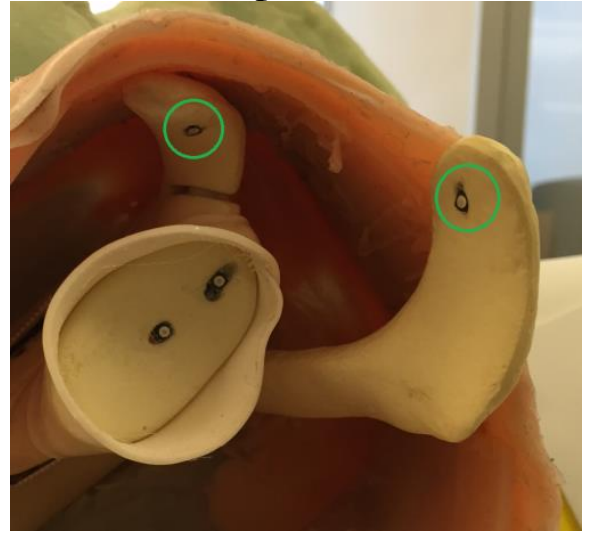

Task 3: You will use the grasper to retrieve a "loose body" from inside the joint capsule.

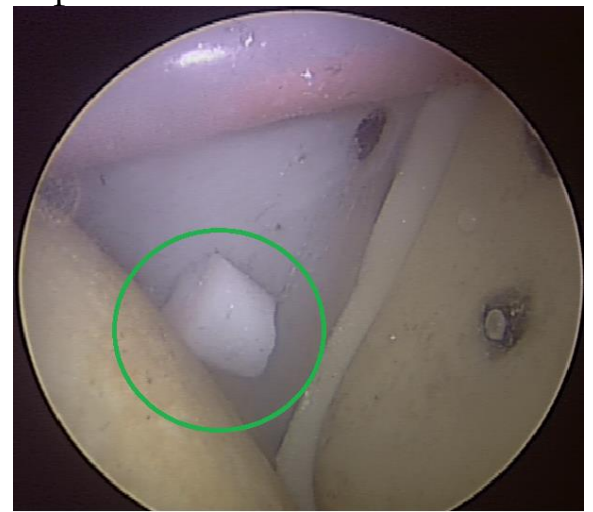

Before you begin, you will be given time to familiarize yourself with the tools and simulator. 


\section{Appendix D: Questionnaire}
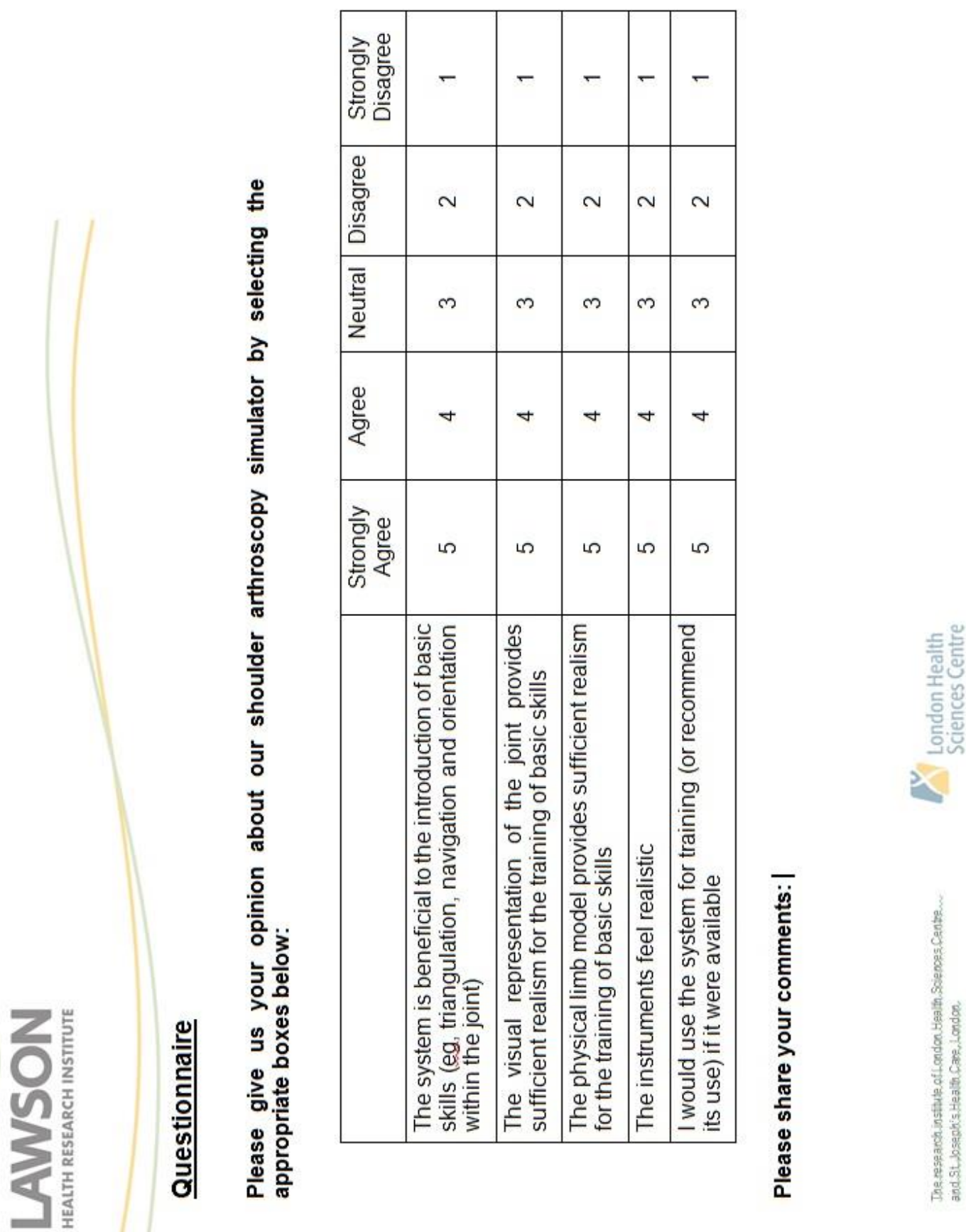


\section{Appendix E: Permissions}

SPRINGER LICENSE TERMS AND CONDITIONS

Jul 01, 2015

This is a License Agreement between Laura McCracken ("You") and Springer ("Springer") provided by Copyright Clearance Center ("CCC"). The license consists of your order details, the terms and conditions provided by Springer, and the payment terms and conditions.

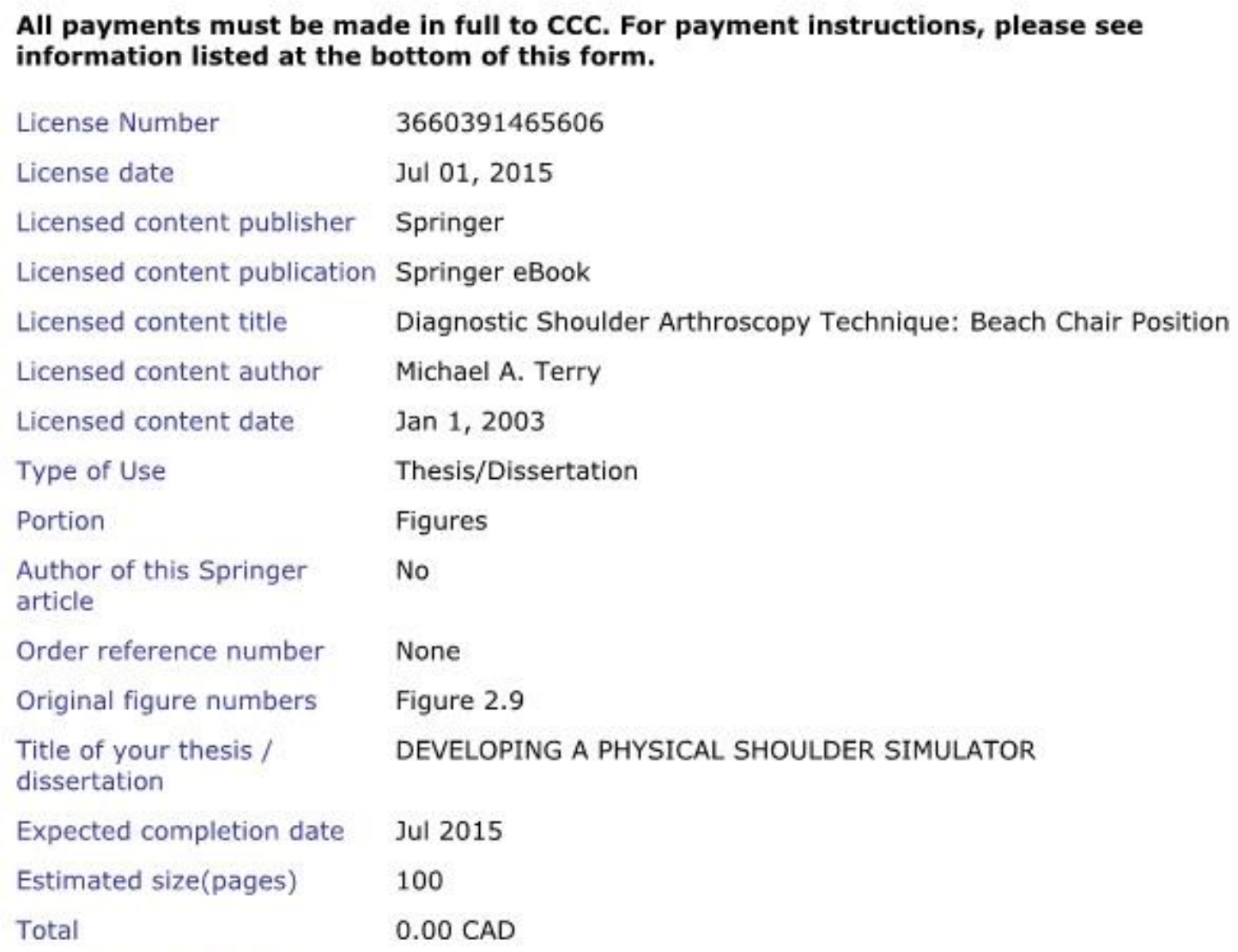

Terms and Conditions 
SPRINGER LICENSE TERMS AND CONDITIONS

Jun 07,2015

This is a License Agreement between Laura McCracken ("You") and Springer ("Springer") provided by Copyright Clearance Center ("CCC"). The license consists of your order details, the terms and conditions provided by Springer, and the payment terms and conditions.

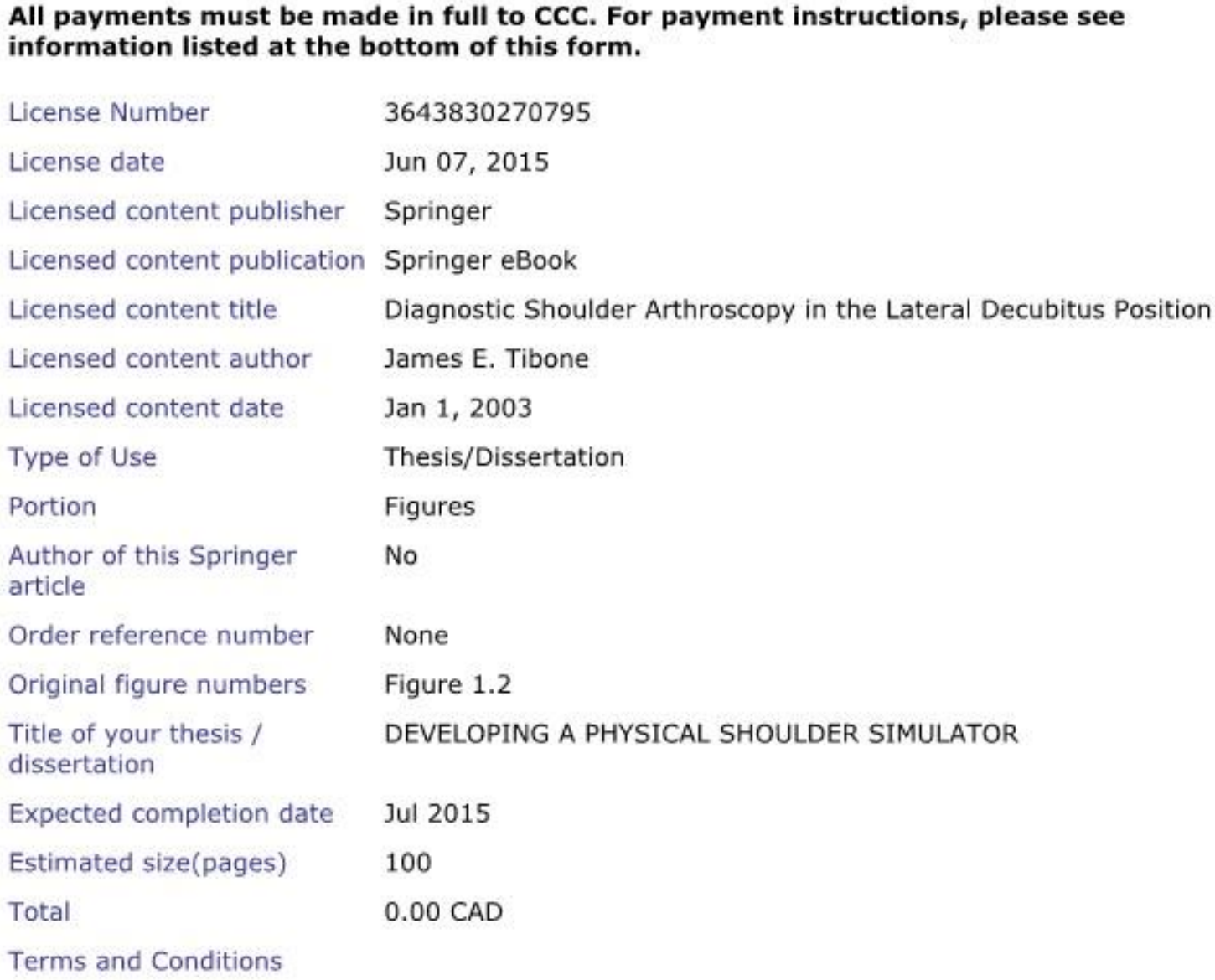

License Number

License date

Licensed content publisher

Licensed content publication

Licensed content title

Licensed content author

Licensed content date

Type of Use

Portion

Author of this Springer

article

Order reference number

Original figure numbers

Title of your thesis /

dissertation

Expected completion date

Estimated size(pages)

Total

Terms and Conditions

3643830270795

Jun 07,2015

Springer

Springer eBook

Diagnostic Shoulder Arthroscopy in the Lateral Decubitus Position

James E. Tibone

$\operatorname{Jan} 1,2003$

Thesis/Dissertation

Figures

No

None

Figure 1.2

DEVELOPING A PHYSICAL SHOULDER SIMULATOR

Jul 2015

100

$0.00 \mathrm{CAD}$ 


\section{Curriculum Vitae}

Name:

Post-secondary Education and Degrees:

Honours and Awards

Related Work Experience
Laura C. McCracken, P.Eng

The University of Western Ontario

London, Ontario, Canada, 2014-2015

M.E.Sc, Biomedical Engineering

University of Waterloo

Kitchener, Ontario, Canada, 2001-2006

B.A.Sc., Chemical Engineering

London Health Research Day, Best Poster Award, 2014

Research Assistant

CSTAR, University Hospital

London, Ontario

2013-2014

Engineer

Lakeside Process Controls

Mississauga, Ontario

2006-2012 